\title{
ESTUDO DA RELAÇÃO ESTRUTURA-ATIVIDADE DE COMPOSTOS BIOLOGICAMENTE ATIVOS DERIVADOS DO ARIPIPRAZOL
}

Dissertação apresentada ao Instituto de Química de São Carlos, da Universidade de São Paulo como parte dos requisitos para a obtenção do título de Mestra em Ciências.

Área de concentração: Físico-Química

Orientador: Prof. Dr. Albérico Borges Ferreira da Silva 


\section{Luar do Sertão \\ (Luiz Gonzaga)}

Oh! Que saudade do luar da minha terra

Lá na terra branquejando folhas secas pelo chão

Este luar cá da cidade tão escuro

Não tem aquela saudade do luar lá do sertão.

Não há, ó gente, ó não

Luar como esse do sertão

Não há, ó gente, ó não

Luar como esse do sertão.

Se a lua nasce por detrás da verde mata

Mais parece um sol de prata prateando a solidão

$E$ a gente pega na viola que ponteia

E a canção e a lua cheia a nos nascer do coração.

Não há, ó gente, ó não

Luar como esse do sertão

Não há, ó gente, ó não

Luar como esse do sertão.

Mas como é lindo ver depois por entre o mato

Deslizar calmo regato, transparente como um véu

No leito azul das suas águas murmurando

E por sua vez, roubando as estrelas lá do céu.

Não há, ó gente, ó não,

Luar como esse do sertão

Não há, ó gente, ó não

Luar como esse do sertão. 
Dedico essa Dissertação a meus pais, José Carlos Pereira, Maria Eunice Nunes e a minha madrinha, Sebastiana Pereira, pela compreensão, incentivo e carinho concedido por anos a fio. Espero atender as expectativas de vocês e luminescer em troca. 


\section{AGRADECIMENTOS}

Não suportaria os fardos dessa jornada se não fosse o apoio, os ensinamentos, os incentivos e as amizades de algumas pessoas. Quero, dessa forma, expressar a todas, que de muitas maneiras contribuíram para a realização desse trabalho, o meu reconhecimento e meus sinceros agradecimentos.

A DEUS, criador maior, por não me deixar cair, mesmo quando os fardos pareciam ser maiores do que a minha força, mesmo quando me julguei incapaz, mas continuei seguindo com essa limitação e assim concluir o que me propus a fazer. Obrigada meu Senhor por ter me dado força, por ser meu refúgio, meu guardião e nunca me desamparar, mesmo quando pensei não existir mais saída. Tenho plena certeza que muitas lutas ainda virão, mas com o Senhor no comando, a vitória será certa;

A meus pais, José Carlos Pereira e Maria Eunice Nunes, por serem exemplos de honestidade, dedicação e confiança. Por terem me concedido as asas necessárias para voar e por serem as pessoas de quem absorvo lições ímpares. Não seria o que sou hoje se não fosse todo o apoio a mim dispensado. $\mathrm{O}$ meu muito obrigado não consegue, ainda, exprimir o quanto me sinto agradecida. Todas as dificuldades que passei foram poucas comparadas às dificuldades que vocês passaram para me apoiar, abrindo mão dos vossos sonhos para a realização dos meus. $\mathrm{O}$ orgulho que vocês sentem por mim não é maior que o orgulho que sinto em ser vossa filha. Mais uma vez, OBRIGADA;

À minha madrinha, Sebastiana Pereira, pelo apoio, preocupação, ensinamentos singulares, pela confiança depositada, pelo amor sempre demonstrado e por muitas vezes que parou para consolar minhas lágrimas. Sentia-me abraçada e adorada mesmo nesta distância física que nos separa. O meu carinho, respeito e adoração se perdurarão por toda a minha existência. Não tenho palavras para expressar o quanto me sinto agradecida. Neste momento, só posso dizer muito obrigada por tudo que fizeste, por tudo que fazes e por tudo que farás se por ventura eu necessitar. É muito reconfortante ser sua afilhada e me sentir muito mais do que isso, uma filha. Tenho certeza que as minhas conquistas também serão como se fossem as suas, e que essa seja uma das formas de agradecer por todo esse suporte físico e, sobretudo emocional a mim concedido;

A todos os meus irmãos, Adriano, Fabiano, Aldemir, Adilson (meu Dodinho), Vânia e Júnior pela torcida; 
$>\quad$ Um agradecimento especial à minha irmã e amiga, Aldineide Nunes, pela presença constante, mesmo nessa distância física que nos separa. Obrigada pelas risadas, descontração e amor sempre demonstrado;

$>\quad$ À minha prima-irmã Ana Paula Pereira (Paulinha) por todos os momentos bons e ruins que compartilhamos. Pelo apoio dado, pela amizade, carinho e amor;

$>\quad$ À minha prima Elisangela, por estar presente, mesmo ausente, durante a minha passagem em São Carlos. Obrigada por sempre estar disposta a me ouvir, se alegrando diante da minha felicidade e se entristecendo diante de momentos ruins;

$>\quad$ Ao meu primo-irmão, Netinho (meu galego lindo), pelo suporte dado e pelo carinho sempre demonstrado. Obrigada por ter me adotado como irmã e me tratar como tal. O meu carinho e respeito por você é e será eterno;

$>\quad$ Aos meus primos, Alexssandro Honorato e Marcos Wagner pelo suporte a mim dispensado. Obrigada Marcos pelas diversas vezes que ligaste para fofocar, isso me descontraia e, de certa forma, me tirava um pouco desse mundo acadêmico que apesar de ser brilhante, às vezes se torna estressante;

$>\quad$ À minha tia, Josilene (Josi linda), que não se furtou em aparecer em um momento difícil da minha passagem em São Carlos. Uma palavra de incentivo, naquele momento, valeu muito. A você, o meu muito obrigado;

$>\quad$ Aos meus amigos, Amanda, Anderson, Virgínia, Lílian, Suzy, Eriosvaldo e Régis por tornar mais fácil e leve os meus dias em São Carlos;

$>\quad$ Um agradecimento especial a minha amiga, Aline Oliveira, pelo apoio e pelas diversas vezes que parou para discutir esse trabalho comigo;

Aos meus colegas de laboratório, Tiago, Ronaldo, Luiz, Rafael e Ana Cristina;

$>\quad$ À minha ex-orientadora, Cíntia Beatriz, por estar sempre disposta a ajudar e pela consideração com essa ex-aluna que a importuna tanto;

Ao meu orientador Albérico B. F. da Silva pela orientação e paciência com essa aluna tão inexperiente. Por me ensinar a "voar" e por me descontrair com suas histórias bizarras. Tenho profunda admiração tanto pela pessoa física como pelo profissional que és. Sinto-me orgulhosa de ser sua aluna. 
Nada na vida deve ser temido, somente compreendido. Agora é hora de compreender mais para temer menos.

(Marie Curie)

O sertanejo é, antes de tudo, um forte.

(Euclides da Cunha) 


\section{RESUMO}

A esquizofrenia é uma doença que, de acordo com a Organização Mundial de Saúde, acomete cerca de $1 \%$ da população mundial. Tendo em vista a sua alta incidência e, portanto, sua relevância, o presente trabalho objetivou estudar uma classe de compostos derivados do aripiprazol, substância ativa que estimula os receptores dopaminérgicos e serotoninérgicos, receptores esses de suma importância para o entendimento da fisiopatologia da esquizofrenia. Para isso, o estudo de QSAR foi realizado através dos métodos PLS e ANN, gerando dois modelos para tentar entender a relação entre a estrutura química e a atividade biológica. Os dois modelos gerados, PLS e ANN, foram satisfatórios, explicando 82,52\% e 72,90\% respectivamente, da variabilidade da atividade biológica. No entanto, como o modelo obtido através do método PLS foi considerado melhor, conclui-se que as variáveis selecionadas possuem comportamento linear frente à atividade biológica.

Palavras chaves: Esquizofrenia, aripiprazol, PLS, ANN, QSAR. 


\begin{abstract}
The Schizophrenia is a disease that affects about $1 \%$ of world population, according to the World Health Organization. Looking into its high incidence and therefore its relevance, the goal of this study was to investigate a class of compounds derived from aripiprazole, the active substance that stimulates dopamine and serotonin receptors, those essential for understanding the pathophysiology of schizophrenia. For the investigation to go on, the QSAR study was performed through PLS and ANN methods, generating two models in order to understand the relationship between chemical structure and biological activity. Both model results, PLS and ANN, were considered satisfactory, explaining 82.52\% and $72.90 \%$, respectively, of the variability of the biological activity. However, since the model obtained by the PLS method showed more satisfactory results, it can be concluded that the selected variables have a linear behavior concerning the biological activity.
\end{abstract}

Keywords: Schizophrenia, Aripiprazole, PLS, ANN, QSAR. 


\section{LISTA DE FIGURAS}

Figura 1-Representação esquemática das vias da dopamina no Sistema Nervoso Central ...... 21

Figura 2- Vias Dopaminérgica e Serotonérgica no cérebro humano..................................... 23

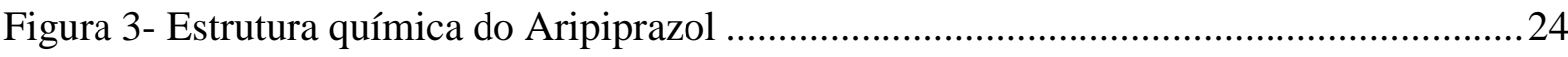

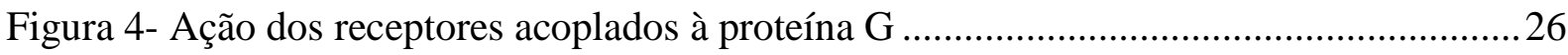

Figura 5- Esquematização de um receptor acoplado à proteína $\mathrm{G}$........................................2 27

Figura 6- Esquema de cálculo do potencial efetivo, vr, do número de elétrons, $\mathrm{N}$, do Hamiltoniano do sistema e consequentemente a energia, E, a partir de $\rho_{(\mathrm{r})}$........................... 31

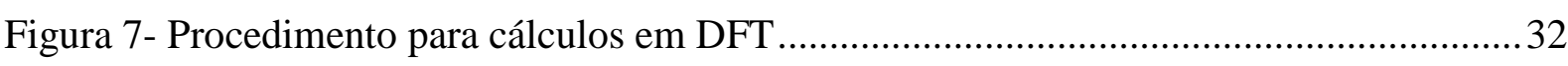

Figura 8-Porcentagem de vários funcionais utilizados, analisados a partir da Web of Science

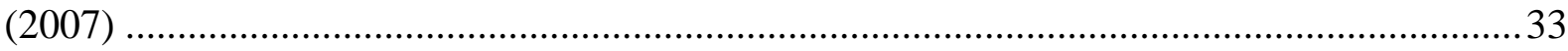

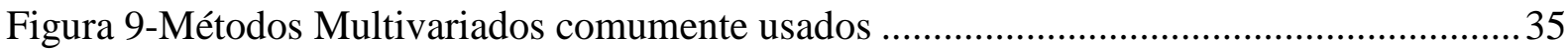

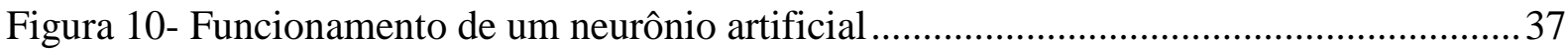

Figura 11-Tipo de função de ativação utilizada nesse trabalho.............................................. 38

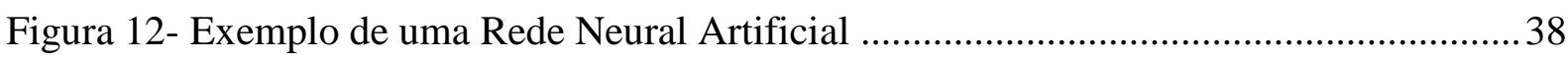

Figura 13- Procedimento interativo do funcionamento de um AG ....................................... 44

Figura 14- Funcionamento de um AG: A) Geração inicial; B) Geração resultante da aplicação da seleção natural; C) Cruzamento e D) Mutação, ................................................................ 45

Figura 15- Estrutura do Aripiprazol e suas 4 regiões exploradas ...........................................56

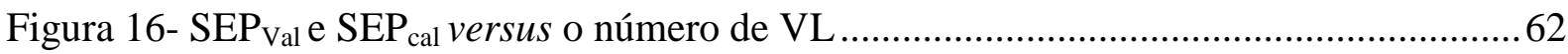

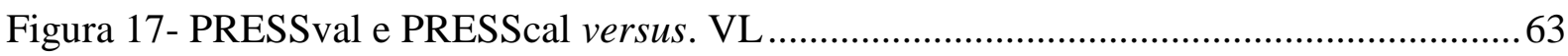

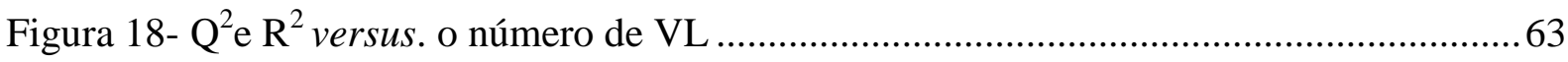

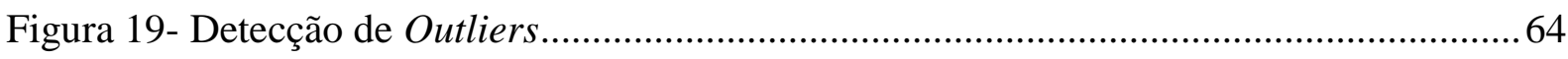

Figura 20- y predito versus y mensurado para a regressão PLS usando todo o conjunto ........ 65

Figura 21- Detecção de amostras anômalas no conjunto de treinamento.................................67

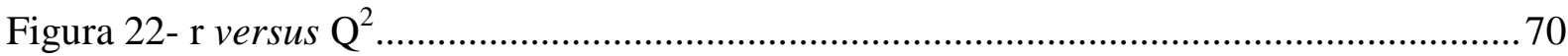

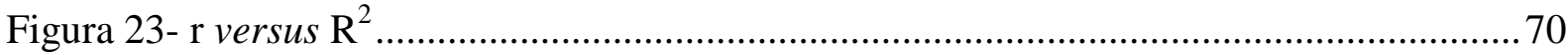

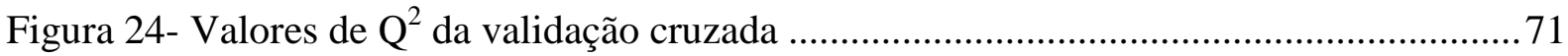

Figura 25- Valores de y predito versus y mensurado para a regressão PLS .......................... 73

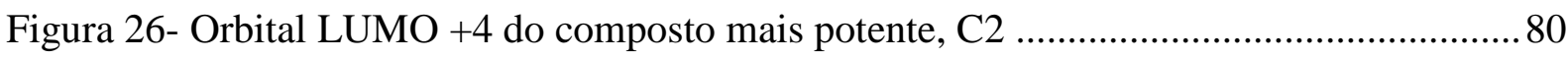

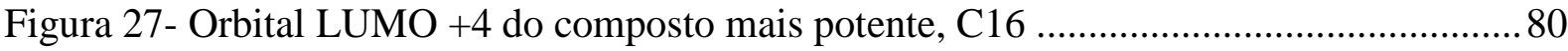

Figura 28- Orbital LUMO +4 do composto mais potente, C20 ….................................... 81

Figura 29- Orbital LUMO +4 do composto mais potente, C26 ............................................ 81 
Figura 30- Orbital LUMO +4 do composto mais potente, $\mathrm{C} 40$ 81

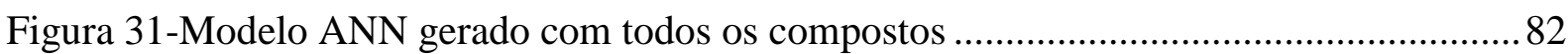

Figura 32- Modelo ANN gerado com os compostos do conjunto de treinamento ................... 83

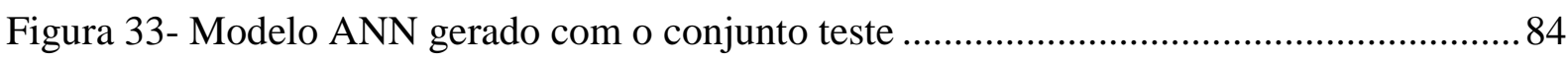

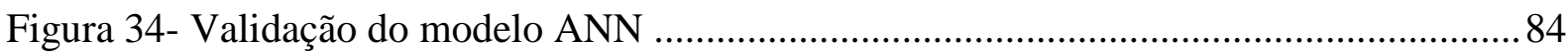

Figura 35- Erro Quadrático Médio para os conjuntos de treino, teste e validação................... 85 


\section{LISTA DE TABELAS}

Tabela 1- Agrupamento dos sintomas da esquizofrenia

Tabela 2- Estrutura química dos compostos sintetizados a partir da exploração das 4 regiões

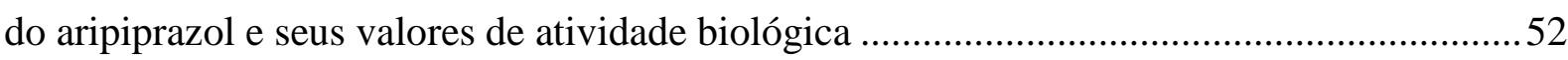

Tabela 3-Seleção das variáveis através do Algoritmo Genético 59

Tabela 4-Compostos com seus respectivos valores de pKi e das variáveis selecionadas no Algoritmo Genético 59

Tabela 5- Descrição das variáveis selecionadas 60

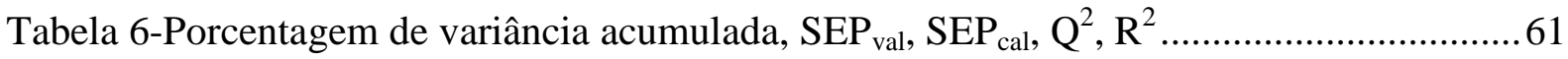

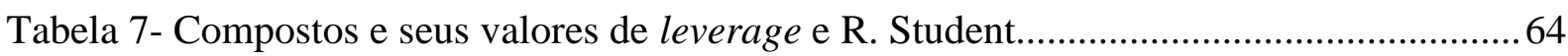

Tabela 8- Resultado estatístico para o conjunto de treinamento .............................................66

Tabela 9- Diferença entre os parâmetros analisados no conjunto auxiliar e no conjunto de treinamento 66

Tabela 10- Valores de leverage e de R. Student para o conjunto de treinamento. 67

Tabela 11- Valores de scores dos compostos para todos os descritores 68

Tabela 12- Resultados da randomização de y para o modelo PLS do conjunto de treinamento.

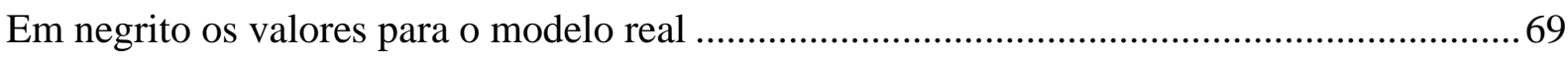

Tabela 13- Resultados da validação cruzada do modelo PLS, excluindo N amostras.............71

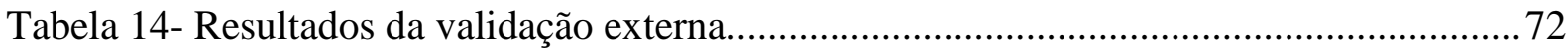

Tabela 15- Contribuição dos descritores para cada fator ...................................................... 74 


\section{LISTA DE ABREVIATURAS E SIGLAS}

SARs- Do inglês: Structure-Activity Relationships

IUPAC- Do inglês: International Union of Pure and Applied Chemistry

OMS- Organização Mundial de Saúde

MS- Ministério da Saúde

UFRJ- Universidade Federal do Rio de Janeiro

DA- Dopamina

cAMP- Monofosfato cíclico de Adenosina

SNC- Sistema Nervoso Central

NMDA- Do inglês: $N$-methil-D-aspartato

mGluR- receptores metabotrópicos

5-HT- 5-Hidroxitriptamina

GPCRs- Receptores Acoplados à Proteína G

GDP- Guanílicos Guanosina Difosfato

GTP- Guanílicos Guanosina Trifosfato

BR- bacteriorodopsina

IC- Intracelulares

EC- Extracelulares

GTO- Do inglês: Gaussian Type Orbital

DFT -Do inglês: Density Functional Theory

KS- Kohn-Sham

QSAR- Do inglês: Quantitative Structure-Activity Relationship

PLS - Do inglês: Partial Least Squares

VL- Variáveis Latentes

AG- Algoritmo Genético

PRESS- Do inglês: Prediction Error Sums of Squares

$\mathrm{SEP}_{\mathrm{Val}}$ - Do inglês: Standart Error of Validation

SEP $_{\text {Cal- }}$ Do inglês: Standart Error of Calibration

ANN- Do inglês: Artificial Neural Network

HOMO- Do inglês: Highest occupied molecular orbital

LUMO- Do inglês: Lowest unoccupied molecular orbital

BCUT- Do inglês: Burden- CAS-University of Texas Eigen Values

RDF- Do inglês: Radial Function Distribution 
WHIM- Do inglês: Weighted Holistic Invariant Molecular

GETAWAY- Do inglês: Geometric Topology and Atom Weights Assembly

MIM- Do inglês: Molecular Influence Matrix 


\section{SUMÁRIO}

INTRODUÇÃO

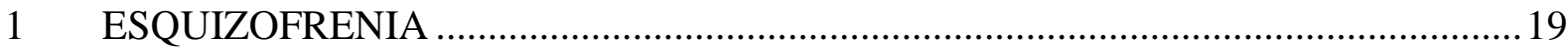

1.1 Abordagens neuroquímicas da fisiopatologia da esquizofrenia ..................................20

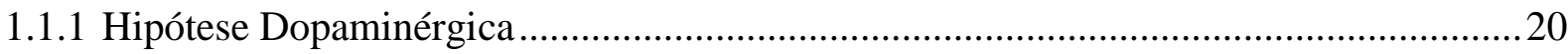

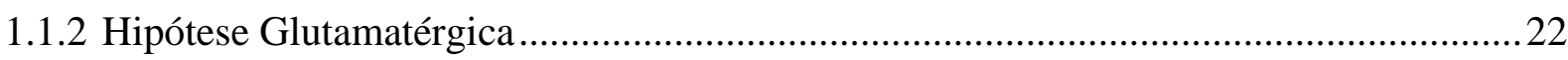

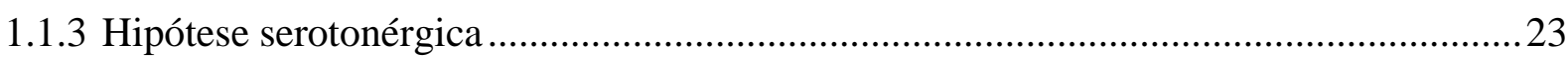

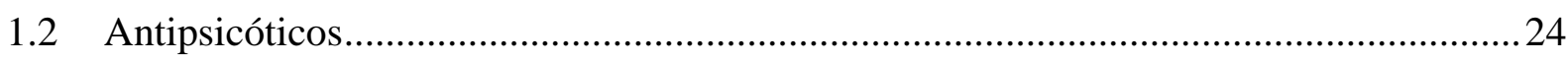

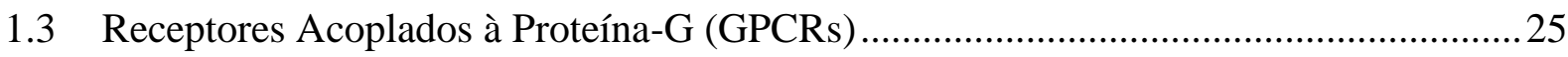

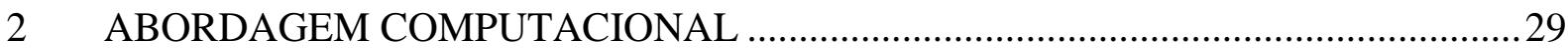

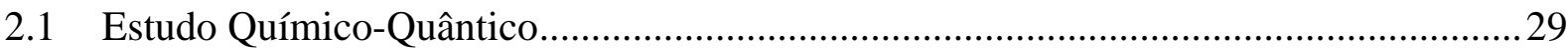

2.2 Funções Gaussianas (Gaussian Type Orbital - GTO) .................................................29

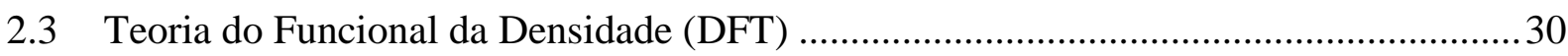

2.4 Estudos de QSAR (Quantitative Structure-Activity Relationships)............................... 34

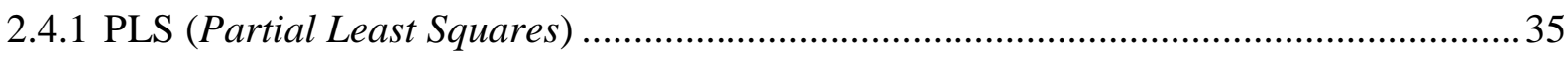

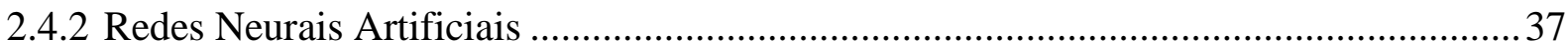

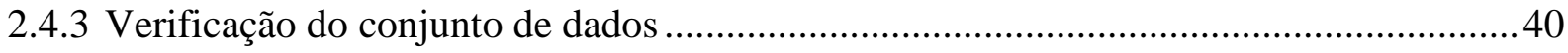

2.4.4 Obtenção dos Descritores Moleculares ........................................................................... 41

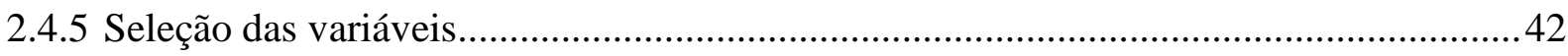

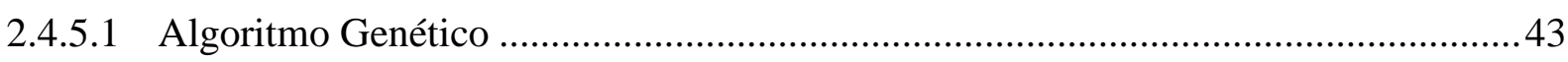

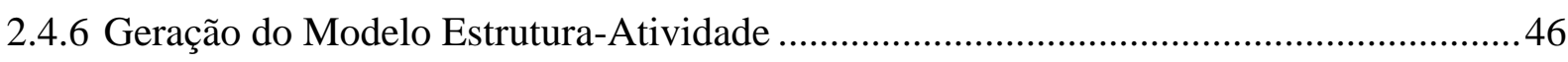

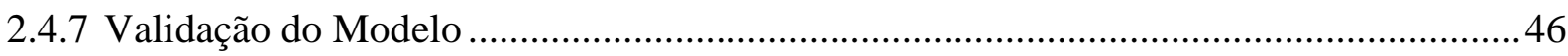

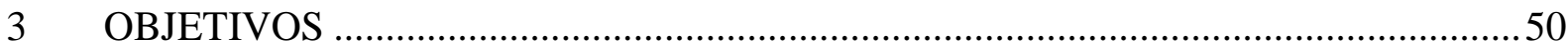

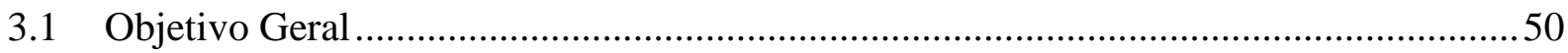

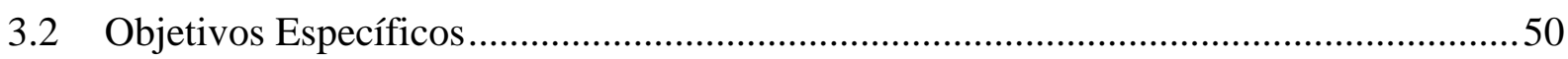

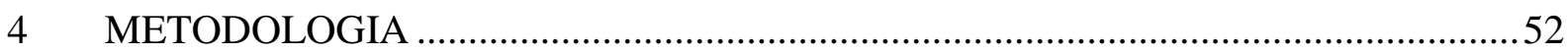

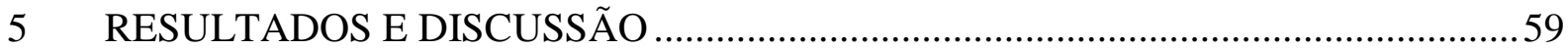

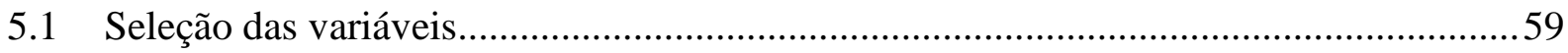

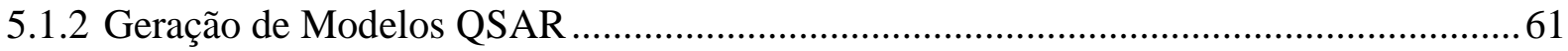

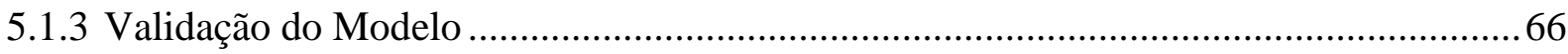

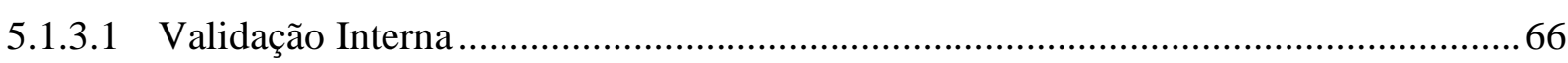




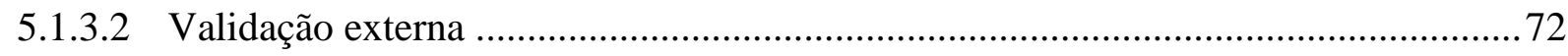

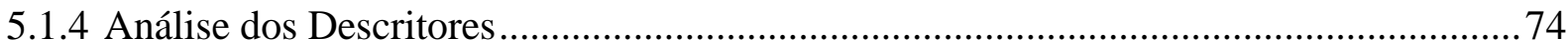

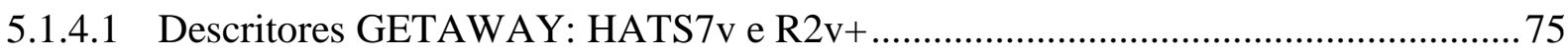

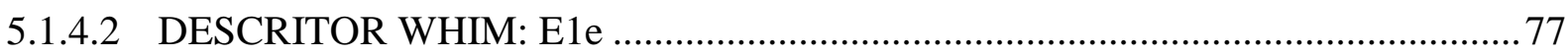

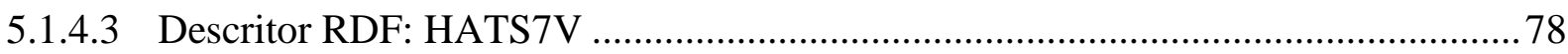

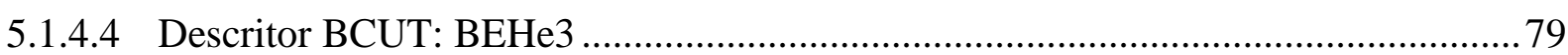

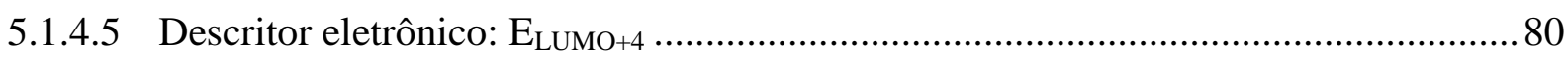

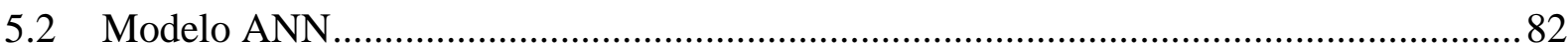

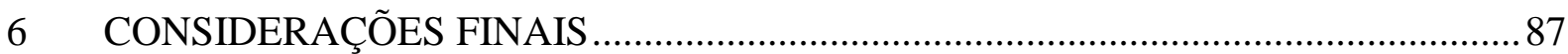

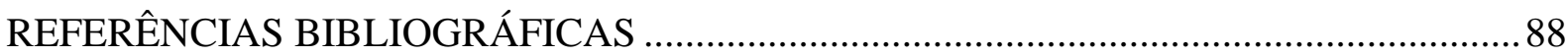




\section{INTRODUÇÃO}

O modo de se fazer ciência foi bastante modificado no decorrer dos anos através da evolução dos computadores. Os métodos computacionais somados a essa evolução possibilitaram a resolução de problemas que antes eram impossíveis de serem resolvidos, permitindo um grande avanço em vários ramos da ciência, como por exemplo, Modelagem Molecular, foco de pesquisa do presente trabalho. No que se refere à Modelagem Molecular, o papel da Química Quântica juntamente com a Mecânica Estatística é de grande importância no entendimento de conceitos Químicos e físicos, facilitando a interpretação de propriedades macroscópicas com fundamentos em nível atômico e molecular (ARROIO et al., 2005).

Os conhecimentos de Modelagem Molecular são bastante usados em Química Medicinal, ramo esse que utiliza os conceitos químicos e físicos para planejar e produzir fármacos para serem utilizados na Medicina com o intuito de prevenir, tratar ou curar doenças. Para reduzir o tempo no planejamento e produção dos fármacos, assim como o desperdício de reagentes, estudos da relação entre a atividade biológica e a estrutura química (Structure-Activity Relationships- SAR) dos compostos podem ser realizados (ROCHA, 2010).

Segundo a IUPAC (International Union of Pureand Applied Chemistry), a Química Medicinal tem como objetivo planejar, descobrir, propor, identificar e preparar compostos biologicamente ativos (protótipos), assim como também, estudar o metabolismo, interpretar o mecanismo de ação a nível molecular e construir relações entre a química dos compostos e a atividade farmacológica (LIMA, 2007).

Um ramo da Química bastante difundido na atualidade e do qual a Química Medicinal usufrui dos seus conhecimentos é a Quimioinformática. Esta faz uso de técnicas computacionais para solucionar problemas Químicos e assim transformar dados em informação e informação em conhecimento (BROWN, 2005).

Utilizando os estudos desse ramo da ciência, o presente trabalho tem por finalidade estudar um conjunto de compostos biologicamente ativos derivados do aripiprazol, medicamento utilizado no tratamento da esquizofrenia. Acoplados à Quimioinformática, temos o estudo Químico-Quântico e Quimiométrico que foram utilizados em nosso alvo de estudo. 
Esta dissertação está organizada em capítulos:

$1^{\circ}$ Capítulo: Versa sobre a fisiopatologia da esquizofrenia, as hipóteses neuroquímicas que tentam explicá-la, os Antipsicóticos e uma breve introdução aos receptores acoplados à proteína G, GPCRs;

$2^{\mathbf{o}}$ Capítulo: Discorre sobrea Abordagem Computacional, DFT e os métodos de QSAR utilizados neste trabalho;

$>\quad 3^{\circ}$ Capítulo: Apresentam os objetivos;

$>\quad 4^{\circ}$ Capítulo: Expõe a Metodologia;

$>\quad 5^{\circ}$ Capítulo: Descreve os Resultados e Discussão;

$>\quad 6^{\circ}$ Capítulo: Apresenta as considerações finais. 


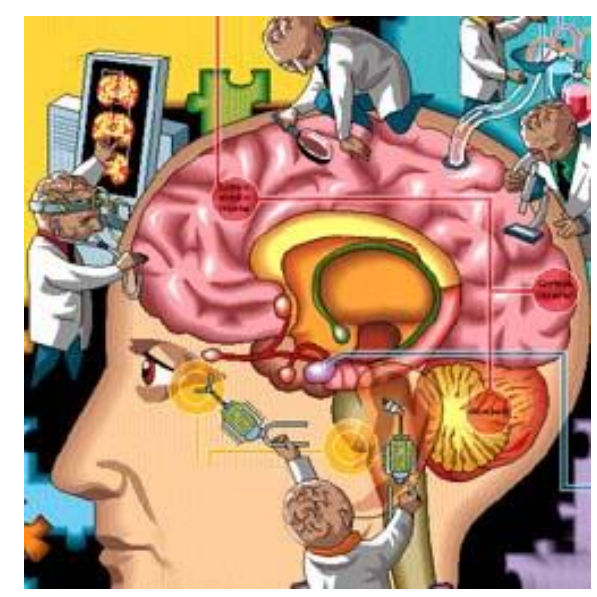

Capítulo 1

"Não me pergunte se isso tem cabimento, se tivesse, caberia em algum lugar, e eu então guardaria essa loucura...".

(Andréia Muniz) 


\section{ESQUIZOFRENIA}

Pode-se dizer que a esquizofrenia é um tipo de doença, na qual o indivíduo acometido vivencia uma realidade diferente da que deveras existe. Um indivíduo esquizofrênico sofre de um desequilíbrio neuroquímico, isto é, falta de comunicação celular dos grupos de neurônios envolvidos no comportamento, pensamento e censo-percepção. Em termos gerais, podemos dizer que a esquizofrenia nada mais é que um tipo de transtorno psiquiátrico, que de acordo com a Organização Mundial de Saúde (OMS) acomete cerca de 1\% da população mundial (ASSIS, VILLARES, BRESSAN, 2007; VILLARES, REDKO, MARI, 1999). Etimologicamente falando, a palavra esquizofrenia significa "mente dividida" ou “dissociada", justamente por que os sentimentos e pensamentos de indivíduos acometidos com essa patologia estão associados de forma desequilibrada (VAN OS, KENIS, RUTTEN, 2010).

De acordo com o Ministério da Saúde (MS), as causas da esquizofrenia não são especificadas, podendo ser decorrente de vários fatores. O que se sabe e é aceito é que existe certa vulnerabilidade associada ao estresse. Essa vulnerabilidade consiste em componentes biológicos, incluindo predisposição genética, que ao interagir com fatores físicos, ambientais e psicológicos a agrava ainda mais. Ainda, segundo dados do Ministério da Saúde, no Brasil, aproximadamente $0,3 \%$ a $2,4 \%$ das pessoas são incididas por essa psicose (Ministério da Saúde, 2012).

Os pesquisadores da Universidade Federal do Rio de Janeiro (UFRJ) estão começando a utilizar uma técnica baseada na recriação dos neurônios de indivíduos esquizofrênicos, permitindo a identificação de alterações nos neurônios destes indivíduos, como por exemplo, o consumo exacerbado de oxigênio, o qual produz mais radicais livres ocasionando em uma maior toxidez no organismo. O principal objetivo da pesquisa é entender melhor o funcionamento da esquizofrenia e assim poder contribuir para o desenvolvimento de fármacos mais eficientes para combatê-la (MARTINS, 2012).

É comum vermos na literatura que os sintomas da esquizofrenia estão agrupados em dois grandes grupos, positivos e negativos (Tabela 1). Essa divisão tem por objetivo mostrar o real estado de um indivíduo esquizofrênico (CARDOSO, 2011; FALKAI et al., 2006). Vale salientar, como é mostrado na tabela 1, que os positivos são mais exuberantes, isto é, chamam mais atenção à doença, enquanto que a fisiopatologia dos sintomas negativos se trata de um componente refratário e altamente debilitante, necessitando, dessa forma, de compreensão e uma atenção mais cuidadosa (TADON, NASRALLAH, KESHAVAN, 2009). 
Tabela 1- Agrupamento dos sintomas da esquizofrenia

\begin{tabular}{c|l}
\hline Sintomas & $\begin{array}{l}\text { Delírios (pensamentos fora do comum, como por exemplo, perseguição } \\
\text { pela polícia secreta), alucinações (alterações na percepção, como por } \\
\text { exemplo, ouvir vozes), desorganização na fala (falas sem sentidos), } \\
\text { pensamentos extremamente fora do comum (confusão mental), }\end{array}$ \\
\hline $\begin{array}{l}\text { Sintomas } \\
\text { Negativos }\end{array}$ & $\begin{array}{l}\text { afetivo (dificuldades em se expressar emocionalmente), Anedonia } \\
\text { (falta de interesse pele vida social), avolição (desânimo para iniciar ou } \\
\text { prosseguir na busca pelos objetivos), }\end{array}$ \\
\hline
\end{tabular}

Fonte: SILVA. Esquizofrenia: uma revisão; Universidade Federal de São Paulo - UNIFESP Psicologia USP, 2006.

De forma geral, a esquizofrenia segue um percurso característico, o qual está envolvido por uma fase pré-mórbida com disfunções motoras, cognitivas e sociais, e a fase prodrômica, associada a sintomas positivos. Aquela anuncia o inicio da esquizofrenia e geralmente os primeiros anos desta patologia são sinalizados por episódios psicóticos repetitivos com variação na duração. Via de regra, após cinco anos do primeiro episódio psicótico ocorre o declínio dessa doença, onde os sintomas positivos são menos notáveis, concomitante ao aparecimento dos sintomas negativos e déficits cognitivos (TADON, NASRALLAH, KESHAVAN, 2009).

$\mathrm{Na}$ tentativa de explicar a fisiopatologia da esquizofrenia, várias são as hipóteses neuroquímicas encontradas. No presente trabalho, apresentamos as principais, abordadas na seção 1.1 .

\subsection{Abordagens neuroquímicas da fisiopatologia da esquizof renia}

As principais abordagens aceitas para explicar o funcionamento do cérebro de um indivíduo incidido por distúrbios esquizofrênicos são as hipóteses dopaminérgica, glutamatérgica e a serotoninérgica. O embate dessas hipóteses está apresentado nos subitens 1.1.1, 1.1.2 e 1.1.3.

\subsubsection{Hipótese Dopaminérgica}

A dopamina (DA) é produzida pelos neurônios, localizada no tronco cerebral e se lança por diferentes vias. Uma delas é a via meso-límbico-cortical que é decorrente da área tegmental ventral e se lança para o núcleo acúmbens, também denominado de via 
mesolímbica, e para a via meso-cortical (Figura 1). De acordo com a hipótese dopaminérgica da esquizofrenia, os sintomas positivos seriam decorrentes de uma vasta atividade dos receptores $\mathrm{D} 2^{1}$ na via mesolímbica, já os sintomas negativos se dá por uma grande diminuição da atividade dos receptores dopaminérgicos na via meso-cortical. Logo, um antipsicótico bom deve atenuar a atividade dopaminérgica no núcleo acúmbens, diminuindo dessa forma os sintomas positivos, como também deverá aumentar a atividade dopaminérgica na via mesocortical, reduzindo os sintomas negativos (MOREIRA, GUIMARÃES, 2007).

Os receptores da DA fazem parte da família de receptores acoplados à proteína $G$, e suas propriedades estão intrinsecamente ligadas aos efeitos sobre a formação de Monofosfato cíclico de Adenosina (cAMP). A ativação dos receptores pertencentes à classe D1 produz aumento do cAMP enquanto que a ativação dos receptores agrupados na classe D2 inibe a formação do cAMP (STANDAERT, G.D; GALANTER, J.M, 2009).

Figura 1-Representação esquemática das vias da dopamina no Sistema Nervoso Central

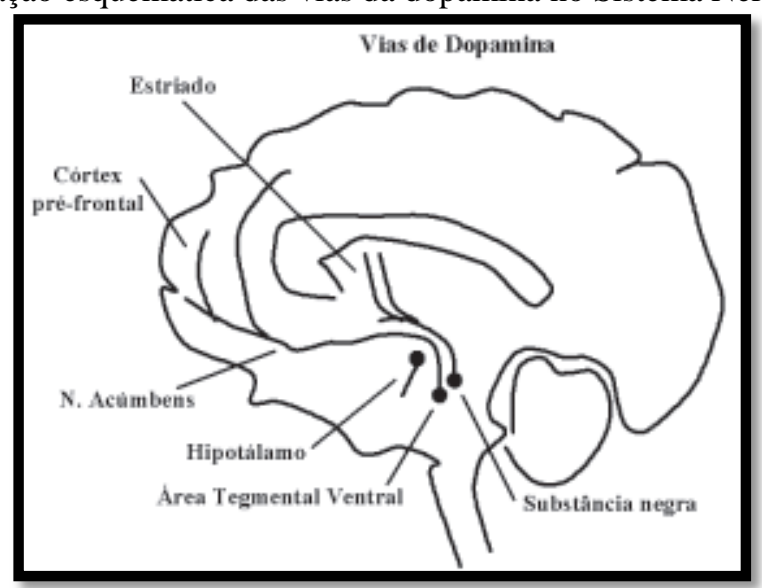

Fonte: MOREIRA, F. A.; GUIMARÃES, F.S; Mecanismo dos Antipsicóticos: Hipótese dopaminérgica, Medicina Ribeirão Preto. Rev. n. 40, p.63-71, 2007.

A hipótese dopaminérgica está associada a níveis desregulares ou elevados da neurotransmissão da dopamina no cérebro. Tal hipótese está sustentada por observações empíricas, em que o tratamento de indivíduos com antagonistas dos receptores DA, em particular o D2, atenua vários dos sintomas, mas não em todos. Outras observações também amparam essa hipótese, por exemplo, indivíduos que fazem uso de substâncias (anfetaminas, cocaína, apomorfina) que aumentam os níveis de DA ou que ativam os receptores da dopamina no Sistema Nervoso Central (SNC) desenvolvem um estado esquizofreniforme, o qual desaparece com a redução da droga (STANDAERT, G.D; GALANTER, J.M, 2009).

\footnotetext{
${ }^{1}$ A dopamina possui 5 receptores, que estão organizados em classes. A classe D1 possui 2, D1 e D5. Já a classe D2 possui 3, D2, D3 e D4.
} 
A hipótese dopaminérgica é a mais bem aceita para explicar a fisiopatologia da esquizofrenia, e seus receptores fazem parte dos receptores acoplados à proteína G. Uma breve introdução dessa classe de receptores está abordada na seção 1.3 para um melhor entendimento da ação dos receptores da DA.

\subsubsection{Hipótese Glutamatérgica}

Apesar de a hipótese dopaminérgica ser bem aceita, estudos evidenciam que outros neurotransreceptores estão envolvidos na fisiopatologia da esquizofrenia, é o caso dos receptores glutamatérgicos do tipo $N$-methil-D-aspartato (NMDA). O sistema glutamatérgico é o maior sistema excitatório presente no sistema nervoso central. Os NMDA são neuroceptores ionotrópicos, os quais estão relacionados a alterações nos canais iônicos onde seus neurotransmissores ligam-se diretamente a proteínas receptoras, integradas a esses canais (BRESSAN, PILOWSKY, 2003).

O sistema glutamatérgico atua tanto nos receptores ionotrópicos como nos receptores metabotrópicos (mGluR). Estes necessitam da produção de um segundo mensageiro para ativação dos canais iônicos (Cálcio e potássio). Eles estão presentes em toda a região do cérebro e são denominados os melhores moduladores no SNC em mamíferos (BRESSAN, PILOWSKY, 2003).

As principais características que diferenciam os receptores ionotrópicos dos metabotrópicos são (BEAR E COLS, 2002):

$>\quad$ Possuem um sítio de ligação para a glicina, como co-agonista do glutamato para sua abertura;

São rapidamente bloqueados pelos íons $\mathrm{Mg}^{2+}$, o qual está associado a uma grande dependência da voltagem, isto é, ocorre em células polarizadas, desaparecendo com a despolarização.

Conforme Bear e Cols, 2002, o glutamato é o neurotransmissor das células piramidais, as quais estão em maior número no neocórtex. Essas células são as fontes das vias eferentes e associativas do córtex cerebral e do sistema límbico, regiões envolvidas nos transtornos esquizofrênicos. 


\subsubsection{Hipótese serotonérgica}

De acordo com Meltzer et al., 1995, há interações entre o sistema serotonérgico e dopaminérgico, sendo que os dois se opõem, isto é, a inibição serotonérgica ocasiona em um aumento da dopamina em algumas regiões do cérebro, como o córtex frontal, reduzindo os sintomas negativos da esquizofrenia e os efeitos extrapiramidais. Sendo assim, podemos afirmar que a serotonina (5-Hidroxitriptamina, 5-HT) é coadjuvante para a explicação dos sintomas esquizofrênicos a nível fisiopatológico.

Acredita-se que agonistas dos receptores da serotonina produzem alucinações semelhantes às dos indivíduos esquizofrênicos. Ainda que alguns fármacos tenham afinidade pelos receptores serotoninérgicos, os estudos disponíveis na literatura não fornecem evidências concretas do envolvimento da hipótese serotonérgica (MANEGATTI et al., 2003).

Figura 2- Vias Dopaminérgica e Serotonérgica no cérebro humano

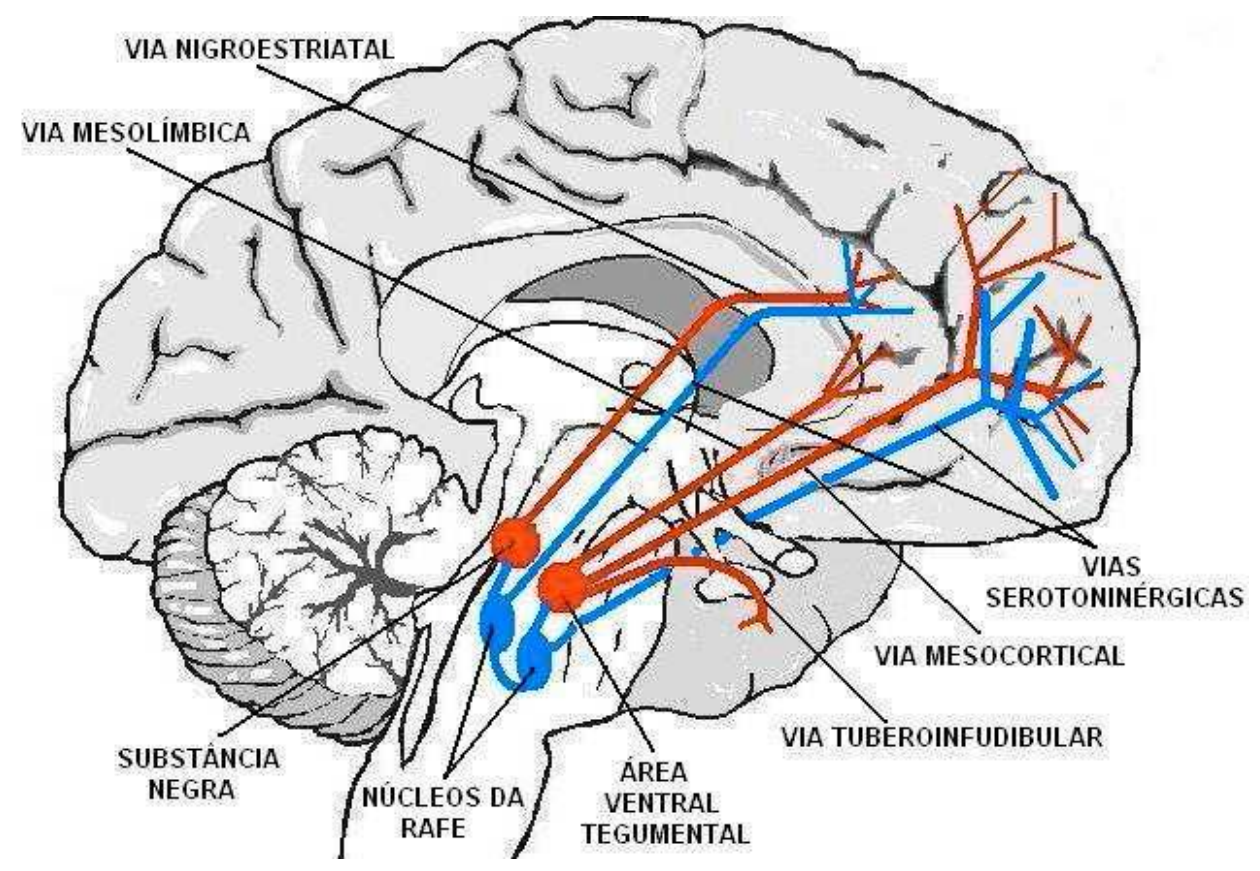

Fonte: BRITO, G.S.L.; Corroboração Computacional por "Docking" Molecular da Hipótese Auto-imune da Esquizofrenia, 2007, 61 p. Tese (Doutorado em Engenharia de Sistemas da Computação)- Universidade Federal do Rio de Janeiro, Rio de Janeiro, 2007.

Uma vez abordada as hipóteses que tentam entender a fisiopatologia da esquizofrenia, faz-se necessário o entendimento da ação dos psicóticos, apresentados no subitem 1.2. 


\subsection{Antipsicóticos}

Os antipsicóticos são substâncias que são caracterizadas por suas ações psicotrópicas, isto é, substâncias que agem no Sistema Nervoso Central (SNC), com efeitos sedativos e psicomotores. Eles são divididos em duas classes: típicos e atípicos (MOREIRA, GUIMARÃES, 2007).

Os antipsicóticos denominados típicos são aqueles que induzem efeitos extrapiramidais, efeitos esses, também denominados de "Síndrome Parkinsoniana". Enquanto que os antipsicóticos atípicos são substâncias que desencadeia a ação antipsicótica com uma redução significativa na redução de efeitos extrapiramidais. Além do mais, eles possuem uma maior eficácia tanto nos sintomas positivos (delírios, alucinações) quanto nos negativos (déficits cognitivos) (MOREIRA, GUIMARÃES, 2007; OLIVEIRA, 2000). Dentre os antipsicóticos atípicos temos o aripiprazol, objeto de estudo do presente trabalho.

É sabido que os neurotransmissores são substâncias químicas mensageiras, oriundas dos neurônios, que tem por função a sinalização celular por meio das sinapses. A atuação dos neurotransmissores ocorre da seguinte forma: supomos que exista um neurônio A e um B. Para cada neurotransmissor do neurônio A existe um receptor no neurônio B, o qual é ativado quando há a neurotransmissão. Quando esse fenômeno ocorre, o neurotransmissor volta para sua célula para ser reciclado para uma nova transmissão, pois eles só podem ser utilizados apenas uma vez. Os antipsicóticos atuam no sentido de impedir o retorno do neurotransmissor para sua célula e assim permanecer por mais tempo, aumentando, dessa forma, o nível de neurotransmissão (PURVES, et al., 2004, GUYTON, HALL, 2006).

O aripiprazol, 7-[4-4-(2,3-diclorofenil)-1-piperazinil]-butoxi]-3,4-dihidrocarbostiril (Figura 3), é uma substância ativa que estimula os receptores dopaminérgicos (D2, D3) e os receptores serotoninérgicos (5HT1A e 5-HT2A). Seus efeitos terapêuticos ocorrem via agonismo parcial D2 e 5-HT1A e antagonismo 5-HT2A (TONELLI, 2006).

Figura 3- Estrutura química do Aripiprazol

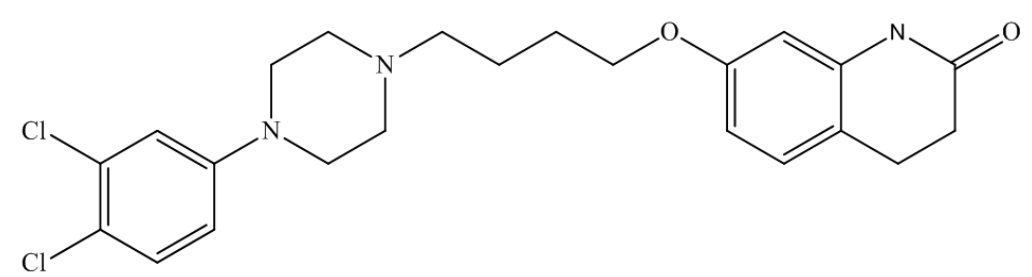

Muscatello et al., 2010, realizaram um estudo a fim de comprovar a eficácia do aripiprazol juntamente com outro antipsicótico, a Clozapina, leponex®. Nessa pesquisa, esses dois fármacos foram administrados em pacientes através de experimentos denominados 
duplo-cego $^{2}$, e concluíram que a adição conjunta deles forneceu resultados benéficos sobre a sintomatologia e psicopatologia geral de pacientes esquizofrênicos.

\subsection{Receptores Acoplados à Proteína-G (GPCRs)}

Proteínas G são compostos com pesos moleculares grandes, denominadas heterotrimétricas, sendo constituídas por três polipeptídios diferentes, $\alpha, \beta$ e $\gamma$. São assim denominadas por interagir com grupos guanílicos Guanosina Difosfato (GDP) e Guanosina Trisfosfato (GTP). Estas proteínas fazem parte de um grupo com cerca de 50 membros, os quais em seus estados inativos acoplam-se aos receptores no meio intracelular. Os receptores que conduzem seus sinais via proteínas $G$ possuem uma região extracelular e uma região transmembranar com sete domínios hidrofóbicos, chamados receptores 7TM (MOURA, VIDAL, 2011).Vale ressaltar que proteínas de membrana ligadas à GTP interagem com os sistemas receptores que inibem ou ativam a adenilatociclase. $\mathrm{O}$ papel da proteína $\mathrm{G}$ é realizar a comunicação entre os GPCRs e efetores múltiplos, como por exemplo, enzimas e canais iônicos (SPIEGEL, 1996).

A ação dos GPCRs ocorre primeiramente por meio de ativação de proteínas regulatórias ligadas ao nucleotídeo guanina, às referidas proteínas G. Ao ser ativado, o receptor se associa a um complexo de proteínas- $\mathrm{G}$ provocando uma alteração de GTP para GDP. Os GPCRs podem ser ativados por ligantes, como hormônios, neurotransmissores, odorantes e fótons de luz. Quando a proteína G é ativada, ocorre o processo de comunicação que é iniciado com a ativação dos GPCRs e finaliza com a resposta mediada pela ação de moléculas efetoras que inclui canais iônicos (cálcio e potássio) e enzimas que produzem segundo mensageiros, tal como o adenilatociclase, enzima que gera o segundo mensageiro cAMP (Figura 4) (SPIEGEL, 1996).

\footnotetext{
${ }^{2}$ Experimento denominado duplo-cego são métodos empregados em seres humanos, onde nem o examinador nem o paciente sabe o que estão utilizando como objeto de estudo em um dado momento.
} 
Figura 4- Ação dos receptores acoplados à proteína $\mathrm{G}$

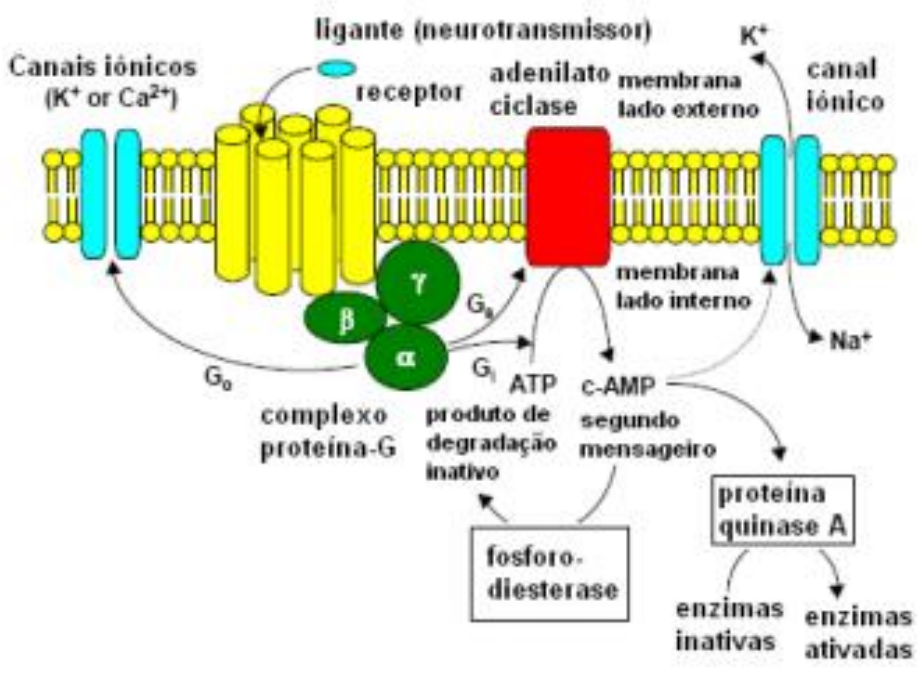

Fonte: LIMA, E. F.; Estudo da Modelagem do receptor carnabinoide CB1 e suas interações com o $\Delta^{\mathbf{9}}$ - THC, 2009, Tese (Doutorado em Ciências- Físico-Química)- Instituto de Química de São Carlos, Universidade de São Paulo, 2009.

De acordo com Flower (1999), os GPCRs contêm sete membranas com alto nível de conservação (Figura 5), os quais possuem de 20 a 30 resíduos de aminoácidos com alto grau de hidrofobicidade, e sua estrutura se assemelha a da bacteriorodopsina (BR).

As hélices transmembranais na figura 5 são mostradas como cilindros conectados por loops (alças) marcados por linhas. A membrana, como mostra a figura 5, está marcada por uma área sombreada, e o diagrama superior mostra um receptor desdobrado, indicando a topologia de uma GPCR. As hélices estão numeradas de 1 até 7 e os loops intracelulares (IC) estão assinalados por IC1 até IC3. Os loops extracelulares (EC) estão assinalados como EC1 até EC3. A parte inferior da figura 5 mostra a união das sete hélices em um modo tridimensional (FLOWER, 1999). 
Figura 5- Esquematização de um receptor acoplado à proteína $\mathrm{G}$

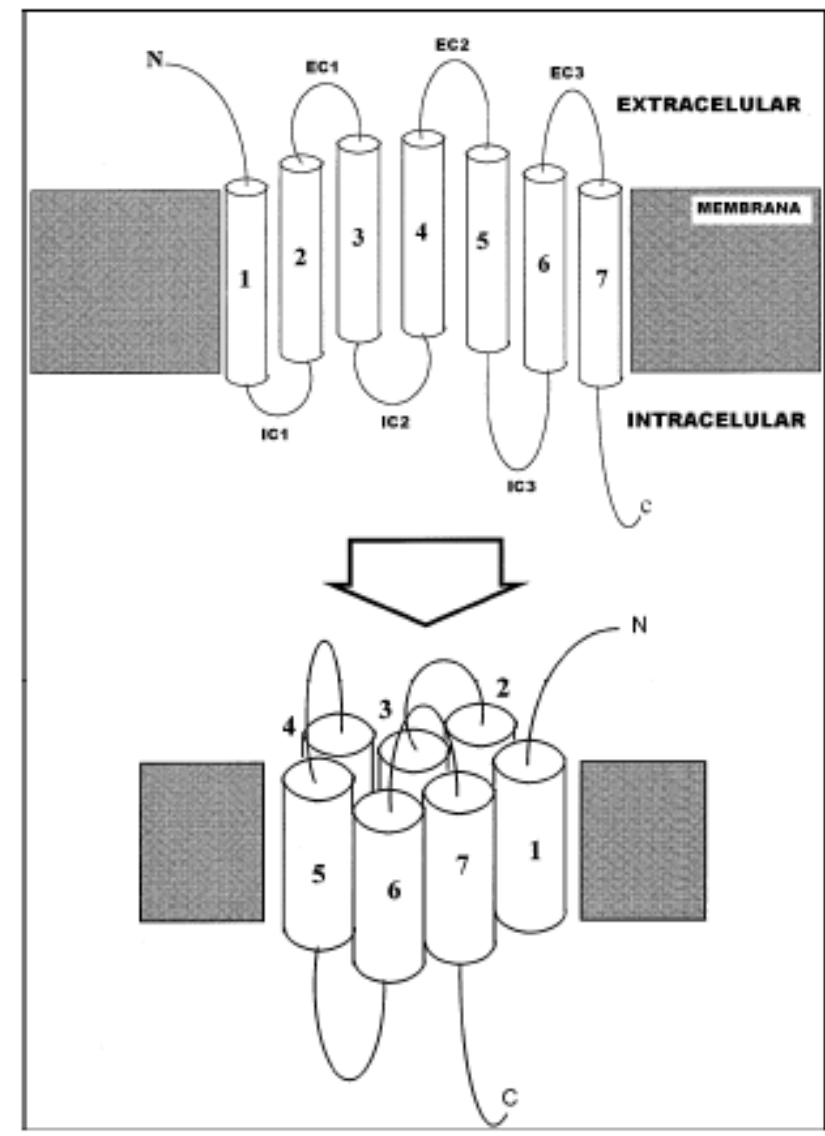

Fonte: FLOWER, D. R.; Modeling G-protein-coupled receptors for drug design. Biochimica et Biophysica Acta. v.1422, p.207-234, 1999.

Portanto, levando em consideração o difícil entendimento da fisiopatologia da esquizofrenia, bem como a pouca quantidade de medicamentos disponíveis para o tratamento, o presente trabalho torna-se relevante, uma vez que poderá contribuir para o desenvolvimento de novos fármacos. 

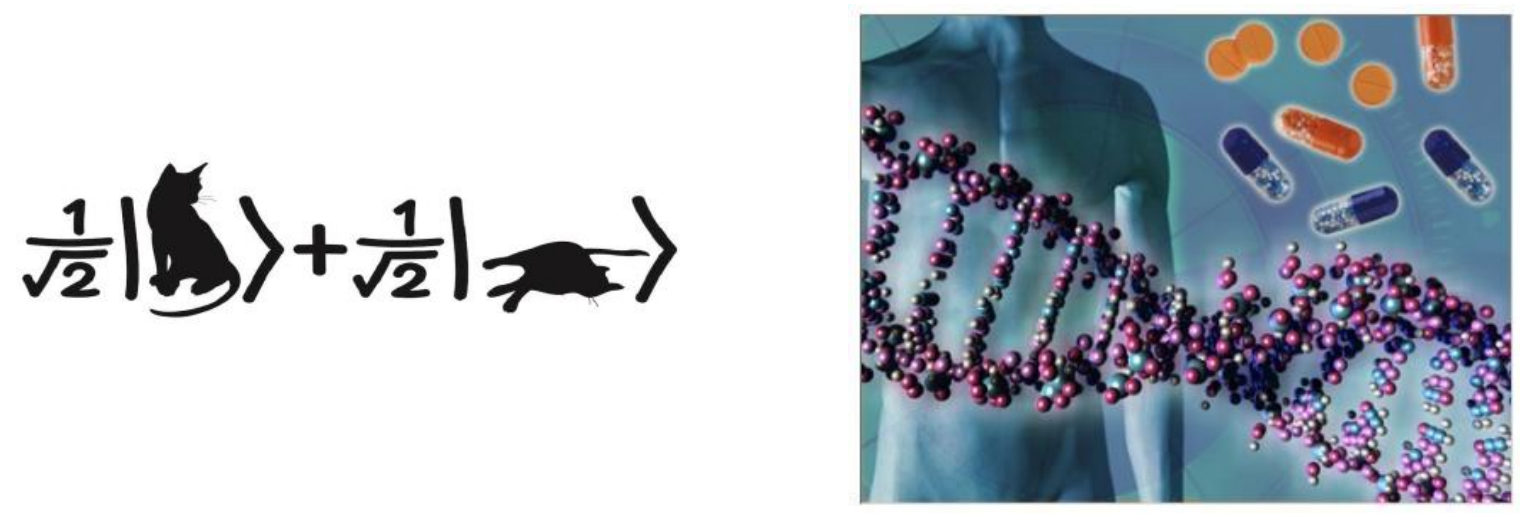

Capítulo 2

"Tudo da Química e muito da Física pode ser obtido a partir da QUÂNTICA"

(Paul Adrien Maurice Dirac)

...Porque ter a mente boa não é o bastante; o principal é aplicá-la bem. As maiores almas são capazes tanto das maiores virtudes quanto dos maiores vícios, e aqueles que marcham lentamente podem avançar muito mais, se seguirem o caminho certo, do que os que correm, porém dele se afastam.

Descartes,

(Discurso sobre o método, parte I), 


\section{ABORDAGEM COMPUTACIONAL}

Neste capítulo introduziremos um pouco sobre as funções gaussianas, o método DFT e os métodos QSAR utilizados nesse trabalho.

\subsection{Estudo Químico-Quântico}

Os grandes avanços da Química-Quântica nos últimos 30 anos e o desenvolvimento de computadores potentes têm permitido mostrar que os métodos teóricos são ferramentas de suma importância em estudos de sistemas Químicos. No que concerne à tecnologia, a possibilidade de estudar fenômenos químicos em nível molecular, vem possibilitando avanços em várias áreas como, por exemplo, a de desenvolvimento de fármacos.

Os cálculos das propriedades de estrutura eletrônica do sistema em estudo (Tabela 2) foram realizados utilizando as funções do tipo Gaussianas (Gaussian Type Orbital- GTO) (subitem 2.2) adicionado ao método DFT (Density Functional Theory) (subitem 2.3).

\subsection{Funções Gaussianas (Gaussian Type Orbital - GTO)}

Uma das grandes dificuldades em cálculos de estrutura eletrônica é a escolha do tipo de função de base. Essa é uma etapa criteriosa para obter êxito nos resultados dos cálculos. Para esse trabalho foram escolhidas as funções do tipo Gaussianas, GTOs, como já foi mencionada anteriormente.

As GTOs foram desenvolvidas por Boys (1950) com o intuito de simplificar os cálculos computacionais de integrais multicêntricas (JENSEN, 2007). A equação 1 mostra a forma dessas funções em coordenadas polares.

$$
\chi_{\varsigma, \eta, \mathrm{l}, \mathrm{m}}(\mathrm{r}, \Theta, \Phi)=N Y_{l, m}(\Theta, \Phi) r^{2(n-1)-l} \exp \left[-\varsigma r^{2}\right]
$$

Em que $r, \Theta, \Phi$ são os ângulos, $N$ é uma constante de normalização e $\varsigma$ (zeta) é um parâmetro que deverá ser ajustado em função de algum critério predeterminado, que na maioria das vezes é o de mínima energia.

As principais desvantagens em utilizar GTOs são:

$>\quad$ No núcleo, as GTOs possuem derivadas zero, indo de encontro com comportamento apropriado no núcleo, pois a energia de interação elétron-núcleo tende ao infinito. 
$>\quad$ As GTOs caem mais rapidamente em regiões distantes do núcleo, impedindo a representação nessas regiões. Para obter uma dada precisão nos cálculos, mais funções GTOs devem ser utilizadas.

A principal vantagem no uso de GTOs é que a combinação linear de várias funções gaussianas resulta em uma única função gaussiana, diminuindo, dessa forma, o número de integrais necessárias ao cálculo, reduzindo o tempo computacional (MORGON, CUSTÓDIO, 2001). Portanto, o uso de funções GTOs em cálculos de estrutura eletrônica se justifica pela eficiência computacional.

No tratamento de moléculas os orbitais atômicos são distorcidos, ou seja, polarizados pelos átomos adjacentes. Para resolver esse problema é necessário acrescentar funções de polarização, que são funções com momentos angulares diferentes do da base original e funções difusas que trata das regiões mais afastadas do núcleo e de elevada densidade eletrônica, por exemplo, 6-31G ++ (d, p), em que o d e p são funções de polarização e representam, respectivamente, 5 funções de polarização para os átomos do $2^{\circ}$ período e 3 funções de polarização para o Hidrogênio. $\mathrm{O}++$ representa funções difusas utilizadas para todos os átomos do sistema. O 6 representa a região mais próxima do núcleo, o 3 a parte interna do orbital de valência, o 1 a parte externa do orbital de valência e o G refere-se as funções gaussianas (MORGON, CUSTÓDIO, 2001).

\subsection{Teoria do Funcional da Densidade (DFT)}

A Teoria do funcional da Densidade emergiu nos anos 60 e foi desenvolvida por Walter Kohn. A DFT é um método bastante vantajoso frente a outros existentes, em se tratando de sistemas moleculares grandes e custo computacional, além de ser um método bastante simplista.

Foi exatamente em 1964 que Walter Kohn e seu aluno Pierre Hohenberg publicaram um artigo no qual foi apresentada uma nova forma de se resolver a equação de Schrödinger (Eq.2), utilizando a densidade eletrônica $\rho(\vec{r})$ ao invés de funções de onda. A $\rho(\vec{r})$ contém toda a informação do sistema. A ideia deles foi simples: a energia total é um observável, então é só colocá-la em termos $\operatorname{de} \rho(\overrightarrow{\mathrm{r}})$, ou seja, $\mathrm{E}[\rho]$. A partir desse funcional o estado fundamental e a densidade do sistema podem ser encontrados (Figura 6). O único problema é que não foi dito a forma com a qual os funcionais variam com a densidade (HOHENBERG, KOHN, 1964). 


$$
\hat{\mathrm{H}} \psi=\mathrm{E} \psi
$$

Figura 6- Esquema de cálculo do potencial efetivo, $\boldsymbol{v}(\overrightarrow{\mathbf{r}})$, do número de elétrons, N, do Hamiltoniano do sistema e consequentemente a energia, E, a partir de $\rho_{(\mathrm{r})}$.

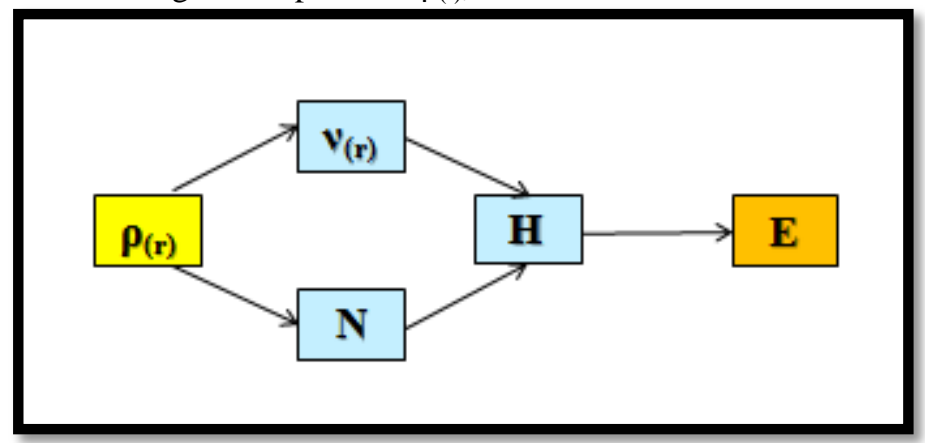

Adaptado de: ROCHA, W.R.; DUARTE, H.A.; Teoria do Funcional da Densidade; In: MORGON, N. H, COUTINHO, K. Métodos de Química Teórica e Modelagem Molecular; São Paulo: editora: livraria da Física, 2007.

Em 1965, em um trabalho conjunto, W. Kohn e L.J. Sham publicaram um artigo, resolvendo o problema supracitado. Nesse artigo eles mostraram como encontrar os funcionais. O problema foi resolvido com a criação de um sistema fictício, no qual não há interação entre os elétrons, no entanto a densidade eletrônica seria igual à densidade do sistema original. E isso era simples de se fazer, é só associar os elétrons fictícios a um potencial efetivo, denominado de potencial de Kohn-Sham (KS), $v_{k s[\rho](\vec{r})}(\mathrm{KONH}, \mathrm{SHAM}$, 1965). A equação de KS possui a mesma forma da equação de Schödinger, exceto que nela trabalhamos com densidade eletrônica ao invés de função de onda (Equação 3).

$$
\left(-\frac{1}{2} \nabla^{2}+\mathrm{v}_{\mathrm{ef}}\right) \psi_{i}^{K S}=\varepsilon_{i} \psi_{i}^{K S}
$$

Em que $v_{\text {ef }}$ é o potencial efetivo e $\psi_{i}^{K S}$ são os orbitais de KS.

A resolução da equação de KS (Eq.3) é realizada de forma iterativa (Figura 7). 
Figura 7- Procedimento para cálculos em DFT

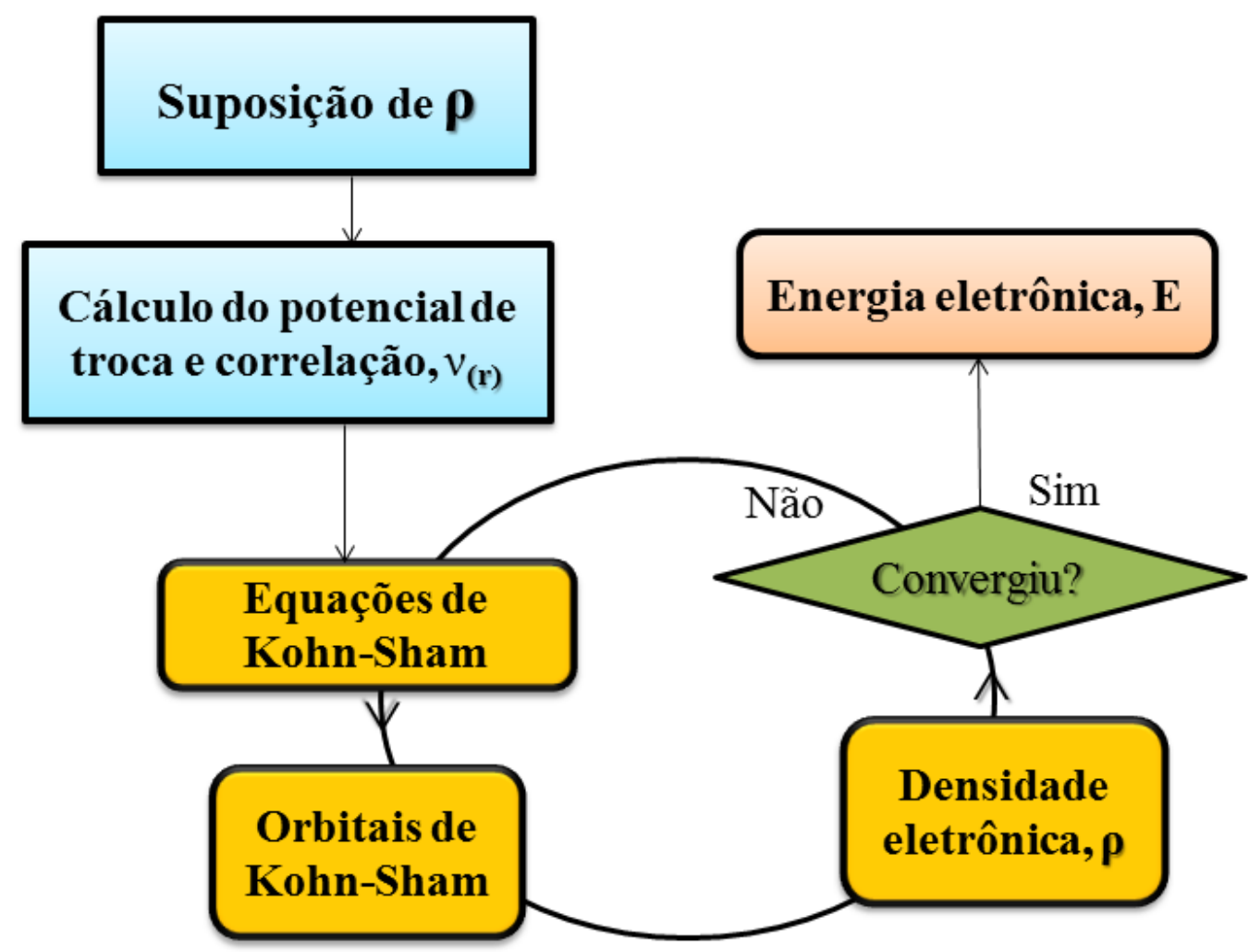

Adaptado de: ATKINS, P., PAULA, J. DE., FRIEDMN., R.; Quanta, Matéria e Mudança- uma abordagem molecular para a Físico-Quimica; Rio de Janeiro: LTC, 2011, 426p.

A eficiência de cálculos em DFT está no termo de troca-correlação, definido como um funcional da densidade eletrônica, que inclui a correlação eletrônica, onde é encontrado o termo de troca, que nada mais é que a correlação entre elétrons do mesmo spin e a diferença entre a energia cinética do sistema real e a energia cinética do sistema fictício (DUARTE, ROCHA, 2007).

No presente trabalho, o funcional utilizado foi o B3LYP (Eq.4). Este funcional faz parte da classe dos funcionais híbridos, que são assim denominados por utilizar em sua fórmula parte do termo de troca exato do método Hartree-Fook ${ }^{3}$. Os funcionais híbridos foram os primeiros a serem desenvolvidos por Levy por uma metodologia denominada de conexão adiabática (PIELA, 2007).

$$
\begin{gathered}
E_{X C}^{B 3 L Y P}=\left(1-a_{0}-a_{x}\right) E_{X}^{L S D}+a_{0} E_{X}^{\text {exato-HF}}+a_{x} E_{X}^{B 88}+ \\
\left(1-a_{c}\right) E_{C}^{V W N}+a_{c} E_{C}^{L Y P}
\end{gathered}
$$

\footnotetext{
${ }^{3} \mathrm{O}$ método Hartree-Fock não será abordado nessa dissertação por não ser foco da presente pesquisa. Para mais informações reportar à literatura.
} 
Em que $E_{X}^{L S D}$ é o termo pertencente à aproximação da Densidade de Spin Local, $E_{X}^{\text {exato-HF é a }}$ energia de troca de Hartree-Fock. Os parâmetros são: $a_{0}=0,20, a_{x}=0,72$ e $a_{c}=0,81$. Estes valores foram escolhidos para reproduzir a energia de atomização. O $E_{X}^{B 88}$ é o termo de troca do funcional do Becke que foi incluído correções em 1988, $E_{C}^{V W N}$ é o termo de correlação do funcional de Vosko- Wilk-Nisair e o $E_{C}^{L Y P}$ é o termo de correlação do funcional de Lee-Yang-Parr.

O B3LYP foi escolhido por ser um dos funcionais mais utilizados (Figura 8) e por possuir uma dada precisão nos cálculos de moléculas orgânicas (SOUSA, FERNANDES, RAMOS, 2007). Essa escolha também foi baseada através de testes com outros funcionais.

Figura 8-Porcentagem de vários funcionais utilizados, analisados a partir da Web of Science (2007)

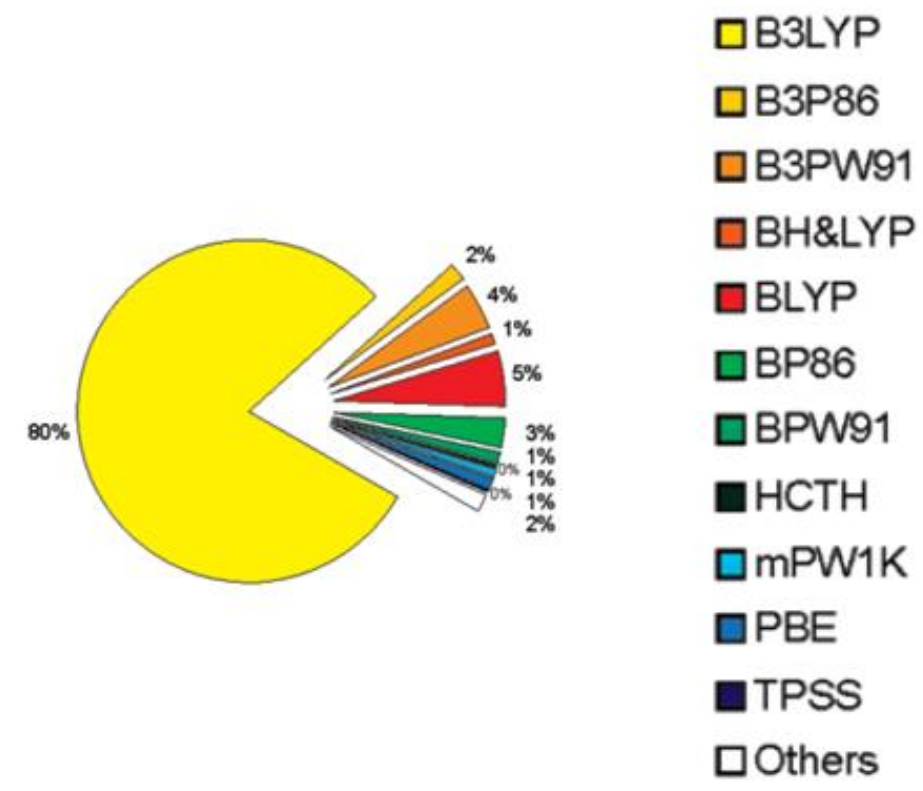

Fonte: SOUSA, F.S., FERNANDES, P.A., RAMOS, M.J.; General Performance of Density Functionals; J.Phys.Chem, 2007, n.111, p.10439-10452.

Portanto, levando em consideração a implementação computacional eficiente da correlação eletrônica, a qual possibilita o tratamento de sistemas grandes com um grau de eficácia considerado, a DFT foi o método escolhido para a realização desse trabalho. Além do mais, a DFT, no que concerne aos aspectos formalismo, conceito e metodologia, está em um grande desenvolvimento e é uma das ferramentas mais utilizadas no estudo de sistemas químicos relacionados à Química Orgânica (sistemas utilizados nesse trabalho), à Química Inorgânica, à Química de superfície, à Ciência de Materiais, à Bioquímica e ao Meio Ambiente (DUARTE, ROCHA, 2007). 


\subsection{Estudos de QSAR (Quantitative Structure-Activity Relationships)}

Estudos de QSAR (Quantitative Structure-Activity Relationships) são aplicados a diversas áreas, principalmente no planejamento de fármacos, e seu principal objetivo é construir modelos matemáticos que sejam capazes de relacionar a estrutura química à atividade biológica de grupos de compostos com estruturas análogas (ALMEIDA et al., 2010).

A estrutura química está relacionada à forma com a qual as unidades constitucionais estão organizadas no espaço. Estas unidades referem-se às moléculas, átomos, íons ou radicais, em que suas propriedades estão descritas em termos de estrutura atômica, molecular, eletrônica e cristalina, enquanto que a atividade biológica é designada como uma medida realizada em laboratório. Essa medida é o resultado de reações químicas e interações intermoleculares entre uma determinada molécula e seu alvo biológico. A estrutura química e a atividade biológica são de especial interesse para a Química Medicinal, pois as várias interações intermoleculares e reações químicas são fatores determinantes no comportamento de uma substância bioativa (FERREIRA, 2002).

A interação de dois ou mais fármacos no sítio ativo de um sistema biológico (receptor, enzima, canais iônicos, ácido nucleico, etc.), assim como suas distribuições no sistema dependem apenas de seus arranjos químicos, desde que o sistema biológico esteja mantido constante. Se as estruturas são análogas, a diferença nas propriedades físico-químicas, assim como as diferenças nas forças de interação podem ser descritas de uma forma quantitativa, de modo que, como afirmado no parágrafo anterior, a variação na atividade biológica está intrinsecamente relacionada a essas propriedades. Dessa forma, através das propriedades físico-químicas bem como das interações químicas, é possível predizer a atividade biológica (KUBINYI, 1993).

Há uma variedade de métodos que são utilizados em estudos QSAR, no entanto nem todos são úteis e aplicáveis, dependendo do sistema a ser estudado. A Figura 9 mostra os métodos multivariados mais utilizados. Os métodos utilizados para o presente estudo foram o PLS, abordado no subitem 2.4.1 e a técnica de Redes Neurais Artificiais (subitem 2.4.2). 
Figura 9-Métodos Multivariados comumente usados

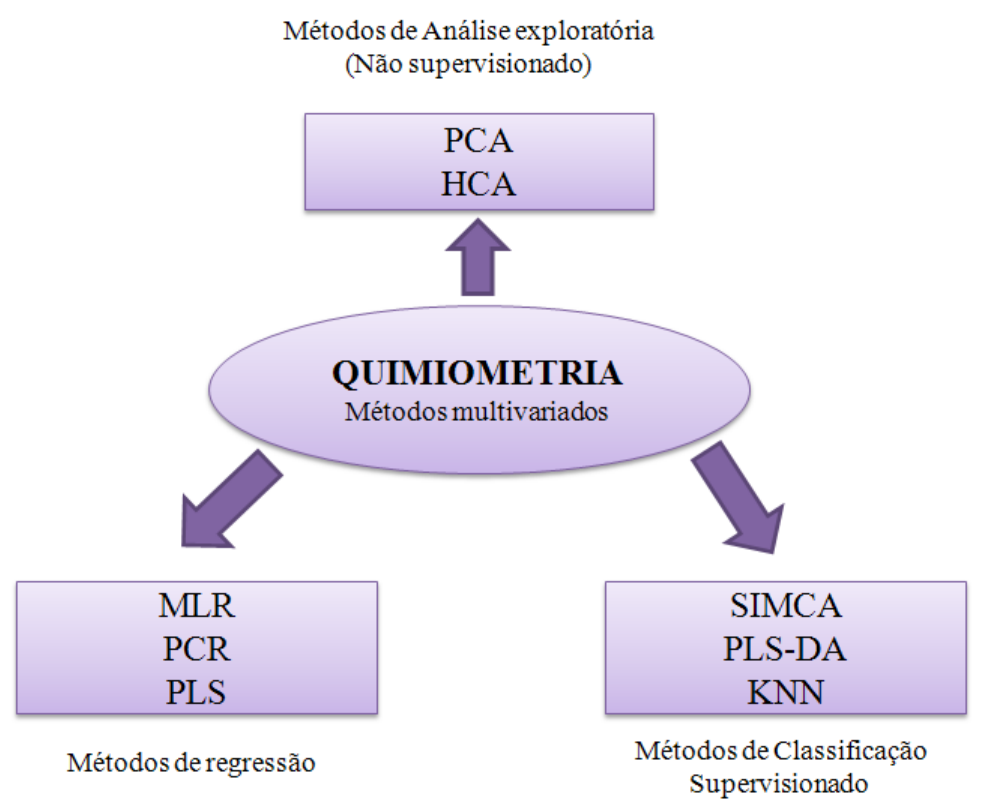

Adaptado de: FERREIRA, M.C.; Multivariate QSAR; J.Braz.Chem.Soc. V. 13. N. 6. p. 52-753, 2002.

Para obter êxito em um estudo de QSAR, alguns fatores devem ser cuidadosamente analisados, a saber:

Conjunto de dados utilizados para a geração do modelo;

Atividade biológica medida;

$>\quad$ Estrutura dos compostos;

$>$ Seleção dos descritores;

$>\quad$ Análise estatística;

$>\quad$ Testes de validação do modelo;

Todos os requisitos supracitados estão abordados nos subitens 2.4.3; 2.4.4; 2.4.5; 2.4.6; 2.4.7. Antes de realizar todos esses testes é necessário escolher o método para a geração do modelo, Para esse trabalho, dois foram os métodos escolhidos (subitem 2.4.1 e 2.4.2).

\subsubsection{PLS (Partial Least Squares)}

O método PLS, Partial Least Squares, foi originalmente introduzido por Wold. Tratase de um método altamente popular e pragmático além de ser um dos mais empregados em análise multivariada, sendo utilizado em vários campos, como por exemplo, o de QSAR (LIU, LONG, 2009; SENA, POPPI, 1999; NILSON, DE JONG, SMILDE, 1997). 
O PLS usa as informações do Y, atividade química, no cálculo das variáveis latentes, referente aos descritores X. Essas duas matrizes, Y e X, são decompostas em “n” variáveis (Equação 5 e 6) (SENA, POPPI, 1999).

$$
\begin{array}{ll}
Y=U Q^{\prime}+F=\sum u_{n} q_{n}^{\prime}+F & \text { Eq.5 } \\
X=T P^{\prime}+E=\sum t_{n} P^{\prime}{ }_{n}+E & \text { Eq.6 }
\end{array}
$$

Em que U e T são as matrizes de scores (expressam relação entre as amostras) das matrizes $\mathrm{Y}$ e X, respectivamente; Q e P referem-se aos pesos, loadings (refere-se às variáveis); F e E são os resíduos. A correlação entre as duas matrizes Y e X nada mais é que uma relação linear obtida pelo coeficiente de regressão linear (equação 7) para "n” variáveis.

$$
U_{n}=b_{n} t_{n}
$$

Os valores de $b_{n}$ são agrupados na matriz diagonal $\mathrm{B}$, que contem os coeficientes de regressão entre as matrizes de scores $\mathrm{U}$ de $\mathrm{Y}$ e $\mathrm{T}$ de $\mathrm{X}$. A melhor relação linear entre essas matrizes é conseguida através de rotações mínimas das variáveis latentes.

A matriz Y pode ser calculada a partir da equação 8

$$
Y=T B Q^{\prime}+F
$$

E a atividade de novas amostras previstas através dos novos scores, $\mathrm{T}^{*}$, substituídos na equação 8,

$$
Y=T^{*} B Q^{\prime}
$$

É necessário encontrar o melhor número de variáveis latentes, VL. Estas, geralmente são encontradas através de um procedimento denominado de validação cruzada (Cross validation). A validação cruzada é uma técnica usada para avaliar a capacidade de generalização do modelo a partir de um conjunto de dados. Nesse tipo de metodologia, o conjunto de dados é dividido em grupos (de tamanho N), a partir daí, vários modelos são obtidos. No entanto, o cálculo é realizado sempre com a exclusão de um dos grupos. Esse procedimento se torna necessário para evitar o superajuste (overfitting). $\mathrm{O}$ uso desse tipo de metodologia tem como finalidade encontrar um modelo bem acurado, que na prática tenha um bom desempenho frente a um novo conjunto de dados (FERREIRA et al., 1999; MARTINS, FERREIRA, 2013).

Uma das características mais pronunciada do PLS é sua robustez, isto é, seus parâmetros não sofrem grandes variações com a inserção ou exclusão de amostras, Isso possibilita o trabalho com outros compostos, cujo processo não é mantido rigorosamente da mesma forma (GELADI, KOWALSKI, 1986). 


\subsubsection{Redes Neurais Artificiais}

É sabido que os fenômenos físico-químicos das moléculas não são originados de apenas uma propriedade, mas de vários fatores, com pesos diferentes, que juntos podem acabar alterando a propriedade em estudo. Sabe-se também que a relação entre estes fatores pode não possuir uma relação de linearidade com a resposta em procura. Desta forma, a tarefa em descobrir a relação entre a interação dos diversos fatores e a resposta obtida torna-se trabalhosa, demandando, muitas vezes, várias variáveis e a utilização de fronteiras não lineares para se chegar à resposta desejada (CROSS, HARRISON, KENNEDY, 1995; GOH, 1995).

Levando em consideração o exposto acima, as Redes Neurais Artificiais (Artificial Neural Network-ANN) são uma excelente alternativa para resolver o problema supracitado. A ANN é uma ferramenta de regressão não linear e de reconhecimento de padrões (CROSS, HARRISON, KENNEDY, 1995). Uma ANN é um modelo matemático inspirado no funcionamento do cérebro e no modo como ele processa as informações, formada por unidades básicas, os neurônios, tal como o sistema nervoso biológico. Os neurônios são ligados entre si por valores numéricos que ditam a natureza e a força de comunicação entre os mesmos, da mesma forma que as conexões sinápticas (excitatórias ou inibitórias) presentes no sistema nervoso (CROSS, HARRISON, KENNEDY, 1995; GOH, 1995).

O neurônio artificial, semelhantemente ao neurônio biológico que propaga o sinal quando a neurotransmissão o ativou, recebe um ou mais sinais de entrada e as processa por meio da soma ponderada de uma função de ativação. Basicamente, os elementos constituintes de uma ANN são (Figura 10): os pesos sinápticos, a função de soma e a função de transferência também conhecida como função de ativação. A Figura 11 mostra um exemplo de função de transferência, utilizada no presente trabalho (DOROFKI et al.; 2012).

Figura 10- Funcionamento de um neurônio artificial

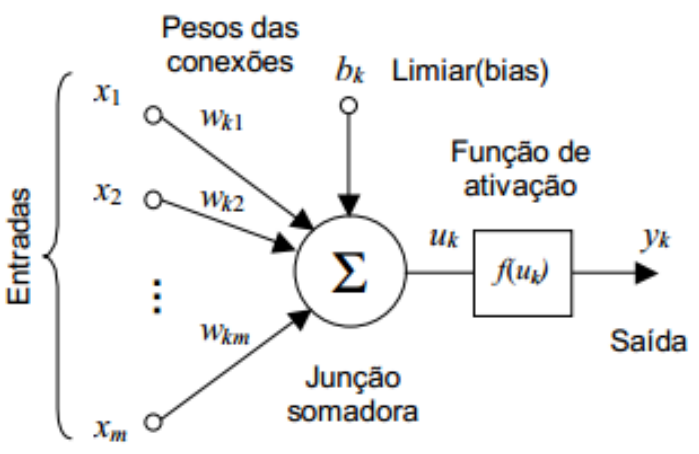

Fonte: CASTRO, L, N DE., ZUBEN, F. J, V.; Redes Neurais Artificiais; DCA/FEEC/Unicamp. 
Figura 11-Tipo de função de ativação utilizada nesse trabalho

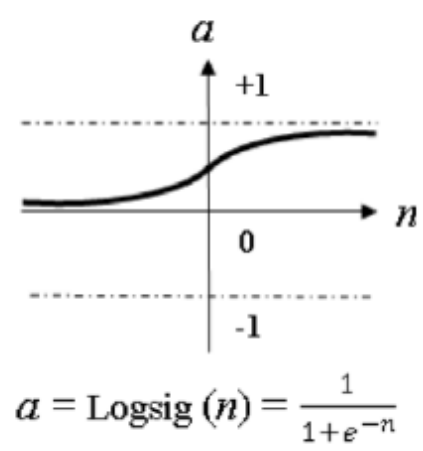

Fonte: DOROFKI, M., ELSHAFIE, A. H., JAAFAR, O., KARIM, O. A.; Comparison of Artificial Neural Network Transfer Functions Abilitiesto Simulate Extreme Runoff Data; IPCBEE, vol. 33, p. 39-44, 2012.

Como já dito, o neurônio artificial se trata de uma estrutura lógica matemática que tenta simular a forma, o comportamento e as funções de um neurônio biológico. Dessa forma, como visto na Figura 11, os dendritos foram trocados por entradas, em que as ligações com o corpo celular artificial são formadas através de pesos, semelhante às sinapses. Os estímulos provenientes das entradas são processados pela função soma, e o limiar de disparo do neurônio biológico foi trocado pela função de transferência.

A Figura 12 mostra um exemplo de uma Rede Neural Artificial, formada a partir da combinação de diversos neurônios.

Figura 12- Exemplo de uma Rede Neural Artificial

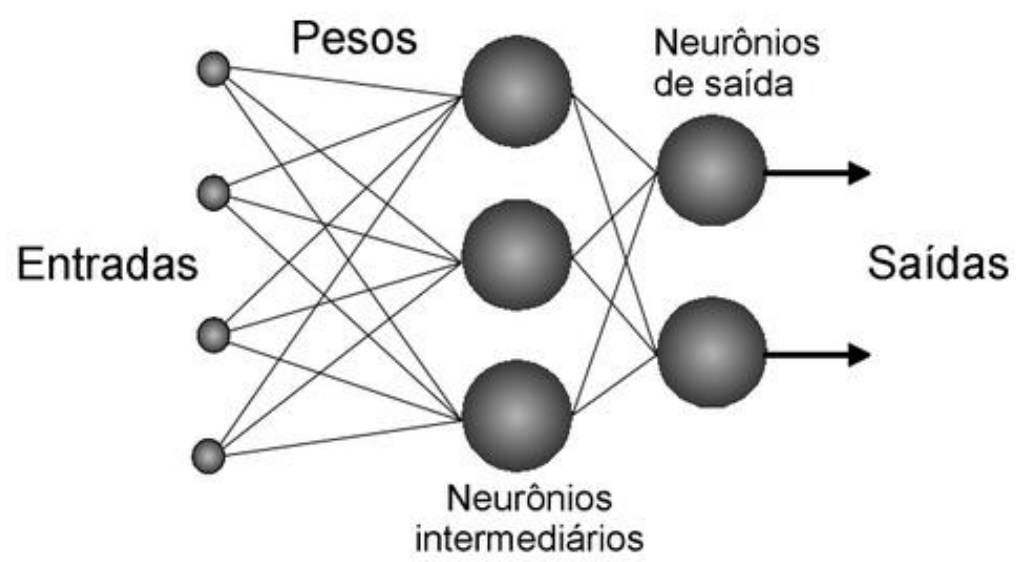

Fonte: TAFNER, M. A.; Redes Neurais Artificiais: Aprendizado e plasticidade. Rev. Cérebro \& Mente, N.5, 1998, Acesso em 04 de Nov. 2013. Disponível em < http://www.cerebromente,org,br/n05/tecnologia/rna,htm>

O número de entrada e saída dependerá da dimensão dos dados fornecidos. Enquanto que o número de neurônios intermediário está intrinsecamente relacionado à complexidade do problema a se resolver. No entanto, deve-se ter cautela para a escolha do mesmo, pois um 
número excessivo na camada intermediária poderá levar a resultados não coerentes, denominado de overfitting (HAYKIN, 1999; BISHOP, 1995; BISHOP, 2006).

Para fazer as previsões corretas, uma ANN deve ser treinada. Para isso, um conjunto de exemplos com a resposta observada deve ser utilizado. Em outras palavras, a ANN irá aprender as relações entre as variáveis de entrada por experiência. Então, a partir das variáveis e da resposta, fazendo uso de um algoritmo de aprendizagem, os valores numéricos irão ser ajustados até se obter outra resposta, nos mesmos moldes da introduzida inicialmente. $\mathrm{O}$ algoritmo mais utilizado para treinar uma ANN é o de retropropagação (backpropagation). O funcionamento desse algoritmo ocorre da seguinte forma: uma vez dada as variáveis de entrada e a geração da resposta, calcula-se o erro (Mean Squre Error- MSE ou Root Mean Square Error) dos valores obtidos em relação aos fornecidos à rede. Esse erro é utilizado para estimar os erros das camadas ocultas, neurônios intermediários (Figura 12), a fim de que ele seja retropropagado até as conexões da camada de entrada, os pesos. Isto é, os pesos são ajustados para obter um erro menor na camada de saída. De forma simples, podemos dizer que a formulação matemática do algoritmo backpropagation nada mais é que atualização de pesos para minimizar o MSE ou RMSE (CROSS, HARRISON, KENNEDY, 1995; GOH, 1995).

Os principais problemas associados ao algoritmo backpropagation é a sua lentidão em superfícies mais complexas e a convergência a mínimos locais (pontos na superfície de erro que apresentam soluções estáveis, mas não aceitáveis), Para evitar tais problemas, geralmente algum critério é usado, e um deles é o termo momentum. Esse critério tem por objetivo acelerar a velocidade de aprendizado, diminuindo o risco de instabilidade. Ele também pode acelerar a taxa de aprendizagem em regiões muito planas de superfícies de erros (DEW et al., 1997).

Levando em consideração o vasto campo de aplicação das ANNs nas áreas de ciências naturais, desde a sua aplicação para diagnósticos médicos e imagiologia, na previsão de propriedades físico-químicas de compostos a controle de muitos processos relacionados à indústria farmacêutica (MILLIE et al., 2012; LEK et al, 1996), esta é mais uma das técnicas utilizadas nesse trabalho para o estudo da relação estrutura-atividade dos compostos em análises (Tabela 2).

Antes e depois da aplicação dos métodos de ANN, PLS ou qualquer outro para a geração do modelo que relacione a estrutura à atividade, o sistema em estudo deve ser cautelosamente analisado. Os subitens posteriores discorrem sobre as principais análises que devem ser realizadas. 


\subsubsection{Verificação do conjunto de dados}

Um dos requisitos mais importantes que deve ser levado em consideração em estudos QSAR é a disponibilidade de uma série de compostos análogos que tenham o mesmo mecanismo de ação, (VAN DE WATERBEEMD, ROSE, 2003; KUBINYI, 1993).

No que concerne à atividade biológica, os dados biológicos que podem ser utilizados, estando na escala correta, são: valores de atividade biológica in vitro (obtidos a partir de culturas de bactérias, fungos e outras, assim como também, órgãos isolados) e in vivo (atividade farmacodinâmicas e tóxicas de fármacos), dados de afinidade, como constantes de interação com um receptor ou substrato, constante de velocidade, como associação/dissociação e constantes de Michaelis-Menten, constantes de inibição, como valores de $K i$ e $I C_{50}$ de diferentes enzimas, parâmetros farmacocinéticos (Constante de velocidade de adsorção), parâmetros de distribuição, constantes de velocidade de degradação metabólica e constantes de velocidade de eliminação (KUBINYI, 1993; WEBER, 2008).

As constantes de equilíbrio e de velocidade estão relacionadas aos valores de energia livre, $\Delta \mathrm{G}$ (equação 10),

$$
\Delta G=-2,303 R T \log K
$$

Logo, somente constantes de equilíbrio (por exemplo, valores de $K_{i}$ ou $I C_{50}$ e não \% de inibição a certa concentração) e constantes de velocidades (como valores de $\log \mathrm{K}$ e não \% de absorção ou \% de concentração) são adequadas para estudos de QSAR. Em outras palavras, todos os dados biológicos necessitam ser configurados adequadamente para serem utilizados em análises quantitativas. Como é observado na equação 10, é necessário que os valores de atividade sejam colocados em escala logarítmica (KUBINYI, 1993, WEBER, 2008).

Por convenção, os negativos dos logaritmos, i,e,; logaritmos dos recíprocos das concentrações molares (p,ex, $\log 1 / \mathrm{C}$ ou pC) são utilizados a fim de adquirir valores maiores para compostos mais ativos. Uma condição para a aplicação das análises de regressão é a distribuição normal do erro experimental na variável dependente. Quando utilizamos dados biológicos, essa premissa é verdadeira para escala logarítmica e não para a linear, sendo assim esse é mais um motivo para justificar o uso da escala logarítmica (KUBINYI, 1993, WEBER, 2008). 


\subsubsection{Obtenção dos Descritores Moleculares}

A simples visualização da estrutura Química não fornece as informações referentes à atividade biológica. Para isso, é necessário analisar a estrutura e obter a informação na forma de descritores moleculares, os quais mostram as diferentes propriedades químicas dos compostos. As propriedades podem ser parâmetros físico-químicos, eletrônicos, químicoquântico, topológicos e geométricos. Tais propriedades podem ser intrinsecamente relacionadas à atividade biológica (FOYE, LEMKE, WILLIAMS, 1995; GANELLIN, ROBERTTS, 1994).

Muitas vezes, os métodos utilizados para prever a atividade biológica utilizam como input vetores numéricos com certas características, como escala homogênea para todos os compostos. Dito de outra forma, os descritores moleculares convertem a estrutura em vetores numéricos para serem utilizados na análise estatística dos dados e assim utilizar os descritores mais relevantes para compreender a atividade biológica (DUDEK, ARODZ, GÁLVEZ, 2006).

Dois são os tipos de descritores, 2D e 3D, que podemos definir utilizando a orientação da molécula e sua forma tridimensional, 3D. Os descritores bidimensionais são independentes da orientação tridimensional do composto em estudo. Trata-se de medidas dos constituintes da molécula, propriedades geométricas e topológicas, descritores eletrônicos, entre outros (DUDEK, ARODZ, GÁLVEZ, 2006).

Os modelos bidimensionais, 2D, utilizados em estudos QSAR são estatisticamente robustos, fornecendo baixo níveis de resíduos, no entanto a sua interpretação é, na maioria das vezes, difícil. Esses tipos de descritores são usados de forma indireta como guias na otimização das estruturas das moléculas em estudo. Mesmo assim, esse modelo é extremamente útil na aplicação da triagem virtual de grandes bancos de dados, onde a qualidade da predição é importante. Já os modelos oriundos dos descritores tridimensionais são mais fáceis de serem interpretados, mostrando, de forma clara, a região onde o composto protótipo deve ser alterado a fim de modular a atividade. No entanto, algumas interpretações se dão de forma subjetiva, o que diminui, na maioria das vezes, o nível de confiança no modelo (BROWN, LEWIS, 2006). Os principais descritores utilizados em estudos QSAR são descritos a seguir: 
Descritores Constitucionais: referem-se aos constituintes da estrutura da molécula, como por exemplo, massa molecular, número total de átomos, tipo de átomo, ligações químicas e número de anéis aromáticos (DUDEK, ARODZ, GÁLVEZ, 2006).

Descritores Geométricos: referem-se ao arranjo espacial dos átomos. Temos como exemplo, a superfície molecular oriunda da área de Van der Waals e o volume molecular (HUGO, GO, 1986; LABUTE, 2000).

Descritores Eletrônicos: obtidos através de cálculos químico-quânticos. Dentre eles, temos: carga atômica, energia dos orbitais, calor de formação, potencial de ionização, momento de dipolo (que indica o quão as cargas são distribuídas dependendo das variações no substituinte), energia eletrônica, polarizabilidade, dentre outros (FOYE, LEMKE, WILLIAMS, 1995).

Descritores Topológicos: referem-se ao tamanho, forma, conectividade, ciclicidade, ramificação molecular, e presença ou a falta de fragmentos estruturais peculiares, variáveis indicadoras, (FERREIRA, KIRALJ, 2011).

\subsubsection{Seleção das variáveis}

O processo de seleção de variáveis inicia com a exclusão das variáveis menos proeminentes ou sem nenhuma informação. Para isso, geralmente, usa-se o cálculo do coeficiente de correlação de Pearson, r, (Eq.11) relacionando a atividade biológica (FERREIRA, KIRALJ, 2011).

$$
r=\frac{\sum_{i=1}^{n}\left(x_{i}-\bar{x}\right)\left(y_{i}-\bar{y}\right)}{\sqrt{\sum_{i=1}^{n}\left(x_{i}-\bar{x}\right)^{2}} \sqrt{\sum_{i=1}^{n}\left(y_{i}-\bar{y}\right)^{2}}}
$$

onde

$$
\bar{x}_{i}=\frac{1}{n} \sum_{n=1}^{n} x_{i}
$$

e

$$
\bar{y}_{i=} \frac{1}{n} \sum_{n=1}^{n} y_{i}
$$

Nesse caso, podemos dizer que os $x_{i}$ representam os valores das variáveis independentes e $y_{i}$ os valores das variáveis dependentes. $\mathrm{O}$ valor de $\mathrm{r}$ está entre +1 e -1 . O sinal indica a 
direção, positivo ou negativo, e o valor indica a força da correlação. Se o valor for negativo, significa uma correlação perfeita negativa, isto é, as variáveis são inversamente proporcionais. Já se os valores forem positivos, a correlação é dita perfeita positiva. $\mathrm{O}$ valor de corte de $\mathrm{r}$ dependerá de caso para caso. As variáveis que estão muito correlacionadas $(r \approx 1)$ também devem ser excluídas, pois possuem quase que a mesma informação. Deve-se evitar ao máximo, descritores com difícil entendimento.

A etapa da seleção de variáveis deve ser cuidadosamente analisada, pois se os descritores não forem selecionados com atenção, o modelo pode não ser aprovado nos teste de validação. Os valores da atividade biológica podem ser um problema também, pois se os valores não variarem muito para os compostos, o modelo poder vir a falhar. Uma das formas de não excluir os descritor que não possui comportamento linear em relação à atividade biológica é converter os valores através de alguma operação, como por exemplo, raiz, quadrado, logaritmo ou usando função gaussiana, dentre outras (FERREIRA, KIRALJ, 2011).

Vários são os métodos utilizados para fazer seleção de variáveis, dentre eles temos a matriz de correlação, peso de Fischer, Busca sistemática, algoritmo genético (Subitem 2.4.5.1), utilizado nesse estudo, dentre outros.

\subsubsection{Algoritmo Genético}

À medida que o tempo passa, as populações evoluem na natureza para garantir sua sobrevivência. Tal evolução é baseada em três processos simples: Cruzamento, para continuar e melhorar a qualidade dos indivíduos de uma mesma espécie; seleção natural, nesse processo apenas as espécies mais adaptadas sobrevivem e mutação genética, referente à produção de novas espécies. Estes processos são regidos pela teoria da evolução de Darwin. Foi baseado nesses princípios que na década de 1960, John Holland propôs os Algoritmos Genéticos, AG, usados como técnica de busca e otimização na resolução de problemas encontrados no mundo real (SUTTON, BOYDEN, 1994). Basicamente, o trabalho de AG é gerar uma população de possíveis soluções para o problema (inicialização) para depois submeter ao processo de evolução (Figura 13). 
Figura 13- Procedimento interativo do funcionamento de um AG

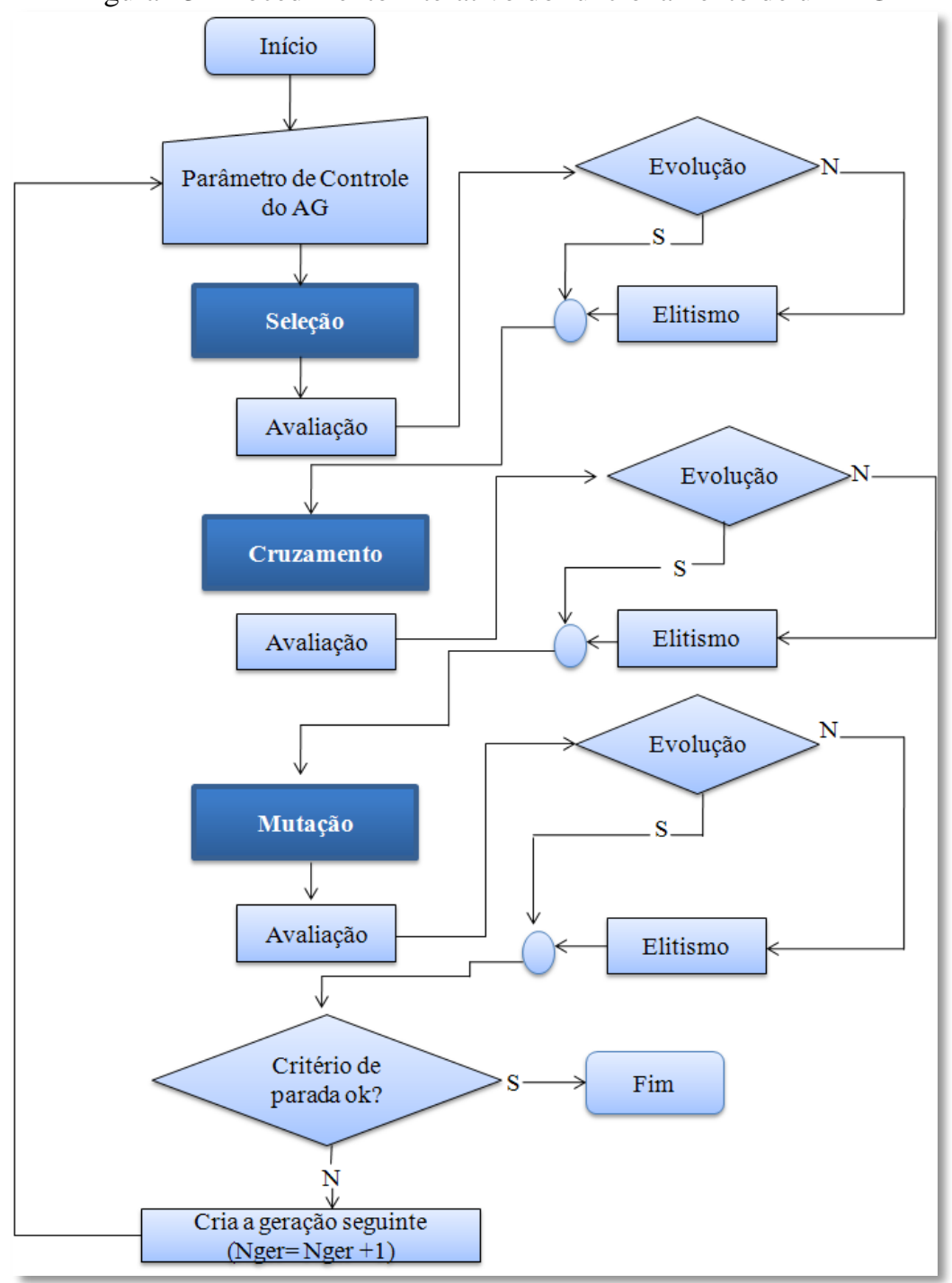

Adaptado de: FERREIRA, M. M. C., MONTANARI, C. A.; GAUDIO, A.C.; Seleção de Variáveis em QSAR; Quim, Nova, V.25, N. 3. p. 439-448, 2002.

A estrutura de um AG pode sofrer variações, no entanto, algumas características são constantes, destas podemos destacar três, citadas anteriormente: seleção natural, cruzamento e mutação. Além destas, temos também o elitismo, que é um processo usado para evitar que indivíduos menos evoluídos, encontrados na primeira seleção passem para a próxima geração. A etapa de avaliação averigua a existência de indivíduos menos evoluídos em relação à geração anterior (Figura 14). Em outras palavras, à medida que avançamos nas gerações, os indivíduos devem ser sempre mais evoluídos (FERREIRA, MONTANARI, GAUDIO, 2002). 
Figura 14- Funcionamento de um AG: A) Geração inicial; B) Geração resultante da aplicação da seleção natural; C) Cruzamento e D) Mutação,

A)

\begin{tabular}{|c|c|c|c|c|c|c|c|c|}
\hline \multirow{3}{*}{$\begin{array}{l}\text { GERAC̨AOAO } \\
\mathrm{G}_{1}\end{array}$} & \multicolumn{8}{|c|}{ INDIVIDUO } \\
\hline & \multicolumn{2}{|c|}{$\mathrm{E}_{1,1}$} & \multicolumn{2}{|c|}{$\mathrm{E}_{1,2}$} & \multicolumn{2}{|c|}{$\mathrm{E}_{1,2}$} & \multicolumn{2}{|c|}{$\mathrm{E}_{1,4}$} \\
\hline & Llm & $E_{\text {lumois }}$ & BEHel & $E_{\text {eumows }}$ & BEHe8 & AGDD & AGDD & Llm \\
\hline & \multicolumn{2}{|c|}{$\mathrm{R}_{1,1}=0,879$} & \multicolumn{2}{|c|}{$R_{1,2}=0,878$} & \multicolumn{2}{|c|}{$\mathrm{R}_{1,3}=0,844$} & \multicolumn{2}{|c|}{$R_{1 e}=0,406$} \\
\hline
\end{tabular}

B)

Seleção

\begin{tabular}{|c|c|c|c|c|c|c|c|c|}
\hline \multirow[b]{2}{*}{$\mathrm{G}_{1}{ }^{\prime}$} & \multicolumn{2}{|c|}{$\mathrm{E}_{1,1^{\circ}}$} & \multicolumn{2}{|c|}{$E_{1,2^{*}}$} & \multicolumn{2}{|c|}{$\mathrm{E}_{1,3^{*}}$} & \multicolumn{2}{|c|}{$\mathrm{E}_{1,4^{\circ}}$} \\
\hline & Llm & $E_{\text {lumow }}$ & BEHel & $E_{\text {cunots }}$ & BEHe8 & AGDD & BEHel & Llm \\
\hline
\end{tabular}

C)

Cruzamento

\begin{tabular}{|c|c|c|c|c|c|c|c|c|}
\hline & & & & & \multicolumn{4}{|c|}{$\overbrace{}^{\lambda}$} \\
\hline & \multicolumn{2}{|c|}{$\mathrm{E}_{1,1}{ }^{*}$} & \multicolumn{2}{|c|}{$\mathrm{E}_{1,2}{ }^{\prime \prime}$} & \multicolumn{2}{|c|}{$\mathrm{E}_{1, z^{\prime}}$} & \multicolumn{2}{|c|}{$\mathrm{E}_{1,4},{ }^{\prime}$} \\
\hline $\mathrm{G}_{1}{ }^{*}$ & Llm & Elumons & BEHel & Elenows & BEHe8 & BEHel & $A G D D$ & Llm \\
\hline & \multicolumn{2}{|c|}{$R_{1,1}{ }^{\prime \prime}=0,879$} & \multicolumn{2}{|c|}{$R_{1,2} "=0,878$} & \multicolumn{2}{|c|}{$\mathrm{R}_{1,3}{ }^{\prime \prime}=0,932$} & \multicolumn{2}{|c|}{$\mathrm{R}_{14}{ }^{\prime \prime}=0,406$} \\
\hline
\end{tabular}

D)

Mutação

\begin{tabular}{|c|c|c|c|c|c|c|c|c|}
\hline \multirow[b]{2}{*}{$\mathrm{G}_{2}$} & \multicolumn{2}{|c|}{$E_{2,1}$} & \multicolumn{2}{|c|}{$\mathrm{E}_{22}$} & \multicolumn{2}{|c|}{$E_{2,}$} & \multicolumn{2}{|c|}{$\mathrm{E}_{2,4}$} \\
\hline & Llm & $E_{\text {sumous }}$ & BEHel & Elemsis & BEHe8 & BEHel & AGDD & $E_{\text {ineos }}$ \\
\hline & \multicolumn{2}{|c|}{$R_{2,1}=0,879$} & \multicolumn{2}{|c|}{$R_{2,2}=0,878$} & \multicolumn{2}{|c|}{$R_{2,}=0,932$} & \multicolumn{2}{|c|}{$R_{Q, 0}=0,936$} \\
\hline
\end{tabular}

Adaptado de: Ferreira, M. M., Montanari, C. A., GAUDIO, A.C.; Seleção de variáveis em QSAR. Quim. Nova, N. 3, V.25, p. 439-448, 2002.

$\mathrm{O}$ funcionamento de um $\mathrm{AG}$ primeiramente requer um conjunto de $\mathrm{N}$ equações de regressão, caracterizado de primeira geração $\left(\mathrm{G}_{1}\right)$, com $\mathrm{N}$ variáveis diferentes entre si. Cada equação, E, simboliza um indivíduo da geração. Na Figura 14, cada indivíduo possui dois genes (variáveis). O conjunto das variáveis de cada indivíduo simboliza o cromossomo (FERREIRA, MONTANARI, GAUDIO, 2002).

Vale salientar que a principal característica de um AG é usar as regras da evolução para criar gerações mais evoluídas, e usar o resultado para tentar solucionar o problema. Notase que na Figura 14 temos 4 indivíduos com dois genes e um cromossomo, cada um. Uma vez definida as variáveis para os indivíduos, segue para a avaliação da $\mathrm{G}_{1}$. Essa avaliação consiste em analisar o coeficiente de correlação, R, de cada indivíduo. Nesse caso, o R da primeira equação (esquerda para a direita, Figura 14) é o melhor, podendo ser considerado a melhor solução até o momento (FERREIRA, MONTANARI, GAUDIO, 2002).

Uma das formas de avaliar as gerações é analisando o somatório dos $\mathrm{R}$ dos indivíduos. A geração seguinte, $\mathrm{G}_{2}$, só é produzida após a execução da seleção natural, cruzamento e mutação. Na primeira, um ou mais indivíduos presentes em $\mathrm{G}_{1}$ serão reproduzidos para $\mathrm{G}_{1}$ ' 
através de sorteio. No entanto, os indivíduos com o valor maior de $\mathrm{R}$ possuem maiores chances. Reportado à Figura 14, vemos que os três primeiros indivíduos foram reproduzidos e um novo sorteio foi realizado para escolher o quarto. Em seguida, temos o cruzamento entre pares de indivíduos, também denominado de crossover. Nessa etapa, há o cruzamento dos genes de um ou mais pares de indivíduos para que o (s) filho (s) herde (m) os genes dos seus genitores, A Figura 14 mostra que o cruzamento foi realizado entre os indivíduos com os piores R's. O cromossomo deles foi dividido ao meio e permutados (FERREIRA, MONTANARI, GAUDIO, 2002).

Na próxima etapa, há a mutação. Nela é substituída aleatoriamente uma ou mais variáveis, de um ou mais indivíduos da geração, por outra que não exista entre as que ficaram. Procedendo à avaliação, notamos que o somatório dos $\mathrm{R}$ 's da $\mathrm{G}_{2}\left(\sum R_{2}=3,625\right)$ é maior do que o da $\mathrm{G}_{1}\left(\sum R_{2}=3,007\right)$, mostrando que os valores de $\mathrm{R}$ evoluíram de G1 para G2, sendo, portanto, melhores soluções para o problema (FERREIRA, MONTANARI, GAUDIO, 2002).

Portanto, de acordo com Ferreira et al., (2002), a utilização de AG como método para separação de variáveis é justificada pela sua eficiência, principalmente quando o número de variáveis for elevado.

Uma vez selecionada as variáveis, segue para a geração do modelo (Subitem 2.4.6).

\subsubsection{Geração do Modelo Estrutura-Atividade}

Uma vez selecionada as variáveis, a última etapa é a geração do modelo QSAR. Vários são os modelos que podem ser produzidos, a depender do sistema em estudo. No presente estudo, os dados são de natureza quantitativa, então é usado métodos de regressão para a construção do modelo quantitativo. O método utilizado nessa pesquisa foi o PLS e o de Redes Neurais Artificiais (Subitem 2.4.1 e 2.4.2, respectivamente).

Após geração do modelo, este deve ser testado e validado para analisar a sua capacidade preditiva e, portanto, sua confiabilidade (Subitem 2.4.7).

\subsubsection{Validação do Modelo}

Uma vez gerado o modelo, este deve ser validado interno e externamente. A validação externa do modelo consiste em estimar a atividade biológica de compostos que ficaram de fora da geração do mesmo. Para isso, devemos ter dois conjuntos, o de treinamento 
(validação interna) e o de teste (validação externa). É recomendado que o conjunto de teste tenha $30 \%$ do conjunto total dos compostos (FERREIRA, 2002).

$\mathrm{Na}$ validação interna, primeiramente é analisado o número ótimo de componentes principais, que no caso do método PLS, chamamos de variáveis latentes, VL, e a presença de outliers, compostos com comportamento diferenciado dos demais. Para determinar o número ótimo de VL, faz-se a validação cruzada (leave-one-out). Nesse tipo de validação, uma amostra é deixada de fora para a construção do modelo. Utilizando o modelo construído, a atividade biológica do composto excluído é predita. Esse procedimento é repetido até que todas as amostras tenham sido retiradas, pelo menos uma vez. Após esse procedimento, o erro de previsão e a soma dos quadrados dos erros de previsão, PRESS (Eq. 12), (PRediction Error Sum of Squares) de cada um desses compostos do conjunto de treinamento são calculados (FERREIRA, KIRALJ, 2011).

$$
\text { PRESS }=\sum\left(y_{\text {iexp }}-\hat{y}_{\text {ival }}\right)^{2}
$$

onde $y_{\text {iexp }}$ representa o valor da atividade biológica do $i$-ésimo compostos e $\hat{y}_{\text {ival }}$ representa a previsão da atividade biológica do composto excluído, O $\mathrm{SEP}_{\text {Val }}$, Standart Error of Validation, (Eq.13) é outro parâmetro utilizado para avaliar a significância do modelo.

$$
S E P_{v a l}=\left[\frac{P R E S S}{I}\right]^{1 / 2}
$$

onde o I é o número de amostras no conjunto de validação externa. Outra forma de avaliar o modelo é por meio do cálculo do erro de calibração, $\mathrm{SEP}_{\text {cal }}$ (Eq.14).

$$
S E P_{c a l}=\left[\frac{\sum\left(y_{i e x p}-\hat{y}_{i c a l}\right)^{2}}{I-V L-1}\right]^{1 / 2}
$$

Nesse caso, o I representa as amostras do conjunto de treinamento, VL são as variáveis latentes e $\hat{y}_{i c a l}$ refere-se ao valor estimado pelo modelo gerado com todas as amostras.

Além da verificação de Variáveis Latentes devemos também verificar a presença de outliers para certificar que os compostos do conjunto de treinamento formam um conjunto análogo e assim retirar os que não apresentam similaridade. Uma das formas de verificar a existência de compostos com comportamento atípico é através da alavancagem (leverage) que mostra o quanto uma amostra influencia em um modelo, a outra é através da análise dos Resíduos de Student, resíduo (diferença entre o valor experimental e o valor obtido no modelo de regressão) padrão de cada composto, obtido através da razão do resíduo pelo desvio padrão. Segundo Ferreira e Kiralj (2011) os compostos devem apresentar valores de alavancagem inferiores a $3 \mathrm{VL} / \mathrm{I}(\mathrm{VL}$ refere-se às variáveis latentes e I as amostras) e os valores de resíduos de Student devem estar abaixo de 2,0. Os compostos que apresentarem 
valores distantes desses padrões devem ser analisados um a um e se for o caso retirar do conjunto de treinamento.

Outras avaliações são necessárias para garantir a robustez do modelo. Duas delas são os cálculos do coeficiente de correlação de validação cruzada, $\mathrm{Q}^{2}$ (Eq.15), (variância explicada na previsão) e o coeficiente de determinação múltipla, $\mathrm{R}^{2}$ (Eq.16), (variância explicada no ajuste).

$$
\begin{aligned}
& Q^{2}=1-\frac{\sum\left(y_{i e x p}-\hat{y}_{i v a l}\right)^{2}}{\sum\left(y_{i e x p}-y_{\text {mean }}\right)^{2}} \\
& R^{2}=1-\frac{\sum\left(y_{i e x p}-\hat{y}_{i c a l}\right)^{2}}{\sum\left(y_{\text {iexp }}-y_{\text {mean }}\right)^{2}}
\end{aligned}
$$

Em que $y_{\text {mean }}$ é o valor da atividade biológica experimental média. É sempre bom obter valores altos de $\mathrm{R}^{2}$, mas não é o mais importante. Este deve ser analisado juntamente com os valores de $\mathrm{Q}^{2}$ e não devem apresentar uma diferença acima de 0,30 , caso contrário, o modelo pode apresentar indícios de ajuste forçado, presença de compostos atípicos ou variáveis sem informação relevante (ERIKSSON et al., 2003). Um modelo é considero bom se os valores de $\mathrm{Q}^{2}>$ 0,5 e $\mathrm{R}^{2}>$ 0,6 (FERREIRA, KIRALJ, 2011). Por fim, o modelo gerado pelo conjunto de treinamento deve ser testado tanto no que se refere a sua robustez quanto para verificar a presença de correlação ao acaso, Para o primeiro caso, usa-se a técnica de validação cruzada com a exclusão de $\mathrm{N}$ amostras (leave- $\mathrm{N}$-out). Para isso é necessário excluir um grupo de compostos do conjunto, gerar o modelo com o mesmo número de fatores utilizados anteriormente na construção do modelo e então prever a atividade biológica do grupo excluso, depois voltar o grupo ou o composto excluído e retirar outro. Esse procedimento deve ser repetido até que pelo menos 20 a $30 \%$ sejam excluídos. O Q ${ }^{2}$ é calculado para cada valor de $\mathrm{N}$ e depois o valor médio do mesmo. O modelo é considerado bom se o valor médio de $\mathrm{Q}^{2}>0,5$ e os desvios de cada $\mathrm{Q}^{2}$ forem de aproximadamente 0,05 . No segundo caso, temos a randomização do vetor y (y-radomization), que tem por objetivo construir o modelo, só que dessa vez com as atividades biológicas randomizadas para depois fazer testes estatísticos desse modelo. Esse teste é considerado bom se os valores de $\mathrm{Q}^{2}$ e $\mathrm{R}^{2}$ obtidos forem menores que 0,3 e 0,4 respectivamente. A ideia de embaralhar os valores de atividade biológica tem por finalidade atribuir os valores de atividade biológica aos compostos errados, e dessa forma, espera-se que o modelo gerado seja insignificante. Feito todos esses teste, o modelo deve ser analisado quimicamente, isto é, analisar as variáveis e verificar a sua significância química (GRAMATICA, 2007). 
"Não basta dar os passos que nos devem levar um dia ao objetivo, cada passo deve ser ele próprio um objetivo em si mesmo, ao mesmo tempo em que nos leva para diante".

(Johann Goethe) 


\section{OBJETIVOS}

\subsection{Objetivo Geral}

Estabelecer relações quantitativas entre a atividade biológica de compostos oriundos do aripiprazol e suas estruturas químicas através dos métodos de PLS e ANN.

\subsection{Objetivos Específicos}

Gerar descritores eletrônicos e moleculares;

Selecionar as variáveis relevantes para a construção do modelo matemático;

Gerar modelos QSAR através dos métodos PLS e ANN;

Analisar os modelos gerados avaliando sua robustez e significância;

D Usar o conjunto de treinamento e teste para validar o modelo interno e externamente;

Analisar o peso de cada variável utilizada para construir o modelo e justificar quimicamente a significância delas; 
"Faça as coisas mais simples que você puder, porém não se restrinja às mais simples".

(Albert Einstein) 


\section{METODOLOGIA}

Inicialmente foi feita uma pesquisa para tentar entender a fisiopatologia da esquizofrenia, bem como a ação dos medicamentos utilizados para o seu tratamento. Sabendo que não existem muitos fármacos disponíveis no mercado para o tratamento e que os que existem possuem algumas limitações, como por exemplo, só agem nos sintomas positivos ou só nos negativos, o presente trabalho é justificado pela necessidade crescente de desenvolvimento de fármacos que possuam atividade mais eficaz frente a essa patologia tão agravante para os pacientes dela acometidos.

Um estudo de QSAR foi realizado, utilizando um conjunto de 38 compostos (Tabela 2) com atividade biológica, derivados do aripiprazol, sintetizados por CHEN e colaboradores (2012). Para a síntese dos compostos, eles exploraram quatro regiões (Figura 15).

Tabela 2- Estrutura química dos compostos sintetizados a partir da exploração das 4 regiões do aripiprazol e seus valores de atividade biológica

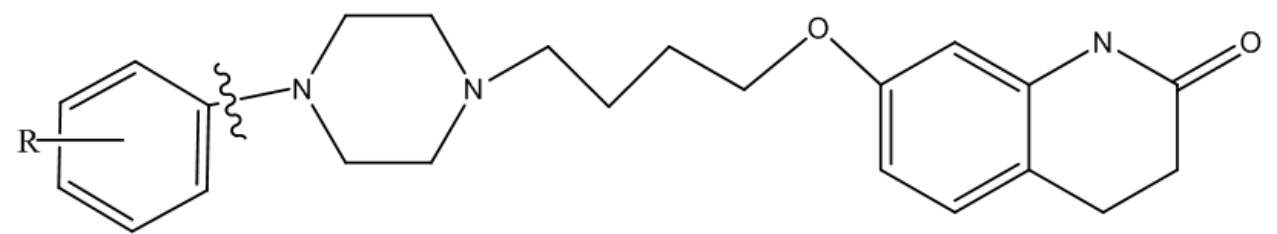

\begin{tabular}{l|l|c}
\hline \multicolumn{1}{c|}{ Composto } & \multicolumn{1}{c|}{$\mathbf{R}$} & pKi \\
\hline 1 & $2,3-(\mathrm{Cl})_{2}$ & 8,409 \\
\hline 2 & $2-\mathrm{OCH}{ }_{3}$ & 9,523 \\
\hline 3 & $2-\mathrm{OEt}$ & 8,553 \\
\hline 4 & $2-\mathrm{OiPr}$ & 8,509 \\
\hline 5 & $2-\mathrm{H}$ & 8,367 \\
\hline 6 & $2-\mathrm{F}$ & 8,260 \\
\hline 7 & $2 \mathrm{Cl}$ & 8,432 \\
\hline 8 & $2-\mathrm{CN}$ & 8,538 \\
\hline 9 & $2-\mathrm{CH}_{3}$ & 8,229 \\
\hline 10 & $2-\mathrm{CF}_{3}$ & 8,377 \\
\hline 11 & $3-\mathrm{OEt}$ & 7,678 \\
\hline 12 & $4-\mathrm{OEt}$ & 7,277 \\
\hline 13 & $2,3-\left(\mathrm{CH}_{3}\right)_{2}$ & 8,092 \\
\hline
\end{tabular}<smiles>[Z6]N1CCN([Z6]([Z])([H])CCCCOc2ccc3c(c2)NC(=O)CC3)CC1</smiles> 

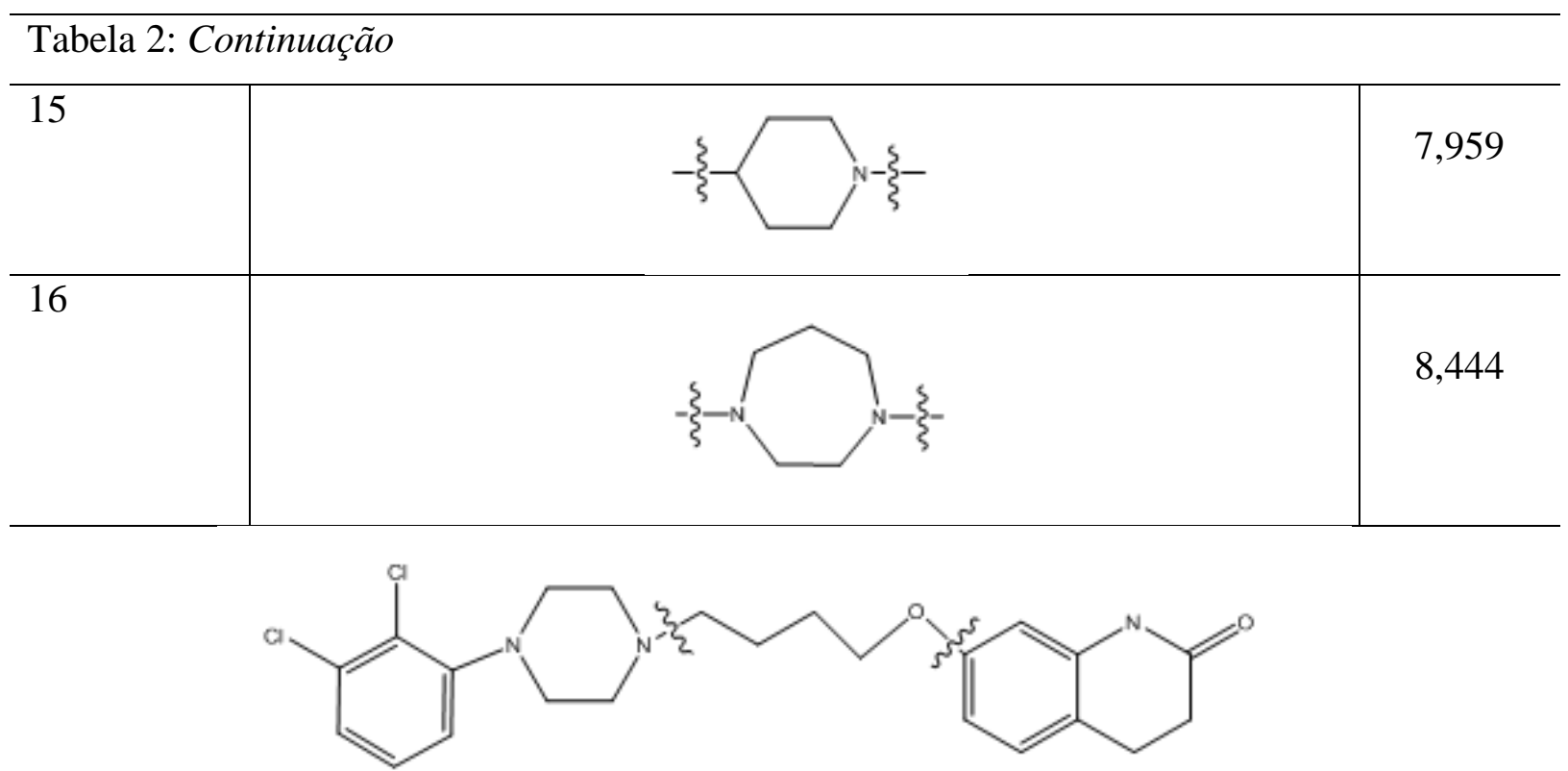

\begin{tabular}{l|l|l|l}
\hline 18 & 7,678 & 6,839 \\
\hline 19 & & & \\
\hline 21 & & & \\
\hline 23 & & & \\
\hline
\end{tabular}

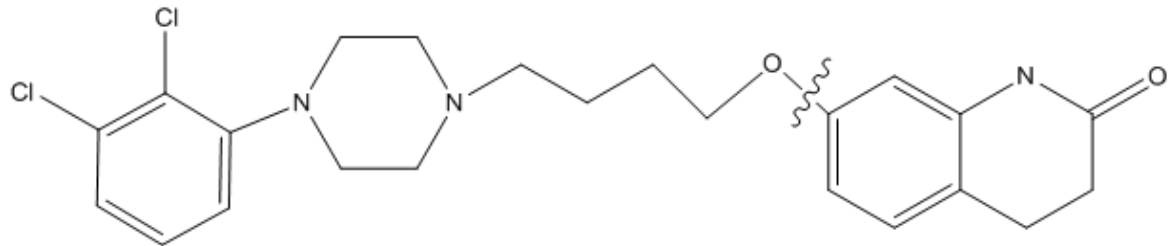




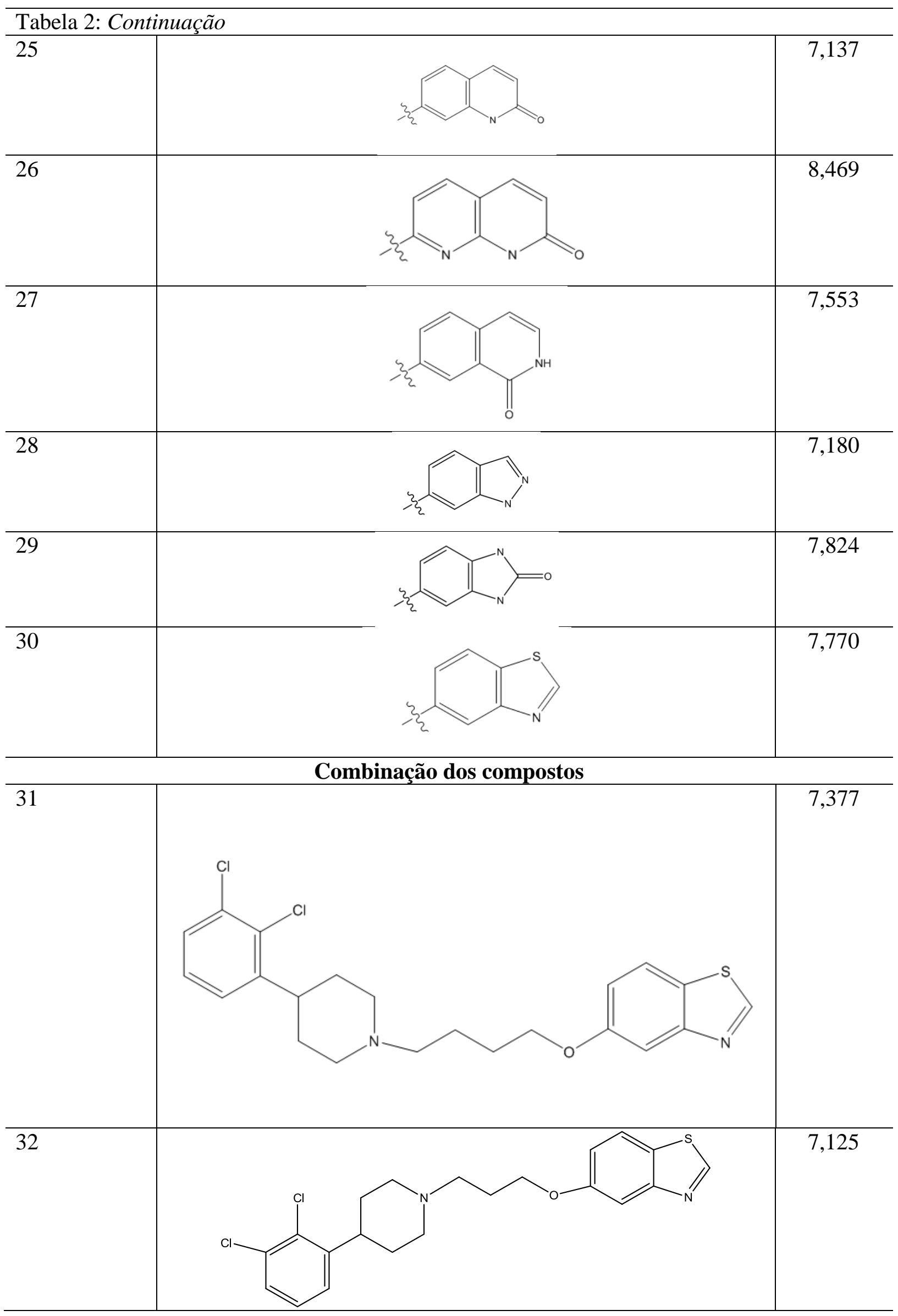




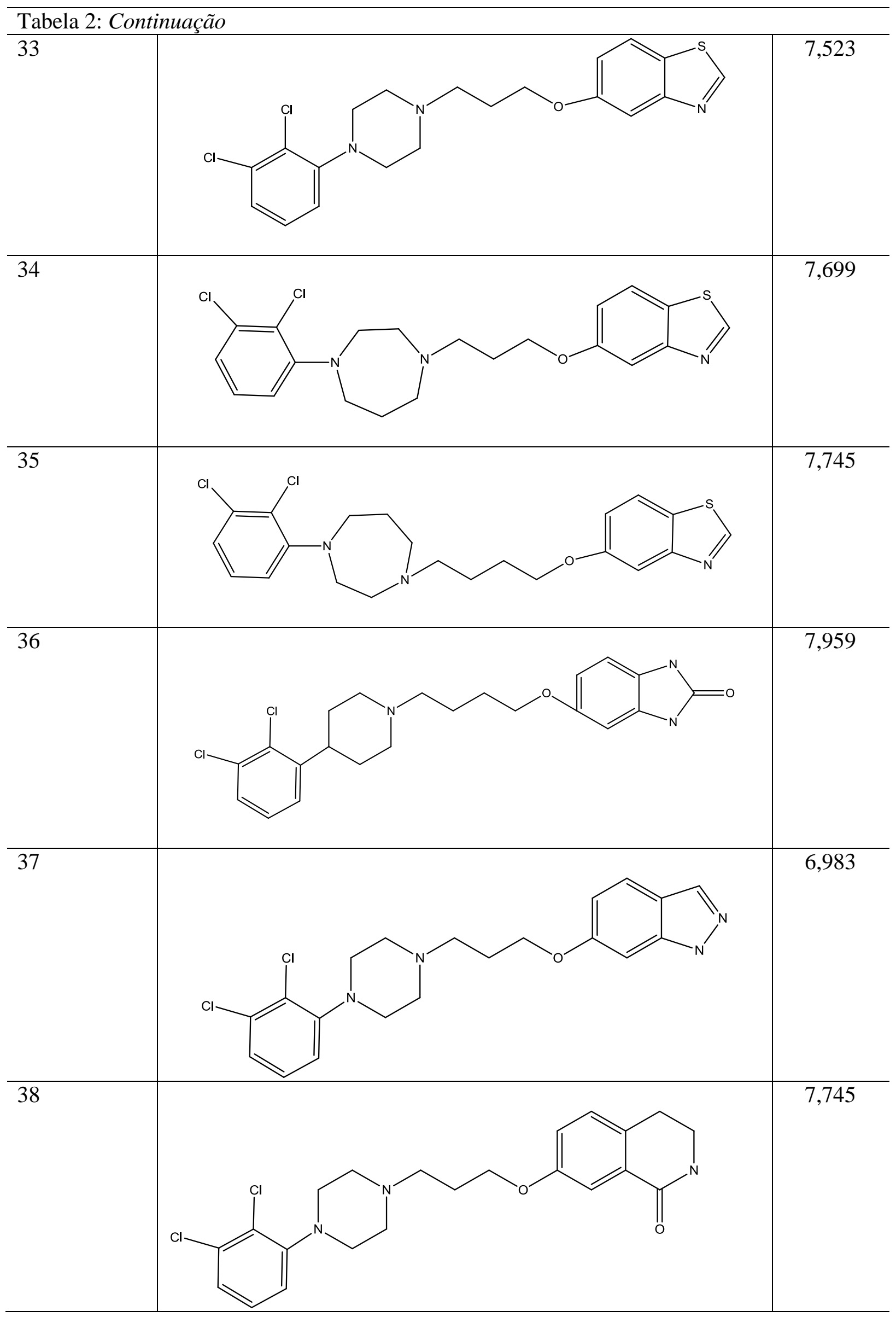




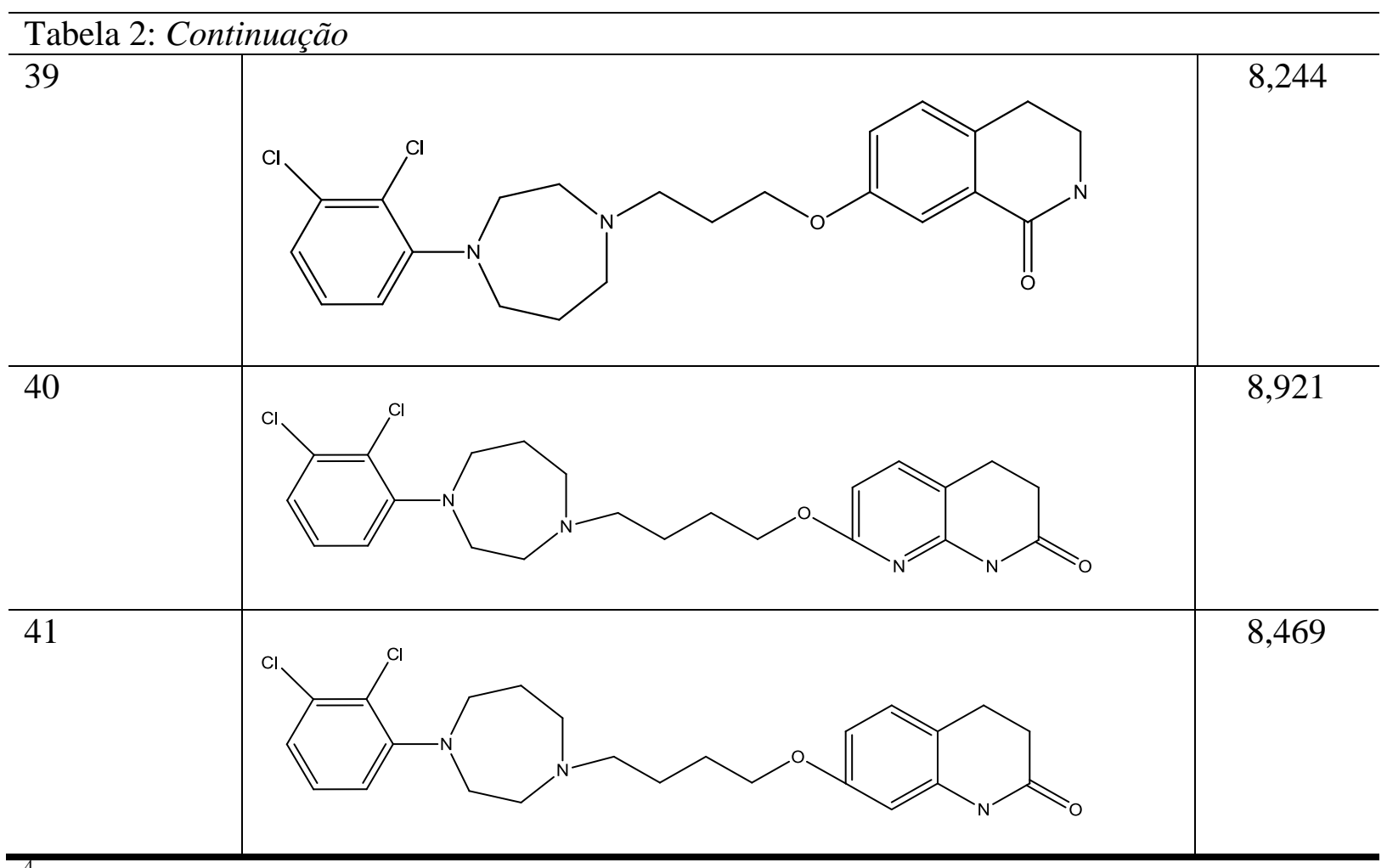

Figura 15- Estrutura do Aripiprazol e suas 4 regiões exploradas

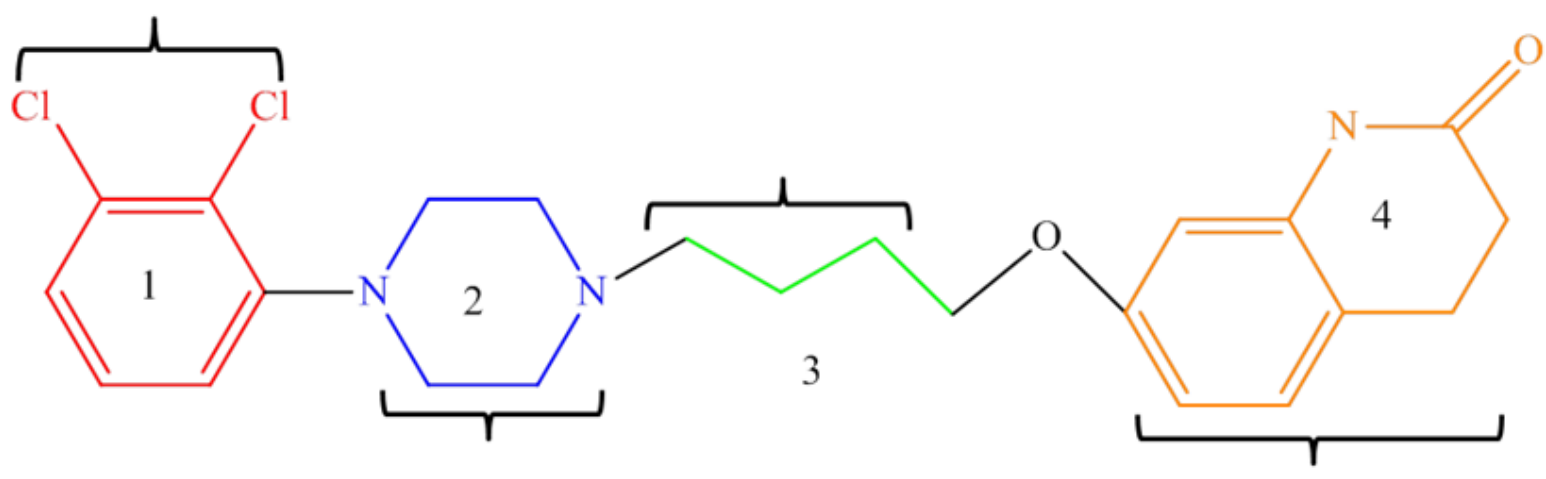

O procedimento computacional para a realização desse trabalho seguiu a seguinte ordem:

$>\quad$ As estruturas dos compostos (tabela 2) foram desenhados no GaussView 5.0 (Dennington et al., 2009);

\footnotetext{
${ }^{4}$ A numeração dos compostos não segue uma ordem numérica, seguindo a numeração dos autores que os sintetizaram.
} 
Os cálculos de otimização e de frequência dos compostos foram realizados utilizando o software Gaussian 09 (FRISCH et al., 2009). Através desse cálculo foram obtidos os descritores eletrônicos, como por exemplo, energia dos orbitais HOMO (Highest Occupied Molecular Orbital) e LUMO (Lowest Unoccupied Molecular Orbital), momento de dipolo, polarizabilidade, dentre outros. O método utilizado para os cálculos de otimização e frequência foi a DFT com o funcional B3LYP e o conjunto de função de base 6-31G ++ (d,p); $>\quad$ Após os cálculos de otimização e frequência das moléculas, estas foram submetidas a cálculos de descritores moleculares com a utilização do software Dragon 2.1 (TODESCHIN, CONSONNI, PAVAN, 2002);

$>$ Com a finalidade de excluir os descritores menos relevantes, estes passaram por cálculos de coeficiente de Pearson, $r$, em que os menos correlacionados com a atividade biológica foram eliminados.

$>\quad$ Feita a triagem anterior, os descritores restantes foram analisados através da técnica de AG através do software BuildQSAR (DE OLIVEIRA, GAUDIO, 2001).Vários cálculos foram realizados para escolher as melhores variáveis, utilizando vários critérios (número de gerações, exclusão de variáveis muito correlacionadas entre si, descritores por modelo, modelo por geração e validação cruzada). Além de escolher as melhores variáveis ${ }^{5}$ (Tabela 3 ), o AG também calcula $\mathrm{R}, \mathrm{Q}^{2}$. A escolha da melhor geração ocorreu avaliando os valores de $\mathrm{Q}^{2}$ e R, isto é, a geração mais evoluída se sobressaiu;

Uma vez escolhidas as melhores variáveis, os modelos foram gerados com todos os compostos, utilizando o método PLS através do software Pirouette versão 3.10 (Infometrix, 2002). Vale salientar que todos os valores das variáveis selecionadas foram autoescalados para garantir que todas tenham a mesma importância, no que se refere às escalas;

$>\quad$ O conjunto de compostos foi separado em teste e treinamento para que o modelo seja validado;

$>\quad$ Os testes de validação (teste de robustez, teste de aleatorização ao acaso e teste de amostras anômalas) foram realizados no programa QSAR Modeling, desenvolvido no laboratório de Quimiometria Teórica e Aplicada, no Instituto de Química da Universidade Estadual de Campinas (MARTINS, FERREIRA, 2013);

$>\quad$ Outro modelo com as mesmas variáveis foi gerado, utilizando a técnica de Redes Neurais Artificiais, através do software MatLab versão R2011a (MATHWORKS, 2011).

\footnotetext{
${ }^{5}$ Neste trabalho, os termos variáveis e descritores possuem o mesmo significado.
} 
"Mesmo que se compreenda que o significado de um conceito jamais será definido com precisão absoluta, alguns conceitos são parte integrante dos métodos da ciência, pelo fato de representarem, pelo menos por algum tempo, o resultado final do desenvolvimento do pensamento humano desde um passado assaz remoto; eles podem mesmo ter sido herdados e são, qualquer que seja o caso, instrumentos indispensáveis na execução do trabalho científico em nosso tempo".

(WERNER HEISENBERG) 


\section{RESULTADOS E DISCUSSÃO}

\subsection{Seleção das variáveis}

Vários foram os descritores calculados para o estudo QSAR, 1217 no total. Por isso, fez-se necessário a seleção dos mais relevantes. Nesta triagem, obteve-se um total de 248 variáveis. Estas foram obtidas através do cálculo da correlação de Pearson, r, O critério foi escolher as varáveis com valores de r entre -0,4 e 0,4. 248 descritores, ainda, são considerados um extenso conjunto, sendo assim, fez-se necessária outra triagem. Esta foi realizada através da técnica de Algoritmo Genético, onde foram gerados 100 modelos. O melhor modelo selecionado obtido está apresentado na Tabela 3.

Tabela 3-Seleção das variáveis através do Algoritmo Genético

\begin{tabular}{ccccc}
\hline Geração & Critério & Variáveis & $\mathbf{R}$ & $\mathbf{Q}^{\mathbf{2}}$ \\
\hline 4000 & 0,8 & $\begin{array}{c}\text { BEHe3, RDF145u, E1e, HATS7v, } \\
\text { R2v+, } \mathrm{E}_{\mathrm{LUMO}+4}(\mathrm{eV})\end{array}$ & 0,935 & 0,828 \\
\hline
\end{tabular}

Notam-se através da Tabela 4, os ótimos valores de $\mathrm{R}$ e $\mathrm{Q}^{2}$, justificando a escolha dessas variáveis. O Critério 0,8 significa que foram excluídos os descritores muito correlacionados entre si. A geração igual a 4000 está informando o número de vezes que o AG procurou a melhor seleção, levando em consideração todos os critérios abordados no subitem 2.4.5.1. As variáveis da Tabela 3 são mostradas na tabela 4 com seus respectivos valores para cada composto e os valores de pki.

Tabela 4-Compostos com seus respectivos valores de pKi e das variáveis selecionadas no Algoritmo Genético

\begin{tabular}{cccccccc}
\hline Compostos & pki & BEHe3 & RDF145u & E1e & HATS7v & R2v+ & E $_{\text {LuMO +4 }}(\mathbf{e V})$ \\
\hline C1 & 8,4089 & 3,6980 & 2,0740 & 0,5600 & 0,1010 & 0,0990 & 0,2245 \\
\hline C2 & 9,5229 & 3,6990 & 9,7560 & 0,6020 & 0,0670 & 0,0780 & 1,1339 \\
\hline C3 & 8,5528 & 3,7010 & 5,8850 & 0,5440 & 0,0770 & 0,0750 & 1,1298 \\
\hline C4 & 8,5086 & 3,7000 & 8,4440 & 0,5490 & 0,0820 & 0,0710 & 1,0814 \\
\hline C5 & 8,3665 & 3,6930 & 10,9570 & 0,5830 & 0,0610 & 0,0880 & 1,0781 \\
\hline C6 & 8,2596 & 3,6950 & 3,6930 & 0,5490 & 0,0810 & 0,0700 & 0,5048 \\
\hline C7 & 8,4318 & 3,6940 & 12,3660 & 0,6110 & 0,0620 & 0,1000 & 0,9587 \\
\hline C8 & 8,5376 & 3,7030 & 2,3830 & 0,5410 & 0,0830 & 0,0730 & 1,0286 \\
\hline C9 & 8,2291 & 3,7010 & 8,4830 & 0,5500 & 0,0670 & 0,0760 & 0,4071 \\
\hline C10 & 8,3768 & 3,6850 & 4,7830 & 0,6210 & 0,0630 & 0,0790 & 1,0991 \\
\hline C11 & 7,6778 & 3,7040 & 5,9190 & 0,5020 & 0,0760 & 0,0690 & 1,0798 \\
\hline C12 & 7,2757 & 3,7020 & 0,1850 & 0,6060 & 0,0590 & 0,0770 & 1,0955 \\
\hline
\end{tabular}




\begin{tabular}{cccccccc}
\hline \multicolumn{7}{l}{ Tabela 5- Continuação } & \multicolumn{7}{l}{0,5640} & 0,0700 & 0,0930 & 0,0471 \\
\hline C15 & 7,9586 & 3,6990 & 5,7890 & 0,560 & 0,2365 \\
\hline C16 & 8,4437 & 3,7050 & 1,4140 & 0,5660 & 0,0910 & 0,0880 & 0,1276 \\
\hline C18 & 7,6778 & 3,6890 & 1,0670 & 0,6020 & 0,0810 & 0,1030 & 0,1317 \\
\hline C19 & 6,8386 & 3,7970 & 4,9190 & 0,5340 & 0,0740 & 0,0880 & 0,1048 \\
\hline C20 & 8,9983 & 3,6740 & 1,8680 & 0,5960 & 0,0800 & 0,0800 & 0,6977 \\
\hline C21 & 6,6289 & 3,8250 & 4,1760 & 0,5350 & 0,0940 & 0,1140 & 0,1902 \\
\hline C22 & 6,9469 & 3,8460 & 4,2880 & 0,5650 & 0,0930 & 0,1000 & 0,3072 \\
\hline C23 & 6,9666 & 3,8450 & 4,7330 & 0,5780 & 0,0910 & 0,0960 & 0,1676 \\
\hline C25 & 7,1367 & 3,700 & 1,6370 & 0,540 & 0,0880 & 0,1010 & 0,2797 \\
\hline C26 & 8,4685 & 3,6970 & 3,6250 & 0,5570 & 0,0850 & 0,1000 & 0,1869 \\
\hline C27 & 7,5528 & 3,6970 & 3,7200 & 0,5630 & 0,0850 & 0,1020 & 0,7766 \\
\hline C28 & 7,1805 & 3,6970 & 2,5710 & 0,5360 & 0,0890 & 0,1150 & 0,5339 \\
\hline C29 & 7,8239 & 3,6990 & 4,8230 & 0,5450 & 0,0860 & 0,1040 & 0,1853 \\
\hline C30 & 7,7696 & 3,6970 & 2,7460 & 0,5030 & 0,1030 & 0,1150 & 0,1192 \\
\hline C31 & 7,3768 & 3,6990 & 4,8850 & 0,5380 & 0,0830 & 0,1180 & 0,1129 \\
\hline C32 & 7,1249 & 3,6920 & 0,0050 & 0,5210 & 0,0980 & 0,1190 & 0,1649 \\
\hline C33 & 7,5229 & 3,6890 & 0,5220 & 0,5570 & 0,0980 & 0,1180 & 0,2305 \\
\hline C34 & 7,6990 & 3,6980 & 2,3010 & 0,5020 & 0,0980 & 0,1130 & 0,1521 \\
\hline C35 & 7,7447 & 3,7050 & 8,6690 & 0,5120 & 0,1010 & 0,1220 & 0,6422 \\
\hline C36 & 7,9586 & 3,7010 & 4,8100 & 0,5770 & 0,0740 & 0,1010 & 0,6675 \\
\hline C37 & 6,9830 & 3,6900 & 0,0000 & 0,4290 & 0,1080 & 0,0920 & 0,2133 \\
\hline C38 & 7,7447 & 3,6890 & 0,9970 & 0,5710 & 0,0820 & 0,1040 & 0,1469 \\
\hline C39 & 8,2441 & 3,6980 & 3,8600 & 0,5650 & 0,0840 & 0,1020 & 0,2944 \\
\hline C40 & 8,9208 & 3,706 & 12,278 & 0,578 & 0,069 & 0,08 & 0,9342 \\
\hline C41 & 8,4685 & 3,708 & 7,359 & 0,565 & 0,075 & 0,087 & 0 \\
\hline & & & & & & & \\
\hline
\end{tabular}

As descrições das variáveis estão apresentadas na Tabela 5.

Tabela 5- Descrição das variáveis selecionadas

\begin{tabular}{|c|c|c|}
\hline Descritor & Tipo & Definição \\
\hline BEHe3 & $\begin{array}{l}\text { BCUT (Burden- CAS-University of Texas } \\
\text { EigenValues) }\end{array}$ & $\begin{array}{l}\text { Refere-se } \\
\text { eletronegatividade } \\
\text { Sanderson. }\end{array}$ \\
\hline RDF145u & RDF (Radial Function Distribution) & $\begin{array}{l}\text { Função de distribuição radial } \\
\text { calculada sobre as distâncias } \\
\text { interatômica de uma } \\
\text { molécula. }\end{array}$ \\
\hline E1e & $\begin{array}{l}\text { WHIM (Weighted Holistic } \\
\text { Molecular) }\end{array}$ & $\begin{array}{l}\text { Baseados na } \\
\text { Componente } \\
\text { (PCA). }\end{array}$ \\
\hline $\begin{array}{l}\text { HATS7v/ } \\
\text { R2v+ }\end{array}$ & $\begin{array}{l}\text { GETAWAY (Geometric Topology and Atom } \\
\text { Weights Assembly) }\end{array}$ & $\begin{array}{l}\text { Volume atômico de van deer } \\
\text { Waals. }\end{array}$ \\
\hline$E_{\text {lumo+4 }}$ & Eletrônico & Energia do orbital Lumo +4 . \\
\hline
\end{tabular}


Uma vez selecionada as variáveis, o próximo passo é a geração do modelo QSAR.

Este foi gerado através do software Pirouette.

\subsubsection{Geração de Modelos QSAR}

O modelo obtido usando o método PLS foi construído primeiramente com todos os 38 compostos. Todos os dados, bloco X e Y, foram autoescalados. Este modelo foi avaliado internamente através do método de validação cruzada, em que foi excluído um composto de cada vez. A Tabela 6 mostra o número de variáveis latentes (VL), erros padrões de validação $\left(\mathrm{SEP}_{\mathrm{val}}\right)$ e de calibração $\left(\mathrm{SEP}_{\text {cal }}\right)$, coeficiente de correlação de validação $\left(\mathrm{Q}^{2}\right)$ e de determinação múltipla $\left(\mathrm{R}^{2}\right)$.

Tabela 6-Porcentagem de variância acumulada, $\mathrm{SEP}_{\mathrm{val}}, \mathrm{SEP}_{\mathrm{cal}}, \mathrm{Q}^{2}, \mathrm{R}^{2}$

\begin{tabular}{llllllll}
\hline $\mathbf{V L}$ & \% Var $_{\text {acumulada }}$ & $\mathbf{S E P}_{\text {val }}^{1}$ & $\mathbf{P R E S S}_{\text {val }}$ & $\mathbf{S E P}_{\text {cal }}^{\mathbf{3}}$ & $\mathbf{Q}^{\mathbf{2}}$ & $\mathbf{P R E S S}_{\text {cal }}$ & $\mathbf{R}^{\mathbf{2 b}}$ \\
\hline $\mathbf{1}$ & 41,8892 & 0,4926 & 9,2196 & 0,4669 & 0,4485 & 7,8477 & 0,5276 \\
\hline $\mathbf{2}$ & 55,4278 & 0,4512 & 7,7357 & 0,3766 & 0,5462 & 4,9645 & 0,7012 \\
\hline $\mathbf{3}$ & 67,7951 & 0,3683 & 5,1543 & 0,3047 & 0,6936 & 3,1562 & 0,8100 \\
\hline $\mathbf{4}$ & 79,1190 & 0,3280 & 4,0875 & 0,2870 & 0,7571 & 2,7176 & 0,8364 \\
\hline $\mathbf{5}$ & 88,8047 & 0,3170 & 3,8188 & 0,2838 & 0,7731 & 2,5775 & 0,8448 \\
\hline $\mathbf{6}$ & 100 & 0,3175 & 3,8303 & 0,2878 & 0,7723 & 2,5678 & 0,8454 \\
\hline
\end{tabular}

${ }^{1}$ Erro padrão de validação cruzada, resultado da remoção de uma amostra de cada vez.

${ }^{2}$ Soma dos Quadrados dos resíduos de predição obtido na validação cruzada.

${ }^{3}$ Erro padrão de calibração calculado uma única vez com todos os compostos.

${ }^{a}$ Coeficiente de correlação de validação cruzada.

${ }^{4}$ Soma dos Quadrados dos resíduos de predição obtido na calibração

${ }^{\mathrm{b}}$ Coeficiente de determinação múltipla.

O número ótimo de VL, 5, contém $88,80 \%$ da informação original dos dados, apresentando o menor erro padrão de validação $\left(\operatorname{SEP}_{\mathrm{val}}=0,3170\right)$, menor $\operatorname{PRESS} S_{\text {Val }}(3,8188)$, menor PRESS cal $(2,5775)$ e o maior coeficiente de correlação $\left(Q^{2}=0,7731\right)$. A Figura 16 mostra o gráfico de $\mathrm{SEP}_{\mathrm{Val}}$ e $\mathrm{SEP}_{\text {cal }}$ contra o número de variáveis latentes, mostrando a diferença entre ambos. É notório que os valores de $\mathrm{SEP}_{\text {val }}$ são sempre mais elevados que os valores de $\mathrm{SEP}_{\text {cal }}$ e que o menor valor de $\mathrm{SEP}_{\text {val }}$ corresponde ao número ótimo de VL. Percebe-se também que os valores de $\mathrm{SEP}_{\text {cal }}$ decrescem e isto é devido ao aumento da complexidade do modelo, em que a descrição da informação presente nos dados (importante ou não) está mais completa, melhorando, dessa forma, o ajuste do modelo aos dados. No 
entanto, um modelo mais complexo nem sempre é o mais apropriado para predições futuras, mostrando que o $\mathrm{SEP}_{\text {cal }}$ não pode ser considerado o único parâmetro para determinar o número ótimo de VL para o modelo.

Figura 16- $\mathrm{SEP}_{\mathrm{Val}}$ e $\mathrm{SEP}_{\text {cal }}$ versus o número de $\mathrm{VL}$

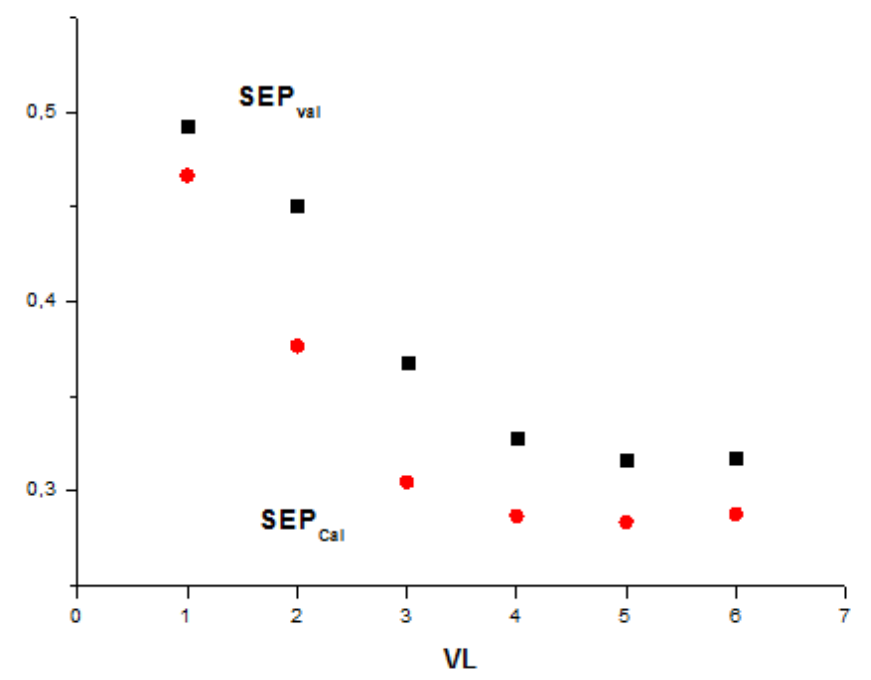

Ficou claro que quanto menor o $\operatorname{PRESS}_{\mathrm{Val}}$ maior o valor de $\mathrm{Q}^{2}$, sendo assim, esse é outro parâmetro usado para avaliar a significância do modelo. De acordo com WOLD e

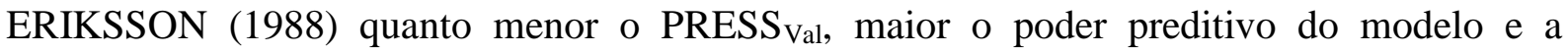
probabilidade de está ocorrendo correlação ao acaso será menor. A mesma premissa é verdadeira para os valores de PRESS $_{\text {cal }}$, quando menor for este valor melhor seja o ajuste do modelo. A Figura 17 mostra a relação entre esses dois parâmetros vs. VL. Os valores de PRESS $_{\text {Val }}$ são sempre maiores que os de PRESS $_{\text {cal }}$ e a explicação para isso é a mesma que a da relação entre $\mathrm{SEP}_{\mathrm{Val}}$ e $\mathrm{SEP}_{\text {cal }}$. 
Figura 17- PRESSval e PRESScal versus. VL

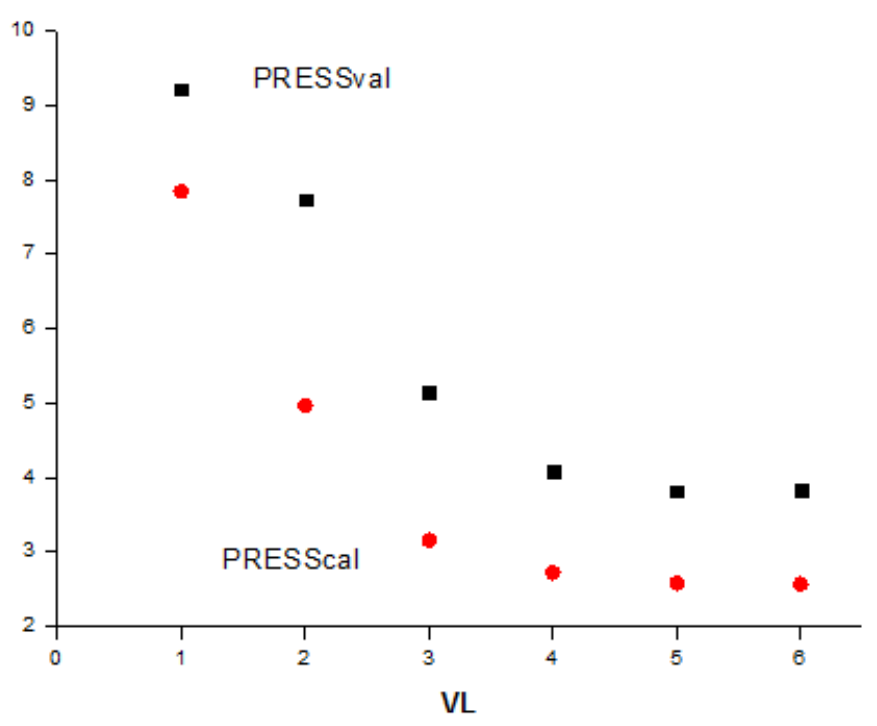

A mesma analogia é feita para os parâmetros $\mathrm{Q}^{2}$ e $\mathrm{R}^{2}$ (Figura 18). Os valores de $\mathrm{R}^{2}$ crescem à medida que o modelo fica mais complexo, indicando um bom ajuste, mas não necessariamente um bom poder de previsão do modelo. Sendo assim, o parâmetro $\mathrm{Q}^{2}$ é o coeficiente indicativo do poder preditivo do modelo. Percebe-se que ao aumentar o número de VL, $\mathrm{Q}^{2}$ aumenta, alcança o valor ótimo e depois decresce. Como foi comentado anteriormente (subitem 2.4.7), a diferença entre $\mathrm{R}^{2}$ e $\mathrm{Q}^{2}$ deve está muito próxima entre si para que o modelo seja considerado aceitável, no presente caso a diferença foi de 0,072 , valor considerado bom, pois é bem menor do que é mostrado na literatura como ideal $(0,30)$.

Figura 18- $\mathrm{Q}^{2} \mathrm{e} \mathrm{R}^{2}$ versus. o número de VL

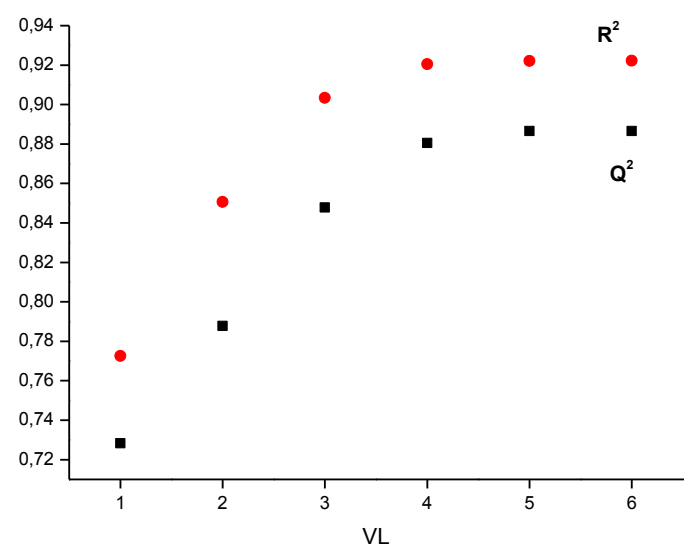

Outro parâmetro analisado foi a detecção de amostras com comportamento anômalo, outliers (Figura 19, Tabela 7). De acordo com a Tabela 7 e a Figura 19 apenas o C2 apresenta um pequeno desvio em relação ao ideal. No entanto, não podemos considerar como uma 
amostra anômala, pois a diferença é muito pequena, além disso, o valor de leverage para esse composto está dentro do limite aceitável. Sendo assim, podemos concluir que todas as amostras apresentam valores de leverage e Resíduos de Student dentro do limite aceitável, $3 \mathrm{VL} / \mathrm{I}$ (VL representa as variáveis latentes e I refere-se às amostras) para leverage e abaixo de 2 para o Resíduo de Student.

Figura 19- Detecção de Outliers

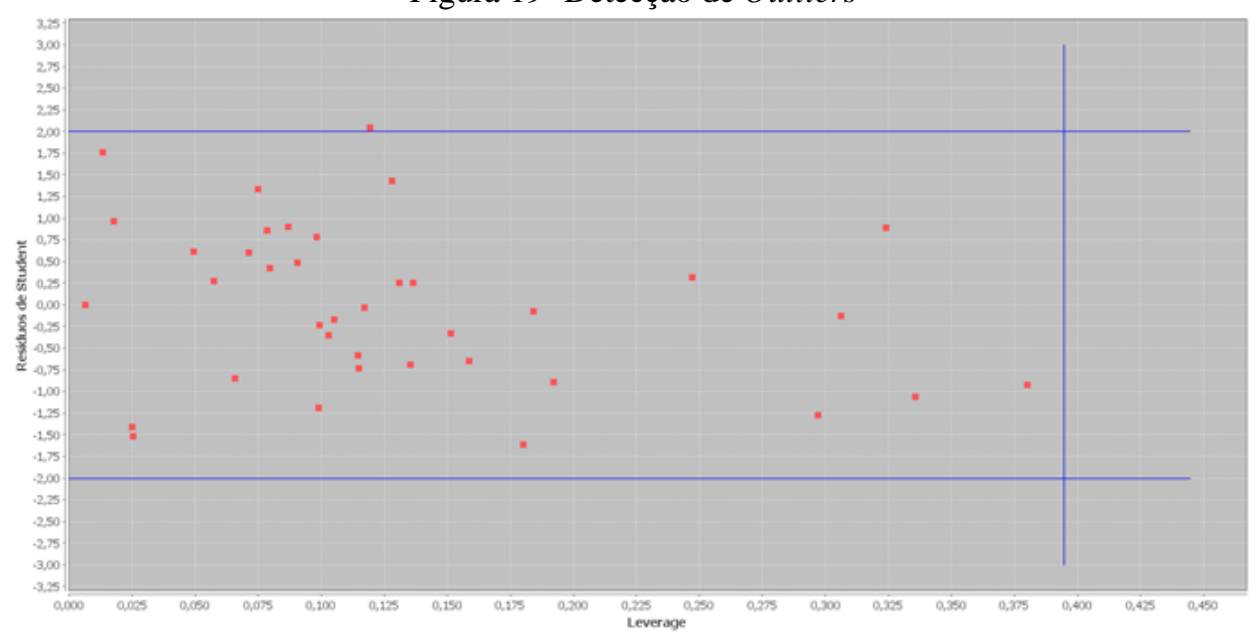

Tabela 7- Compostos e seus valores de leverage e R. Student

\begin{tabular}{ccc}
\hline Composto & Leverage & R. Student \\
\hline C1 & 0,1843 & $-0,0708$ \\
\hline C2 & 0,1195 & 2,0402 \\
\hline C3 & 0,0869 & 0,9040 \\
\hline C4 & 0,1800 & $-1,6100$ \\
\hline C5 & 0,0991 & $-0,2329$ \\
\hline C6 & 0,0659 & $-0,8518$ \\
\hline C7 & 0,1353 & $-0,6918$ \\
\hline C8 & 0,1279 & 1,4323 \\
\hline C9 & 0,1514 & $-0,3277$ \\
\hline C10 & 0,1587 & $-0,6500$ \\
\hline C11 & 0,1920 & $-0,8899$ \\
\hline C12 & 0,2970 & $-1,2787$ \\
\hline C13 & 0,0796 & 0,4244 \\
\hline C15 & 0,1365 & 0,2562 \\
\hline C16 & 0,0714 & 0,6078 \\
\hline C18 & 0,0988 & $-1,1895$ \\
\hline C19 & 0,2470 & 0,3191 \\
\hline C20 & 0,0981 & 0,7781 \\
\hline C21 & 0,3241 & 0,8924 \\
\hline C22 & 0,3061 & $-0,1256$ \\
\hline C23 & 0,3355 & $-1,0636$ \\
\hline C25 & 0,0253 & $-1,5212$ \\
\hline C26 & 0,0132 & 1,7573 \\
\hline & & \\
\hline
\end{tabular}




\begin{tabular}{ccc}
\hline \multicolumn{3}{c}{ Tabela 7- Continuação } \\
\hline C27 & 0,0250 & $-1,4087$ \\
\hline C28 & 0,1028 & $-0,3516$ \\
\hline C29 & 0,0065 & $-0,0035$ \\
\hline C30 & 0,0785 & 0,8544 \\
\hline C31 & 0,1311 & 0,2544 \\
\hline C32 & 0,1050 & $-0,1680$ \\
\hline C33 & 0,1147 & $-0,5831$ \\
\hline C34 & 0,0749 & 1,3397 \\
\hline C35 & 0,1151 & $-0,7348$ \\
\hline C36 & 0,0494 & 0,6106 \\
\hline C37 & 0,3802 & $-0,9262$ \\
\hline C38 & 0,0573 & 0,2728 \\
\hline C39 & 0,0178 & 0,9681 \\
\hline C40 & 0,1172 & $-0,0376$ \\
\hline C41 & 0,0906 & 0,4882 \\
\hline & &
\end{tabular}

A Figura 20 mostra o gráfico de atividade predita (y predito) versus experimental (y mensurado). É notório como os valores estão ajustados à reta com alguns poucos desvios.

Figura 20- y predito versus y mensurado para a regressão PLS usando todo o conjunto

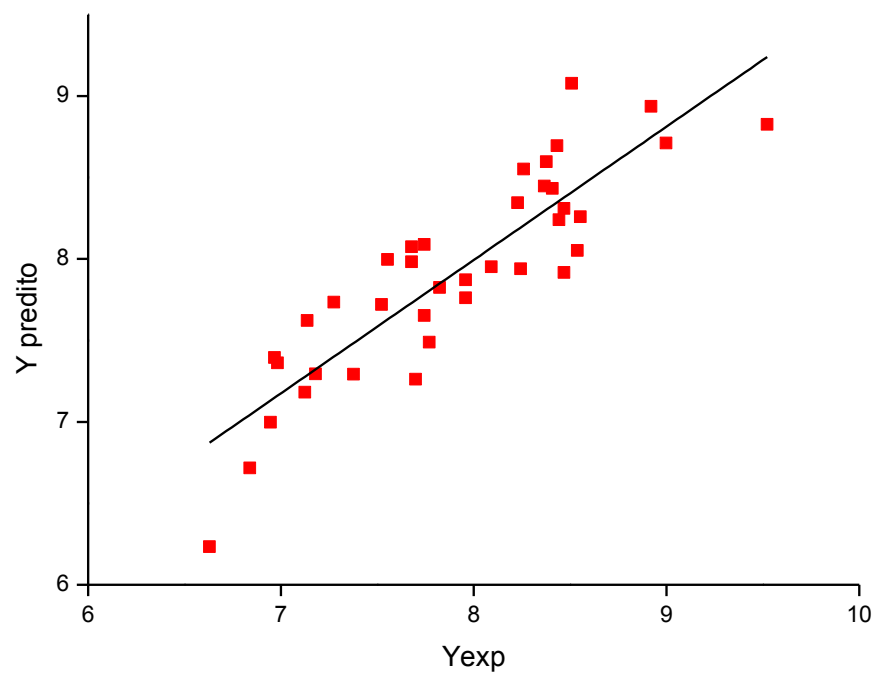

Após a geração do modelo com todas as amostras, estas foram divididas em grupo de treinamento e grupo de teste (formado por $30 \%$ do conjunto total), para que o modelo seja validado interno e externamente (Subitem 5.3). 


\subsubsection{Validação do Modelo}

A divisão do conjunto em treinamento e teste foi realizada após a construção do modelo com todas as amostras, denominado de modelo auxiliar. O conjunto de compostos utilizados na validação externa é denominado conjunto de teste, este deve conter aproximadamente $30 \%$ do conjunto total e deve estar de forma mais uniforme possível pelo intervalo da atividade biológica do conjunto de treinamento.

\subsubsection{Validação Interna}

A validação interna é realizada com o conjunto de treinamento. Os compostos selecionados para fazerem parte desse conjunto foram $70 \%$ do total $(\mathrm{C} 1, \mathrm{C} 3, \mathrm{C} 4, \mathrm{C} 5, \mathrm{C} 6, \mathrm{C} 7$, C8, C9, C11, C12, C18, C20, C22, C23, C25, C28, C29, C30, C31, C32, C33, C34, C35, C36, C38, C39, C41). A Tabela 8 mostra os resultados estatísticos para o modelo obtido.

Tabela 8- Resultado estatístico para o conjunto de treinamento

\begin{tabular}{llllllll}
\hline $\mathbf{L V}$ & \% Var $_{\text {acumulada }}$ & $\mathbf{S E P}_{\text {val }}$ & $\mathbf{P R E S S}_{\text {Val }}$ & $\mathbf{S E P}_{\text {cal }}$ & $\mathbf{Q}^{\mathbf{2}}$ & $\mathbf{P R E S S}_{\text {cal }}$ & $\mathbf{R}^{\mathbf{2}}$ \\
\hline $\mathbf{1}$ & 38,9406 & 0,4711 & 5,9934 & 0,4346 & 0,2960 & 4,7208 & 0,4334 \\
\hline $\mathbf{2}$ & 51,3012 & 0,4893 & 6,4652 & 0,3461 & 0,3325 & 2,8742 & 0,6550 \\
\hline $\mathbf{3}$ & 68,8225 & 0,3832 & 3,9638 & 0,2705 & 0,5424 & 1,6830 & 0,7980 \\
\hline $\mathbf{4}$ & 74,8919 & 0,3076 & 2,5202 & 0,2632 & 0,6994 & 1,5235 & 0,8171 \\
\hline $\mathbf{5}$ & 84,5349 & 0,3055 & 2,5202 & 0,2628 & 0,7039 & 1,4503 & 0,8259 \\
\hline $\mathbf{6}$ & 100 & 0,3085 & 2,5694 & 0,2692 & 0,6996 & 1,4494 & 0,8260 \\
\hline
\end{tabular}

Para esse conjunto de treinamento o número ótimo de variáveis latentes foi 5 , corroborando com o modelo obtido com todas as amostras, contendo 84,53\% das informações dos dados originais. A Tabela 9 mostra a diferença entre os parâmetros analisados no primeiro modelo gerado com todas as amostras e o modelo gerado com as amostras do conjunto de treinamento.

Tabela 9- Diferença entre os parâmetros analisados no conjunto auxiliar e no conjunto de treinamento

\begin{tabular}{l|c|l|c|c|c|c}
\cline { 2 - 7 } & SEP $_{\text {val }}$ & $\mathbf{P R E S S}_{\text {Val }}$ & $\mathbf{S E P}_{\text {cal }}$ & $\mathbf{Q}^{2}$ & PRESS $_{\text {cal }}$ & $\mathbf{R}^{2}$ \\
\hline Conjunto auxiliar & 0,3170 & 3,8188 & 0,2838 & 0,7731 & 2,5775 & 0,8448 \\
\hline $\begin{array}{l}\text { Conjunto } \\
\text { treinamento }\end{array}$ & 0,3055 & 2,5202 & 0,2628 & 0,7039 & 1,4503 & 0,8259 \\
\hline
\end{tabular}

É notável a pequena diferença entre os dois modelos, concordando com o que é colocado na literatura, que a diferença deve ser pequena. Vale salientar que essa diferença é referente aos resultados obtidos com o número ótimo de 5 variáveis latentes. 
Outro parâmetro analisado no conjunto de treinamento foi a presença de amostras anômalas (Figura 21 ).

Figura 21- Detecção de amostras anômalas no conjunto de treinamento

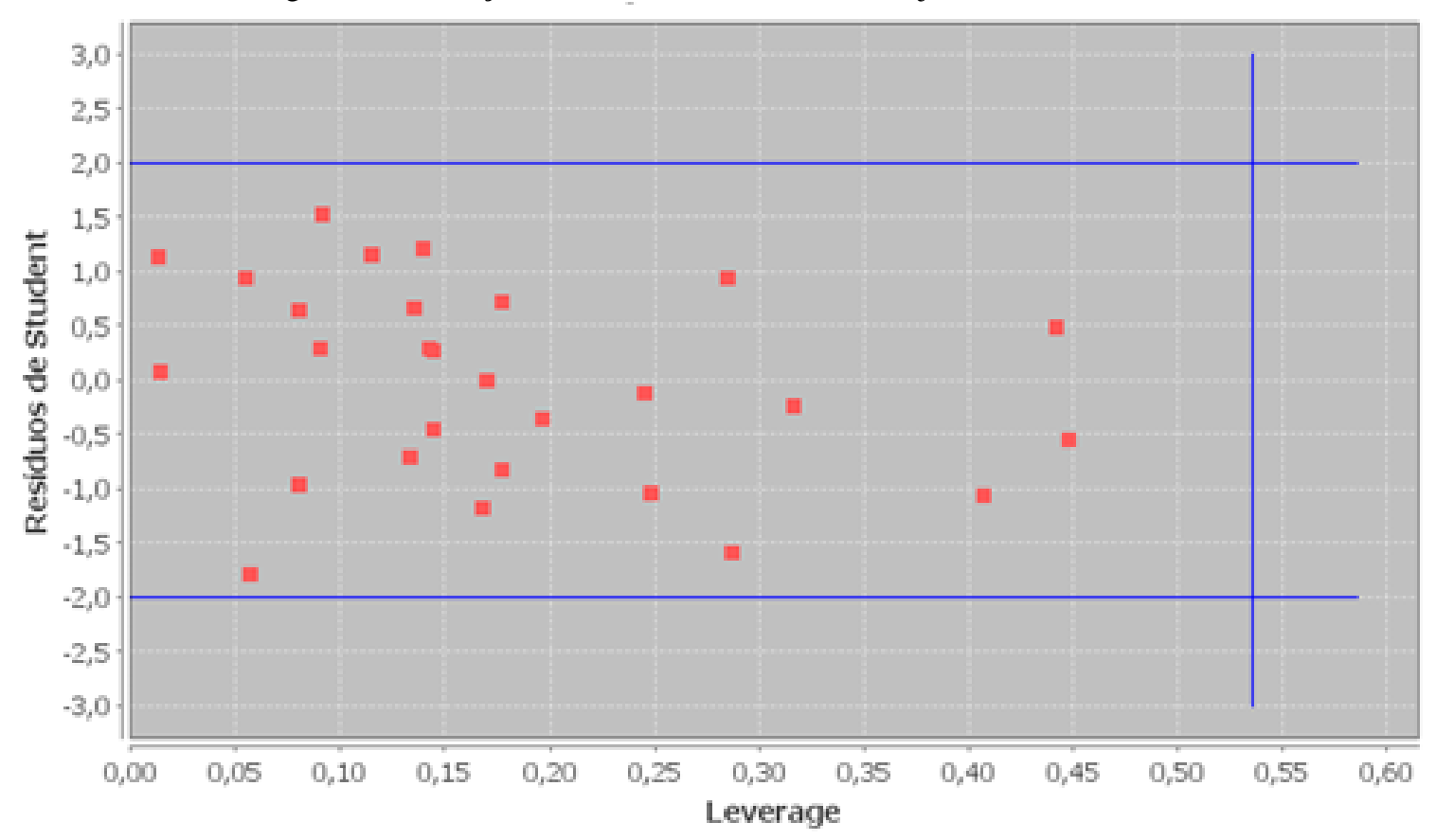

A Tabela abaixo (Tabela 10) mostra os valores de Leverage e R. Student.

Tabela 10- Valores de leverage e de R. Student para o conjunto de treinamento.

\begin{tabular}{ccc}
\hline Composto & Leverage & R. Student \\
\hline C1 & 0,2449 & $-0,1152$ \\
\hline C3 & 0,1148 & 1,1573 \\
\hline C4 & 0,2867 & $-1,5860$ \\
\hline C5 & 0,1425 & 0,2956 \\
\hline C6 & 0,0797 & $-0,9659$ \\
\hline C7 & 0,1695 & 0,0051 \\
\hline C8 & 0,0914 & 1,5298 \\
\hline C9 & 0,3169 & $-0,2350$ \\
\hline C11 & 0,2480 & $-1,0512$ \\
\hline C12 & 0,4072 & $-1,0597$ \\
\hline C16 & 0,0800 & 0,6439 \\
\hline C18 & 0,1680 & $-1,1813$ \\
\hline C20 & 0,2853 & 0,9462 \\
\hline C22 & 0,4419 & 0,4957 \\
\hline C23 & 0,4488 & $-0,5504$ \\
\hline C25 & 0,0564 & $-1,7808$ \\
\hline C28 & 0,1962 & $-0,3518$ \\
\hline C29 & 0,0140 & 0,0727 \\
\hline C30 & 0.1356 & 0.6706 \\
\hline C31 & 0.1444 & 0.2768 \\
\hline C32 & 0.1441 & -0.4626 \\
\hline & & \\
\hline & & \\
\hline
\end{tabular}




\begin{tabular}{ccc}
\hline \multicolumn{3}{c}{ Tabela 10- Continuação } \\
\hline C33 & 0.1331 & -0.7101 \\
\hline C34 & 0.1388 & 1.2106 \\
\hline C35 & 0,1765 & $-0,8264$ \\
\hline C36 & 0,0542 & 0,9321 \\
\hline C38 & 0,0907 & 0,2998 \\
\hline C39 & 0,0133 & 1,1262 \\
\hline C41 & 0,1772 & 0,7262 \\
\hline
\end{tabular}

Analisando a detecção de amostras anômalas, é notório tanto na Figura 21 quanto na Tabela 10 que todas as amostras estão dentro dos padrões desejados discutidos no subitem 5.2 .

No que concerne aos parâmetros $\mathrm{Q}^{2}$ e $\mathrm{R}^{2}$, estes devem sem analisados juntamente com a verificação de outros parâmetros com o objetivo de garantir a robustez dos mesmos. Um deles está relacionado ao grau de degeneração do bloco X (descritores). A Tabela 11 mostra os valores de scores dos compostos para todos os descritores.

Tabela 11- Valores de scores dos compostos para todos os descritores

\begin{tabular}{ccccccc}
\hline Composto & Fator1 & Fator2 & Fator3 & Fator4 & Fator5 & Fator6 \\
\hline C1 & $-0,9148$ & 1,1488 & 0,1247 & 0,6170 & 0,1767 & $-0,5562$ \\
\hline C3 & 1,6726 & $-0,6264$ & $-0,3797$ & 0,8719 & $-0,6226$ & 0,4232 \\
\hline C4 & 1,9640 & $-0,1658$ & 0,0968 & 0,9476 & $-0,4510$ & 0,9747 \\
\hline C5 & 2,6600 & $-1,2996$ & 0,2991 & $-0,5064$ & 0,8828 & 0,9060 \\
\hline C6 & 0,9681 & 0,2195 & 0,1816 & 0,2952 & $-1,1416$ & $-0,3852$ \\
\hline C7 & 2,5023 & $-1,2651$ & 0,8346 & $-0,8421$ & 1,9580 & 0,8998 \\
\hline C8 & 0,9994 & $-0,3696$ & $-0,4987$ & 1,2811 & $-1,0310$ & $-0,3406$ \\
\hline C9 & 1,6072 & $-0,3524$ & 0,4681 & $-0,9324$ & $-0,7378$ & 0,6721 \\
\hline C11 & 1,5171 & $-0,5017$ & $-1,0112$ & 0,7621 & $-1,7144$ & 1,0241 \\
\hline C12 & 1,8199 & $-2,0013$ & 0,2118 & 0,3601 & $-0,0306$ & $-2,0911$ \\
\hline C18 & $-0,2814$ & 0,1237 & 0,5617 & $-0,5168$ & 0,8351 & $-1,7266$ \\
\hline C20 & 0,6687 & 0,5668 & 0,8415 & $-0,4235$ & $-0,0910$ & $-1,7437$ \\
\hline C22 & $-2,5672$ & $-0,9542$ & 2,4819 & 0,2083 & $-0,5646$ & 0,8487 \\
\hline C23 & $-2,3406$ & $-0,9115$ & 2,9371 & $-0,0290$ & $-0,5192$ & 0,6692 \\
\hline C25 & $-0,8733$ & 0,5095 & $-0,4136$ & $-0,1634$ & $-0,3412$ & $-0,4880$ \\
\hline C28 & $-0,6421$ & $-0,0630$ & $-1,2991$ & 0,5528 & 0,5544 & 0,0494 \\
\hline C29 & $-0,1335$ & 0,1597 & $-0,4852$ & 0,0593 & 0,2936 & 0,2969 \\
\hline C30 & $-1,8025$ & 1,3573 & $-1,2695$ & 0,2773 & $-0,2036$ & 0,5971 \\
\hline C31 & $-0,9081$ & 0,3094 & $-0,5904$ & $-0,9521$ & 0,4883 & 0,3819 \\
\hline C32 & $-1,9984$ & 1,0306 & $-1,2672$ & 0,0371 & 0,0188 & $-0,4254$ \\
\hline C33 & $-1,5716$ & 0,9539 & $-0,5685$ & 0,1503 & 0,7470 & $-0,8640$ \\
\hline C34 & $-1,6284$ & 1,0352 & $-1,3610$ & 0,1520 & $-0,3762$ & 0,4528 \\
\hline & & & & & & \\
\hline
\end{tabular}




\begin{tabular}{ccccccc}
\hline \multicolumn{7}{l}{ Tabela 11- Continuação } \\
\hline C35 & $-1,3081$ & 1,3444 & $-0,6629$ & $-0,2977$ & 0,6376 & 1,9814 \\
\hline C36 & 0,5990 & $-0,6729$ & 0,0216 & $-0,2724$ & 0,6929 & $-0,3056$ \\
\hline C38 & $-0,4835$ & 0,1673 & $-0,1508$ & $-0,4006$ & 0,3331 & $-1,2317$ \\
\hline C39 & $-0,2053$ & 0,2230 & 0,0620 & $-0,2923$ & 0,3807 & $-0,3477$ \\
\hline C41 & 0,6804 & 0,0345 & 0,8354 & $-0,9434$ & $-0,1743$ & 0,3285 \\
\hline
\end{tabular}

A literatura coloca que o ideal é que cada composto seja descrito por um conjunto de variáveis com valores diferentes (FERREIRA, KIRALJ, 2011). Dessa forma os valores do conjunto de variáveis dos compostos do grupo de treinamento (Tabela 4) corroboram com tal afirmação.

Os dois últimos parâmetros analisados para a validação interna do modelo foram o teste de randomização e teste de validação cruzada (leave-one-out). Os resultados para a randomização estão na Tabela 12.

Tabela 12- Resultados da randomização de y para o modelo PLS do conjunto de treinamento. Em negrito os valores para o modelo real

\begin{tabular}{ccc}
\hline $\mathbf{R}^{\mathbf{2}}$ & $\mathbf{Q}^{\mathbf{2}}$ & $\mathbf{r}^{*}(\mathbf{y a l}, \mathbf{y})$ \\
\hline 0,3326 & $-0,3951$ & 0,1506 \\
\hline 0,1189 & $-0,5444$ & 0,0068 \\
\hline 0,2435 & $-0,3417$ & 0,1262 \\
\hline 0,0842 & $-0,6252$ & 0,2277 \\
\hline 0,1551 & $-0,6343$ & 0,1858 \\
\hline 0,1931 & $-0,4497$ & 0,2508 \\
\hline 0,3497 & $-0,0443$ & 0,1040 \\
\hline 0,2992 & $-0,1565$ & 0,3147 \\
\hline 0,3938 & $-0,1471$ & 0,2037 \\
\hline 0,0886 & $-0,5673$ & 0,3259 \\
\hline 0,2404 & $-0,4869$ & 0,2111 \\
\hline 0,2847 & $-0,4624$ & 0,2927 \\
\hline $\mathbf{0 , 8 2 5 9}$ & $\mathbf{0 , 7 0 3 9}$ & $\mathbf{1 , 0 0 0 0}$ \\
\hline
\end{tabular}

*Valor absoluto do coeficiente de correlação entre o vetor y e os respectivos vetores randomizados

O teste de randomização para o conjunto de treinamento foi realizado 12 vezes para a atividade biológica, usando o mesmo número de variáveis latentes. Para um bom modelo, é esperado que os valores de $Q^{2}$ e $R^{2}$ depois da randomização sejam menores que 0,3 e 0,4 , respectivamente. Portanto, levando em consideração os péssimos valores tanto de $\mathrm{Q}^{2}$ quanto de $\mathrm{R}^{2}$ comparados com o do modelo real, esse foi mais um teste que valida o modelo obtido, 
indicando que a variância explicada pelo modelo não é devido à correlação ao acaso. Logo, o modelo pode ser considerado robusto.

Outra maneira mais quantitativa de verificar a presença de correlação ao acaso é através dos gráficos $\mathrm{r}$ versus $\mathrm{Q}^{2}$ e $\mathrm{r}$ versus $\mathrm{R}^{2}$ (Figura 22 e 23).

Figura 22- $\mathrm{r}$ versus $\mathrm{Q}^{2}$

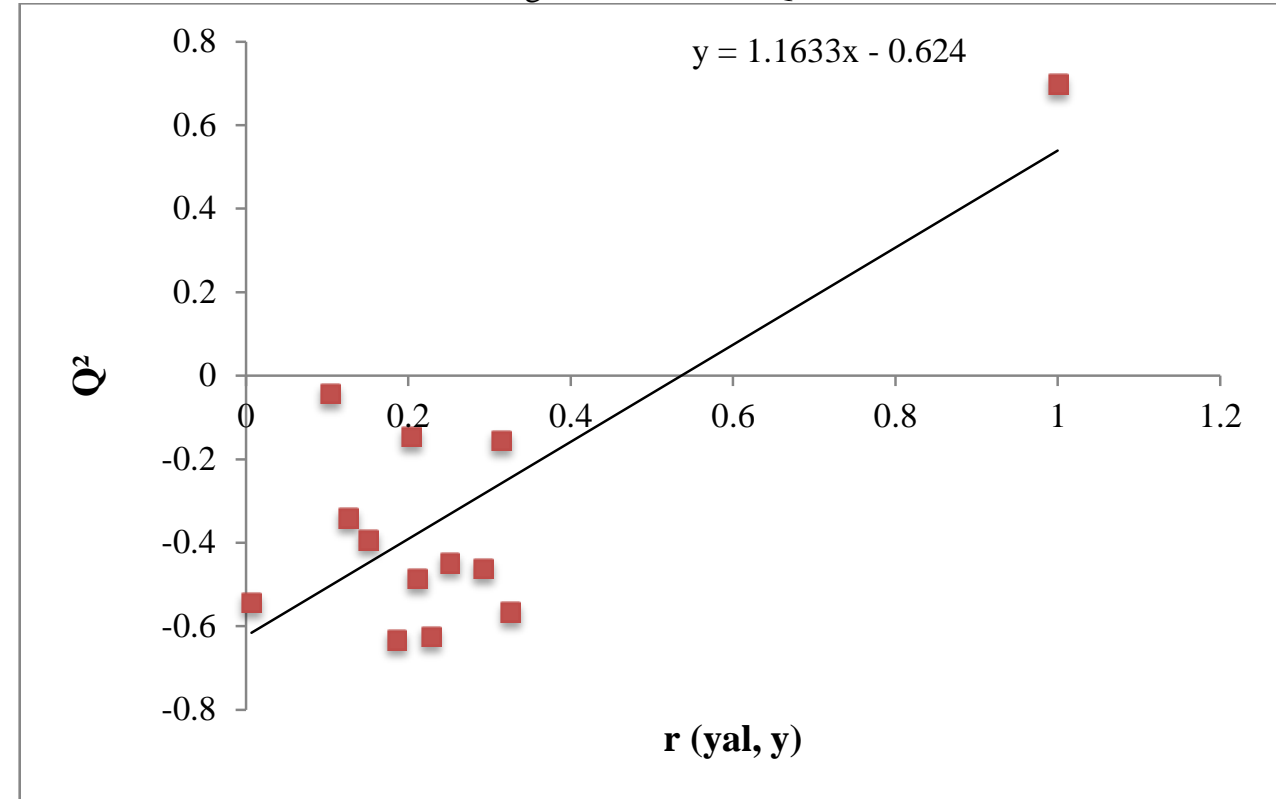

O intercepto do gráfico $\mathrm{r}$ versus $\mathrm{Q}^{2}$ deve ser menor que 0,05 (FERREIRA, KIRALJ, 2011), sendo assim, podemos considerar esse teste foi positivo, pois o valor do intercepto da equação do gráfico (Figura 22) foi (- 0.624) menor que o exigido, demostrando, dessa forma, que não existe correlação ao acaso.

Figura 23- $\mathrm{r}$ versus $\mathrm{R}^{2}$

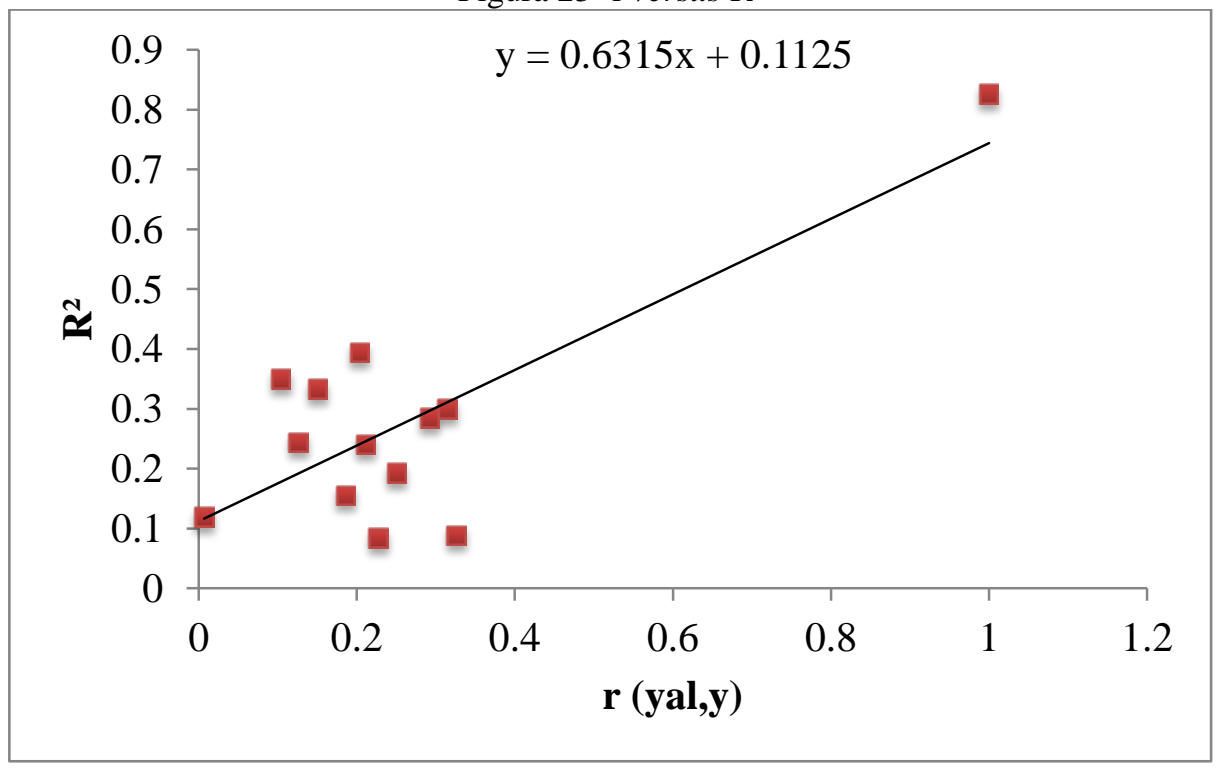


Quanto ao gráfico $r$ versus $R^{2}$ o valor do intercepto deve ser menor que 0,3 (FERREIRA, KIRALJ, 2011). O resultado do intercepto do gráfico acima (Figura 23) também apresentou um valor $(0,1125)$ abaixo do valor limite.

Portanto, todos os testes, $\mathrm{r}$ versus $\mathrm{Q}^{2}$ e $\mathrm{r}$ versus $\mathrm{R}^{2}$, apresentaram resultados positivos, contribuindo para a validação do modelo.

$\mathrm{O}$ último teste da validação interna foi a validação cruzada excluindo $\mathrm{N}$ compostos ( $\mathrm{N}=8$ para o conjunto de treinamento) realizado com o mesmo número de variáveis latentes, 5. A Tabela 13 e a Figura 24 mostram os resultados para esse teste.

Tabela 13- Resultados da validação cruzada do modelo PLS, excluindo N amostras.

${ }^{\mathrm{a}}$ Média de $\mathrm{Q}^{2}$.

\begin{tabular}{cc}
\hline $\mathbf{N}$ & $\mathbf{Q}^{\mathbf{2}}$ \\
\hline 1 & 0,6975 \\
\hline 2 & 0,6728 \\
\hline 3 & 0,6720 \\
\hline 4 & 0,6965 \\
\hline 5 & 0,6992 \\
\hline 6 & 0,6917 \\
\hline 7 & 0,6492 \\
\hline 8 & 0,7293 \\
\hline Média $^{\mathbf{a}}$ & 0,6885 \\
\hline Des. Pd $^{\mathbf{b}}$ & 0,0223 \\
\hline Variação $^{\mathbf{c}}$ & 0,0801 \\
\hline
\end{tabular}

${ }^{\mathrm{b}}$ Desvio padrão de $\mathrm{Q}^{2}$.

${ }^{\mathrm{c}}$ Desvio entre os valores máximos e mínimos.

Figura 24- Valores de $\mathrm{Q}^{2}$ da validação cruzada

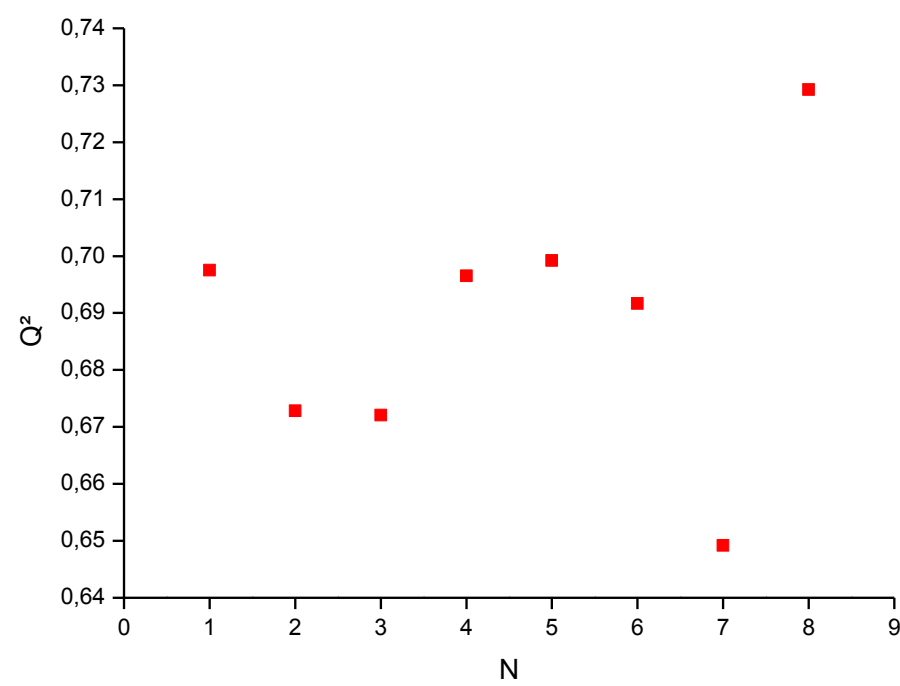


O modelo é considerado aceitável para os valores de $\mathrm{N}$ testados, pois os valores de $\mathrm{Q}^{2}$ continuam altos $\left(Q^{2}>0,5\right)$, com oscilações mínimas em relação ao valor médio $(0,6885)$. A taxa de variação $(0,0801)$ é menor que 0,1 , mostrando que todos os valores de $\mathrm{Q}^{2}$ são aceitáveis.

Portanto, todos os testes da validação interna deram resultados positivos, indicando que o modelo gerado é robusto. O último teste realizado para confirmar essa robustez é o teste de validação externa, discutida no subitem 5.3.2.

O modelo de regressão obtido com o conjunto de treinamento está apresentado na equação 17.

$$
\begin{array}{r}
\mathrm{pK}_{\mathrm{i}}=-0,2047(\mathrm{BEHe} 3)+0,2591(\mathrm{RDF} 145 \mathrm{u})+0,5878(\mathrm{E} 1 \mathrm{e})+0,1367(\text { HATS7v })+ \\
0,6925(\mathrm{R} 2 \mathrm{v}+)+0,2172\left(\mathrm{E}_{\mathrm{LUMO}}+4\right)
\end{array}
$$

A partir da equação 17 pode observar que o BEHe3 contribui negativamente, enquanto que os demais descritores contribuem positivamente (RDF145u, E1e, HATS7v, R2v+, $\left.\mathrm{E}_{\mathrm{LUMO}+4}\right)$. Sendo assim, é possível afirmar que a contribuição dos seis descritores (multiplicadas por seus coeficientes) é capaz de descrever quantitativamente a atividade biológica. Os descritores dessa equação estão discutidos no subitem 5.1.4.

O modelo gerado (Eq. 17) é capaz de explicar $82,59 \%\left(\mathrm{R}^{2}\right.$ x 100) da variabilidade da atividade biológica, isto é, ajusta $82,52 \%$ da informação disponível no modelo.

\subsubsection{Validação externa}

Os compostos que fazem parte do conjunto de teste, utilizados para a validação externa, são: C2, C10, C13, C15, C16, C19, C21, C26, C27, C37, C40. A Tabela 14 mostram os resultados das atividades para esses compostos.

Tabela 14- Resultados da validação externa

\begin{tabular}{cccc}
\hline Compostos & y Mensurado & y Predito & Resíduo \\
\hline C2 & 9,5229 & 8,7754 & 0,7475 \\
\hline C10 & 8,3768 & 8,4179 & $-0,0411$ \\
\hline C13 & 8,0915 & 7,9291 & 0,1624 \\
\hline C15 & 7,9586 & 7,8705 & 0,0881 \\
\hline C16 & 8,4437 & 8,2402 & 0,2035 \\
\hline C19 & 6,8386 & 6,6949 & 0,1437 \\
\hline
\end{tabular}




\begin{tabular}{cccc}
\hline \multicolumn{4}{l}{ Tabela 14- Continuação } \\
\hline C21 & 6,6289 & 6,2746 & 0,3543 \\
\hline C26 & 8,4685 & 7,9243 & 0,5442 \\
\hline C27 & 7,5528 & 7,9537 & $-0,4009$ \\
\hline C37 & 6,9830 & 7,3759 & $-0,3930$ \\
\hline C40 & 8,9208 & 8,7850 & 0,1358 \\
\hline SEP & 0,3583 \\
\hline PRESS & 1,4119 \\
\hline $\mathbf{R}^{\mathbf{2}}$ & 0,8568 \\
\hline $\mathbf{V L}$ & 5,0000 \\
\hline
\end{tabular}

Analisando a tabela acima (Tabela 14), observa-se que a maioria dos compostos possuem valores de resíduos pequenos, com exceção dos $\mathrm{C} 2$ com um resíduo um pouco acima. No entanto, o modelo é aceito, pois apresenta baixos erros de predição ( $\mathrm{SEP}=0,3583$; PRESS $=1,4119)$ e um valor alto do coeficiente de determinação múltipla $\left(\mathrm{R}^{2}=0,8568\right)$, com uma pequena de diferença, 0,032 , em relação ao $\mathrm{R}^{2}$ do conjunto de treinamento.

Figura 25- Valores de y predito versus y mensurado para a regressão PLS

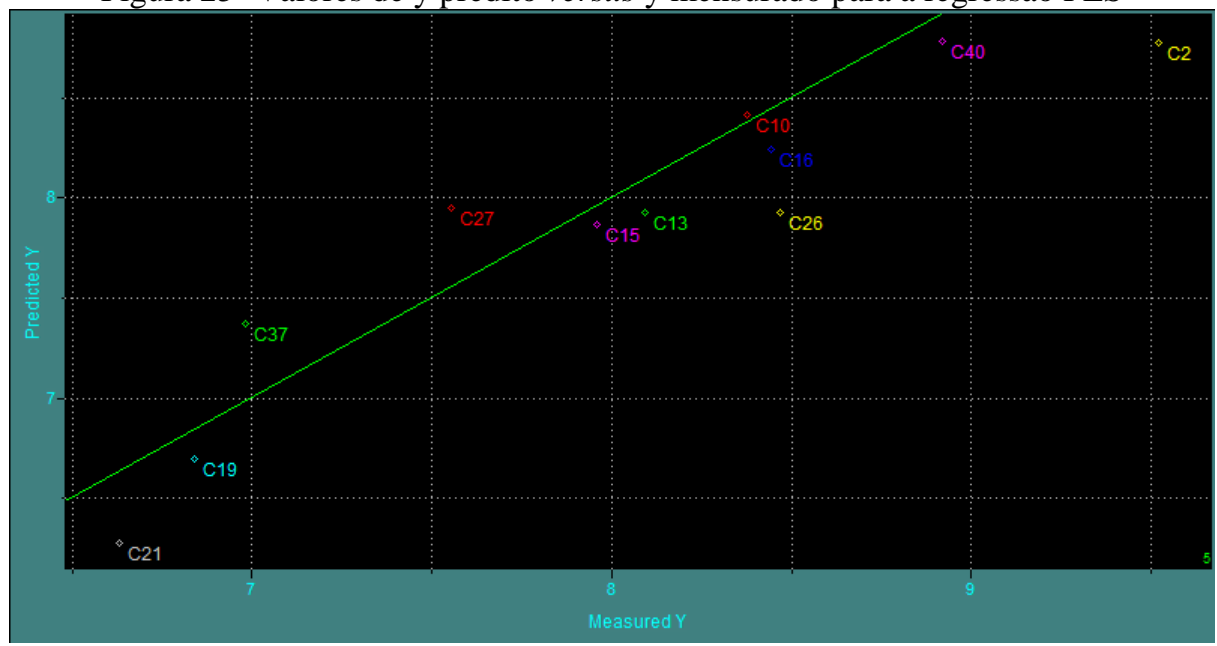

A Figura 25 mostra a reta de regressão para o conjunto de teste usado na validação externa, gerada no Pirouette. Como o $\mathrm{C} 2$ apresenta um valor de resíduo um pouco diferente dos demais, esse poderá ser o motivo pelo qual ele não se ajustou à reta.

Todos os testes, validação externa e interna, foram positivos, validando, dessa forma o modelo gerado, no entanto faz-se necessário que os descritores selecionados sejam explicados da melhor forma possível. Nem sempre o significado químico dos descritores é de fácil interpretação, podendo ser bastante complexo. Os descritores mais complexos são aqueles baseados em informação topológica e geométrica da molécula. O fato de ser complexo não quer dizer que não tenha informação ou relação com a atividade biológica. A literatura sugere 
que tais descritores sejam usados como uma medida quantitativa da falta de homogeneidade estrutural ou variedade de um grafo molecular, estando relacionado à simetria referente às estruturas. Porém, as informações que podem estar presentes em um grafo não são as únicas e irá depender da equivalência entre elas. Esses tipos de descritores são colocados pela literatura como relacionado à importância da forma, tamanho, simetria e/ou ramificação de um conjunto de substâncias químicas para uma atividade biológica em estudo (KATRITZKY, GORDEEVA, 1993; NEVES, COSTA, NDUJAE, 1998; TODESCHINI, CONSONNI, 2000; PADRÓN, CARRASCO, PELLÓN, 2002; GARCIA et al., 2005).

No subitem 5.1.4 há um apanhado geral da importância dos descritores gerados, na tentativa de explicar a relação deles com a atividade biológica dos compostos.

\subsubsection{Análise dos Descritores}

Os descritores selecionados para gerar o modelo foram R2V+, E1e, RDF145u, E $_{\mathrm{LUMO}+4}, \mathrm{HATSTv}, \mathrm{BEHe}$. Essa é a ordem de importância dos descritores, segundo os valores absolutos dos coeficientes (Tabela 15), referentes ao fator 5 (VL), o escolhido para gerar o modelo.

Tabela 15- Contribuição dos descritores para cada fator

\begin{tabular}{lcccccc} 
& \multicolumn{7}{c}{ Tabela 15- Contribuição dos descritores para cada fator } \\
\cline { 2 - 7 } & Fator1 & Fator2 & Fator3 & Fator4 & Fator5 & Fator6 \\
\hline BEHe3 & $-0,4790$ & $-0,5877$ & 0,4926 & 0,2150 & $-0,2047$ & 0,3073 \\
\hline RDF145u & 0,3982 & 0,1463 & 0,2637 & $-0,2124$ & 0,2591 & 0,7989 \\
\hline E1e & 0,2132 & $-0,0866$ & 0,6152 & 0,0582 & 0,5878 & $-0,4686$ \\
\hline HATS7v & $-0,3526$ & 0,6504 & 0,1284 & 0,6313 & 0,1367 & 0,1378 \\
\hline R2v+ & $-0,5285$ & $-0,1502$ & $-0,3797$ & $-0,2410$ & 0,6925 & 0,1276 \\
\hline E $_{\text {LUMO }+4}(\mathrm{eV})$ & 0,4037 & $-0,4244$ & $-0,3856$ & 0,6698 & 0,2172 & 0,1115 \\
\hline
\end{tabular}

$\mathrm{O}$ descritor com maior contribuição é o R2V+, pertencente à classe dos geométricos, enquanto o segundo mais importante, E1e, refere-se à eletronegatividade de Sanderson (SANDERSON, 1995). Como esses dois descritores apresentaram os maiores valores de coeficientes, isso pode ser indício de que a distribuição eletrônica é um fator importante para atividade biológica. Todos esses descritores, os de valores de coeficientes maiores e menores, estão descritores nos subitens posteriores. 


\subsubsection{Descritores GETAWAY: HATS7v e R2v+}

Os descritores GETAWAY (Geometric Topology and Atom Weights Assembly) consistem em uma matriz de leverage denominada molecular influence matrix (MIM) H, dada como uma representação molecular que pode ser facilmente calculada usando as coordenadas espaciais dos átomos de uma molécula em dada conformação. A magnitude do leverage máximo depende do tamanho e da forma da molécula. Informações das relações entre dois átomos em uma dada molécula podem ser adquiridas, com o objetivo de codificar as informações referentes à forma, a sua dependência de mudanças conformacionais. (CONSONNI, TODESCHINI, PAVAN, 2002).

Os descritores GETAWAY são divididos em dois grupos: (i) H-GETAWAY, que são gerados através das informações oriundas do MIM. São ponderados pelas propriedades atômicas como massa atômica, eletronegatividade, polarizabilidade e volume de Van der Waals; e (ii) R-GETAWAY, obtido através da combinação dessas informações com as distâncias geométricas interatômicas da molécula através de uma matriz geométrica, comumente chamada de matriz de distância G. O descritor HATS7v (leverage-weighted autocorrelation of lag 7 / weighted by atomic van der Waals volumes) faz parte do primeiro grupo enquanto o $\mathrm{R} 2 \mathrm{v}+(R$ maximal autocorrelation of lag 2 / weighted by atomic van der Waals volumes) se enquadra no segundo grupo. O lag refere-se à distância topológica ou todas as contribuições de cada caminho diferente no grafo molecular. Quanto maior for o lag maior a distância entre os átomos (CONSONNI, TODESCHINI, PAVAN, 2002).

$\mathrm{O}$ maior valor de coeficiente $(0,6925)$ está associado ao descritor $\mathrm{R} 2 \mathrm{v}+$ e possui influência positiva na atividade biológica. $\mathrm{O}$ descritor $\mathrm{R} 2 \mathrm{v}+$ pode ser calculado a partir da equação 18.

$$
R_{K}(w)=\sum_{i=1}^{A-1} \sum_{j>i} \frac{h_{i i} h_{j j}}{r_{i j}} w_{i} w_{j} \delta\left(k ; d_{i j}\right)
$$

Em que $i \neq j$ e representam os átomos. O R é a matriz de influencia/distância que utiliza os valores de leverage $\mathrm{h}_{\mathrm{ii}}$ e $\mathrm{h}_{\mathrm{ij}}$ (elementos diagonais da matriz de influencia molecular- $\mathrm{H}$ ) de dois átomos i e j da molécula e sua distância geométrica $\mathrm{r}_{\mathrm{ij}}$. $\mathrm{k}$ é a distância topológica entre os átomos i e j, $w_{i}$ e $w_{j}$ são as propriedades atômicas respectivamente dos átomos i e j, que no caso representa o volume atômico de Van der Waals e $\delta\left(k ; d_{i j}\right)$ é a função delta de Dirac definida a seguir: 
$\delta\left(k, d_{i j}\right)=\left\{\begin{array}{l}1 \text { se } d_{i j}=k \\ 0 \text { se } d_{i j}=k\end{array}\right\}$

Já o descritor HATS7v possui um valor menor $(0,1367)$, mas também possui influencia positiva na atividade biológica. $\mathrm{O}$ mesmo pode ser calculado a partir da equação 19.

$$
H_{K}(w)=\sum_{i=1}^{A-1} \sum_{j>i} h_{i j} W_{I} W_{J} \delta\left(K ; d_{i j} ; h_{i j}\right)
$$

Em que $\mathrm{k}$ é a distância topológica fixada, $\mathrm{W}_{\mathrm{i}}$ e $\mathrm{W}_{\mathrm{j}}$ são as propriedades atômicas respectivamente dos átomos $\mathrm{i}$ e $\mathrm{j}, \mathrm{d}_{\mathrm{ij}}$ representa a distância topológica entre os átomos i e j, $\mathrm{h}_{\mathrm{ij}}$ são elementos fora da diagonal da matriz de influencia molecular e refere-se ao grau de acessibilidade entre os átomos i e j, $\delta\left(K ; d_{i j} ; h_{i j}\right)$ é a função de Dirac, definida a seguir:

$\delta\left(k, d_{i j} h_{i j}\right)=\left\{\begin{array}{c}1 \text { se } d_{i j}=k \text { e } h_{i j}>0 \\ 0 \text { se } d_{i j}=k \text { ou } h_{i j} \leq 0\end{array}\right\}$

Analisando a equação 18 é possível afirmar que a distância $r_{i j}$ é inversamente proporcional ao valor do descritor. Esta informação sugere que quanto menor for $\mathrm{r}_{\mathrm{ij}}$, isto é, mais compacta a molécula, maior o valor do descritor, no caso o volume atômico de Van der Waals. Dessa forma, podemos concluir que quanto menor o $r_{i j}$ (mais compacta a molécula), mais reativos serão os compostos. Enquanto que a equação 19 sugere que o elemento $\mathrm{h}_{\mathrm{ij}}$ é diretamente proporcional ao valor do descritor. Estes são descritores de correlação, em que apenas as propriedades dos átomos são consideradas desde que estejam numa distância topológica determinada $(\mathrm{k})$, apresentando valores de acessibilidade positivos $\left(\mathrm{h}_{\mathrm{ij}}\right)$, indicando que há uma dada probabilidade destes átomos interagirem. Logo, quanto maior o valor do descritor, maior a probabilidade que o átomo tem de interagir com outro (TODESCHINI, PAVAN, 2002; GONZÁLEZ et al., 2005).

Assim, pode-se afirmar que os descritores GETAWAY selecionados para o modelo fornece principalmente informações referentes à forma da molécula. Sendo assim, é possível supor que as moléculas com um dado grau de liberdade conformacional, favorecendo as geometrias com valores altos de $\mathrm{r}_{\mathrm{ij}}$, tenderão a ser mais ativas. 


\subsubsection{DESCRITOR WHIM: E1e}

Os descritores 3D WHIM (Weighted Holistic Invariant Molecular) são baseados em cálculos que usam as Componentes Principais (PCA) com uma matriz de covariância gerada através das coordenadas moleculares ponderadas por propriedades atômicas (TODESCHINI, CONSONNI, 2000; GONZÁLEZ et al., 2005; GRAMATICA, 2006).

Os descritores WHIM tem como finalidade gerar informações referentes ao tamanho, à simetria, forma e distribuição dos átomos. Tais descritores são subdivididos em dois grupos menores, direcionais e não-direcionais. Aquele fornece informações de uma propriedade em particular relacionada ao eixo principal. Enquanto o segundo está relacionado às características da molécula como um todo (GRAMATICA, 2006).

$\mathrm{O}$ descritor WHIM selecionado foi o E1e (1st component accessibility directional WHIM index / weighted by atomic Sanderson electronegativities). A Tabela 5 mostra os valores desse descritor para todos os compostos. Os valores não variam muito, com diferença apenas na segunda casa decimal, e isso é decorrente do fato deles variarem de 0 a 1 . Como o valor do coeficiente (Tabela 15) autoescalado é positivo, pode-se inferir que a simetria dos compostos em estudo, em função do segundo eixo interno apresenta influencia positiva na molécula. $\mathrm{O}$ valor nulo sugere que a molécula seja assimétrica e o 1 é decorrente de moléculas simétricas (TODESCHINI, CONSONNI, 2000).

Ainda, segundo análises dos valores do descritor E1e, a tendência observada foi que os compostos com os valores maiores desse descritor são os mais potentes, com poucas variações.

No que se refere à eletronegatividade (Eq.20) a presença de átomos muito eletronegativos ocasionará em termos da matriz menor. Isso sugere que os parâmetros atômicos podem ser um fator importante para a interação ligante/receptor.

$$
S_{j k}=\frac{\sum_{i=1}^{A} w_{i}\left(q_{i j}-\bar{q}_{j}\right)\left(q_{i k}-\bar{q}_{k}\right)}{\sum_{i=1}^{A} W_{i}}
$$

$S_{j k}=$ covariância ponderada entre as $j$-ésimas e $k$-ésimas coordenadas atômicas

$A=$ número de átomos

$w_{i}=$ fator de ponderação do $i$-ésimo átomo

$q_{\mathrm{ij}}$ e $q_{\mathrm{ik}}=j$-ésima e $k$-ésima coordenada $(j, k=x, y, z)$

$q=$ valor médio das coordenadas 
Logo, é possível concluir que esse descritor, apesar de ser de interpretação complexa, tem uma grande importância para a atividade biológica, principalmente se for levado em consideração o seu alto valor de coeficiente (Tabela 15).

\subsubsection{Descritor RDF: HATS7V}

Os descritores RDF (Radial Function Distribution) são gerados através da função de distribuição radial calculada sobre as distâncias interatômicas de uma molécula. Essa função pode ser entendida como sendo a probabilidade para encontrar um átomo em um volume esférico com raio de valor r. Como o valor do coeficiente desse descritor é positivo, isso sugere que ele apresenta uma influencia positiva para a atividade biológica (Tabela 15). A equação 21 mostra como é calculado esse descritor

$$
G(r)=f \sum_{i}^{n-1} \sum_{j>i}^{n} A_{i} A_{j} e^{-\beta\left(r-r_{i j}\right)^{2}}
$$

$\mathrm{N}=$ número de átomos da molécula;

$\mathrm{f}=$ refere-se ao escalonamento;

$\mathrm{A}_{\mathrm{i}}$ e $\mathrm{A}_{\mathrm{j}}=$ propriedades dos átomos (massa atômica, eletronegatividade, volume de Van der Waals, polarizabilidade) i e j respectivamente;

$\beta=$ parâmetro de aplainamento, que define a distribuição de probabilidade das distâncias individuais;

$\mathrm{r}=$ raio pré-definido;

$\mathrm{r}_{\mathrm{ij}}=$ distância entre os átomos i e j.

Quanto maior o valor de $\beta$ maior a influência da diferença das distâncias nos valores $g(r)$.

Gonzáles et al., (2005) fizeram um estudo sobre a importância do descritor de distribuição radial para predição de agonistas para o receptor $\mathrm{A}_{2 \mathrm{~A}}$ da adenosina mostrando o importante papel do volume atômico de Van der Waals e da estereoseletividade para a afinidade dos compostos com o receptor. Segundo eles, o descritor RDF está intrinsecamente relacionado com a probabilidade de encontrar um átomo em um volume esférico de raio $\mathrm{r}$ em uma molécula. Então, de acordo com a equação 21, quanto menor a distância $r_{i j}$, maior a interação entre os átomos, valendo salientar, que essa distância possui um determinado limiar, que irá depender dos átomos envolvidos. De acordo com Gonzáles et al., (2005), uma influencia positiva desse tipo de descritor sugere que eles podem acomodar diferentes átomos ou grupo de átomos em posições diferentes, mesmo com tamanho grande. De forma análoga, 
o presente trabalha vai ao encontro do achado deles, pois o grupo composto estudado possui vários substituintes de diferentes tamanhos, no entanto o grau de influencia desses substituintes para o receptor ainda não é conhecido, por isso estudos posteriores deverão ser realizados, através de Docking e Dinâmica Molecular, para analisar a interação desses compostos com o receptor da dopamina.

\subsubsection{Descritor BCUT: BEHe3}

Os descritores BCUT (Burden-CAS-University of Texas EigenValues) descrevem a geometria da molécula e pertencem a uma classe de compostos híbridos, que combina várias propriedades dos átomos em um único valor. Seus valores são calculados através dos autovalores de uma matriz quadrática simétrica que representa um grafo molecular (TODESCHINI e CONSONNI, 2000; STANTON, 1999). Esses tipos de descritores faz parte do método proposto por Burden (1989) para identificar estruturas orgânicas utilizando matrizes em que os elementos $b_{i i}$ são usados para fornecer informações sobre cargas atômicas, polarizabilidade, eletronegatividade, ligação de hidrogênio, entre outras propriedades. Já $b_{i j}$ fornece informações sobre a conectividade entre os átomos, como por exemplo, distância interatômica e ordens de ligação (TODESCHINI e CONSONNI, 2000).

Alguns pesquisadores sugerem que os descritores BCUT são capazes de fornecer várias informações, como por exemplo, propriedades atômicas referentes a interações fármaco-receptor, decorrentes de suas matrizes diagonais (PIRARD, PICKETT, 2000; STANTON, 1999).

Esse descritor é ponderado pela eletronegatividade, método proposto por Sanderson (1955; 1983), utilizando uma teoria denominada equalização de eletronegatividade: eletronegatividade atômica é obtida por meio de uma função inversa do volume de um átomo. Utilizando esse valor, a eletronegatividade molecular pode, então, ser calculada. Partindo do pressuposto que os átomos mais eletronegativos são aqueles que apresentam uma quantidade maior de pares de elétrons livres, supõe-se um valor alto de eletronegatividade pode está relacionado com prováveis interações no sítio da ligação. Tal premissa pode está relacionada com os valores positivos desse descritor para todos os compostos (Tabela 5), corroborando com a eletronegatividade de Sanderson, que é um parâmetro positivo. No entanto, essa hipótese só será confirmada em estudos posteriores, quando forem realizadas as análises de Dinâmica Molecular e Docking. 


\subsubsection{Descritor eletrônico: $\mathbf{E}_{\mathrm{LUMO}+4}$}

Uma das classes de descritores mais utilizadas em estudos QSAR está relacionada à energia dos orbitais de fronteira, HOMO e LUMO. Para o presente trabalho, o descritor dessa classe selecionado foi a energia do orbital LUMO + 4. Este descritor está relacionado com a capacidade dos átomos em aceitar elétrons. Quanto menor a energia do LUMO maior a capacidade em aceitar elétrons. Observando a Tabela 5, os valores desse descritor para os compostos possuem valores pequenos, logo há uma grande probabilidade desses compostos em aceitar elétrons. As Figuras 26 a 30 mostram as representações dos orbitais LUMOs + 4 para o composto mais potente de cada região explorada (Tabela 2, Figura 15).

Figura 26- Orbital LUMO +4 do composto mais potente, $\mathrm{C} 2$

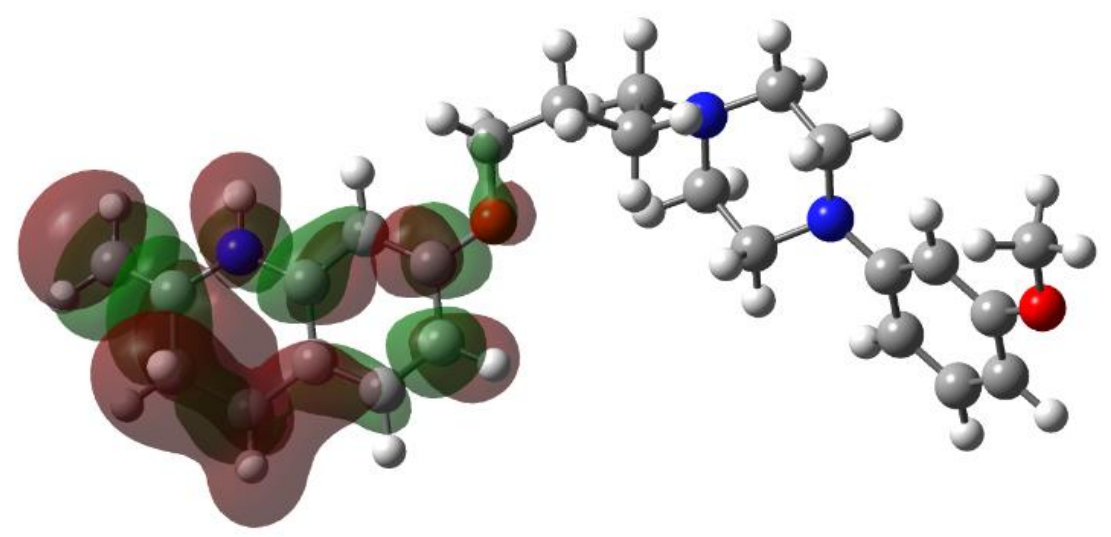

Figura 27- Orbital LUMO +4 do composto mais potente, C16

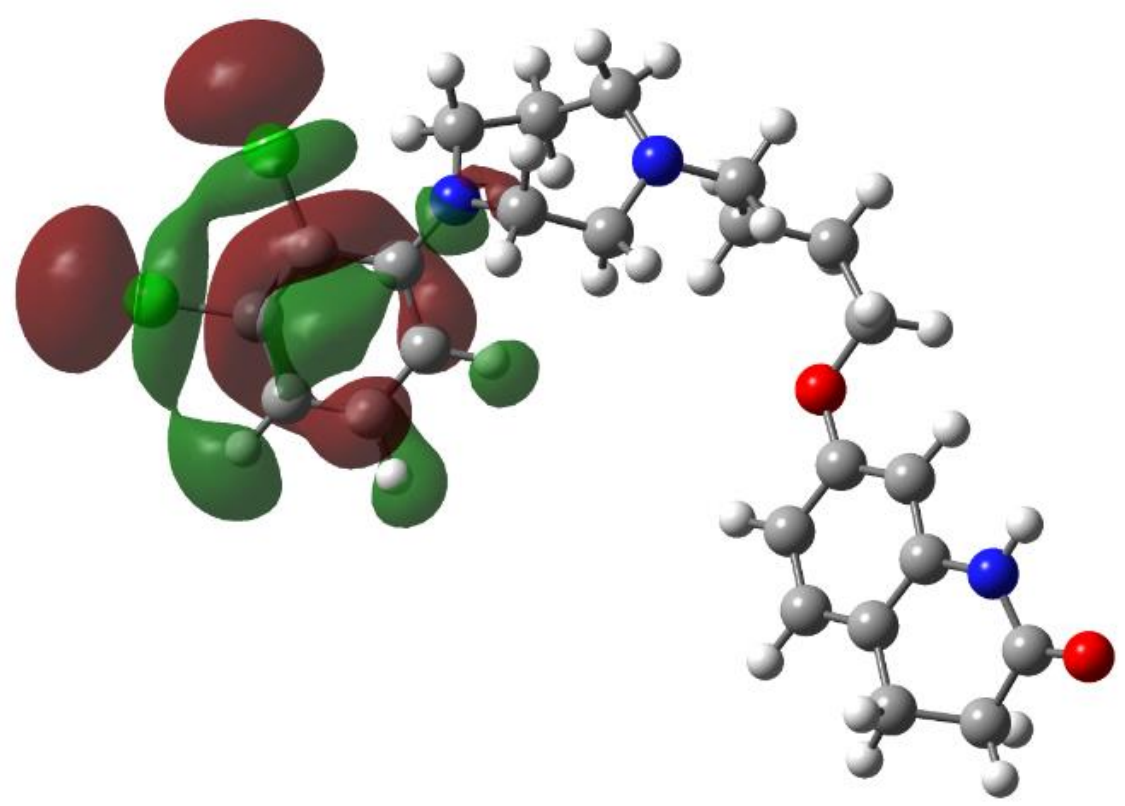


Figura 28- Orbital LUMO +4 do composto mais potente, C20

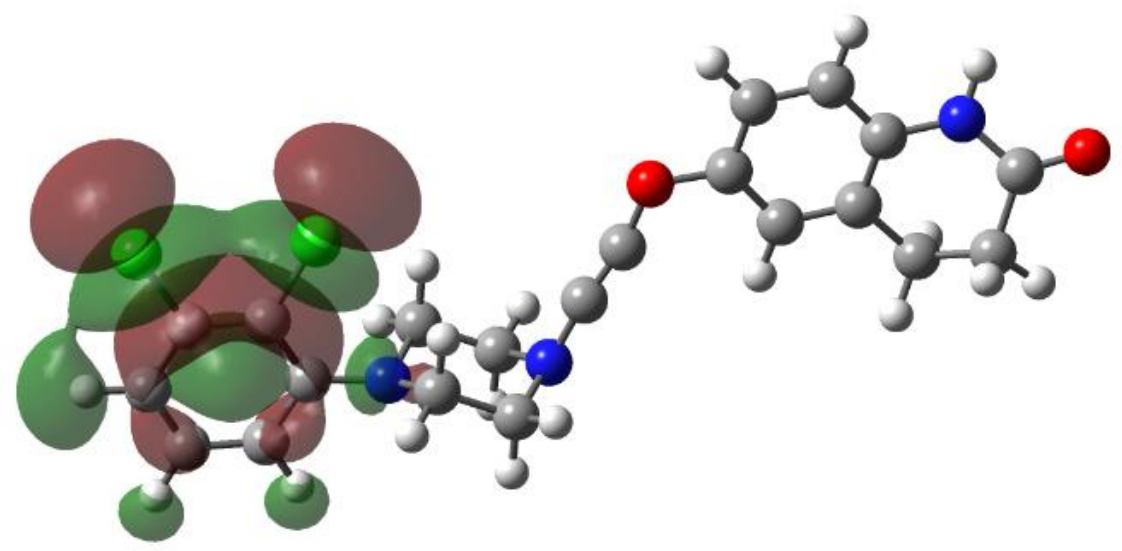

Figura 29- Orbital LUMO +4 do composto mais potente, $\mathrm{C} 26$

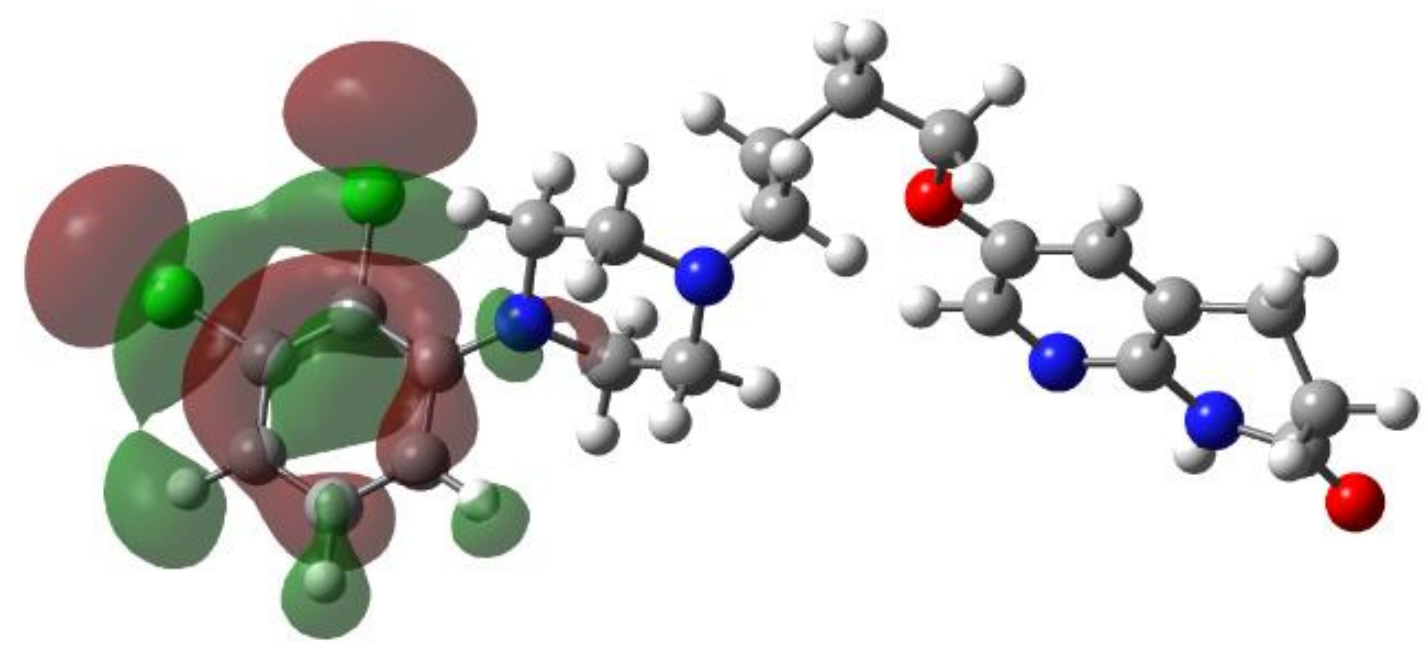

Figura 30- Orbital LUMO +4 do composto mais potente, C40

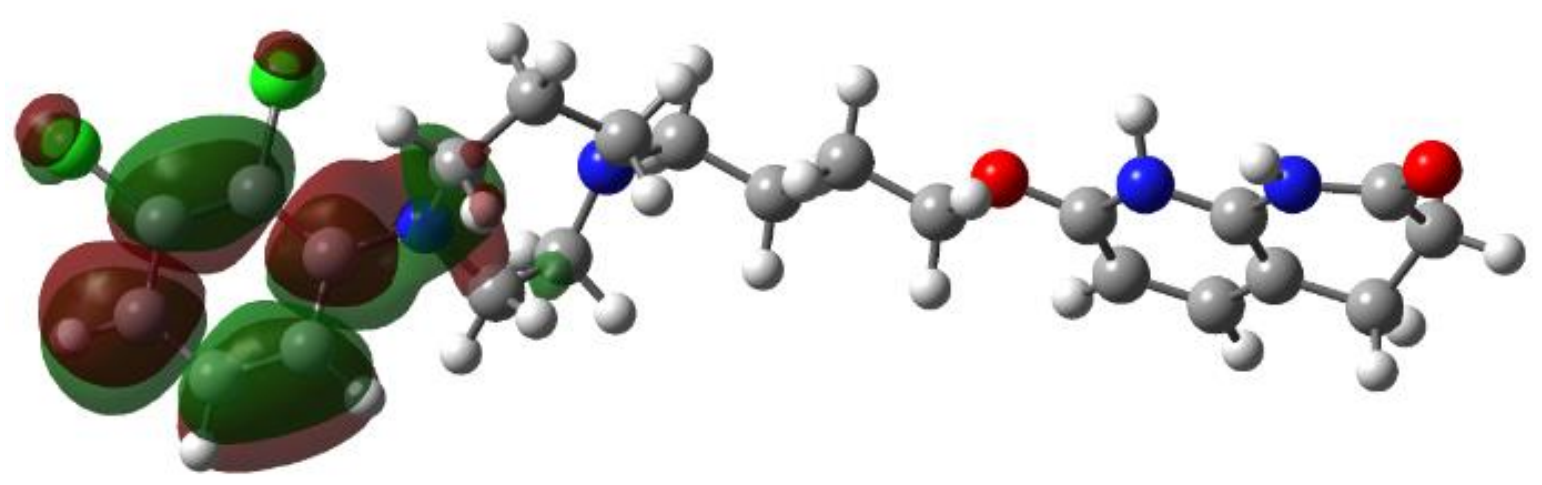

Através da análise das Figuras, 26 a 30, é notório que os orbitais LUMOs para todos os compostos analisados, com exceção do C2, possuem grandes influencias do sistema $\pi$ do anel aromático e de seu substituinte, $\mathrm{Cl}$, área com grande densidade eletrônica. Isso sugere que há uma probabilidade maior para que a interação do receptor da dopamina, D2, aconteça 
nessa região. No entanto, como já foi dito, essa suposição só será confirmada quando estudos posteriores (Docking e Dinâmica Molecular) forem realizados. O composto C2 foi o único que apresentou uma região diferente, mas os orbitais LUMO também possuem influência do sistema $\pi$ em uma grande área de densidade eletrônica.

\subsection{Modelo ANN}

A técnica de Redes Neurais foi usada para gerar outro modelo. Foram escolhidos $60 \%$ do sistema total para conjunto de treinamento, $30 \%$ para o conjunto de teste e $10 \%$ para validar o modelo. As Figuras 31 a 34 mostram os resultados para o modelo gerado com todo o conjunto, para o conjunto de treinamento, para o conjunto de teste e para a validação, respectivamente. É notório como não há grandes oscilações para os valores de $\mathrm{R}$, consequentemente também não haverá para os valores de $\mathrm{R}^{2}$.

A Figura 31 mostra o valor de $\mathrm{R}(0,84)$ para o modelo gerado com todos os compostos, a partir daí, obtemos o valor de $\mathrm{R}^{2}=0,71$. É notório como os dados estão ajustados na reta do Fit (ajuste), com pequenas oscilações.

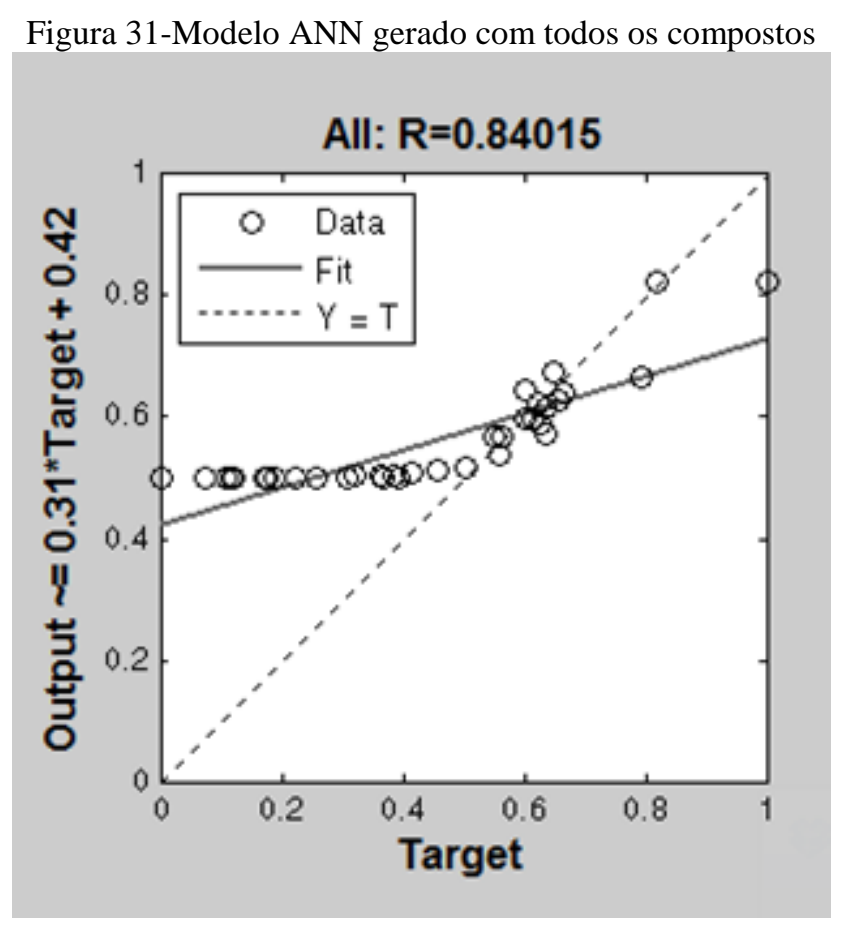

A Figura 32 mostra o resultado para o conjunto de treinamento. O conjunto de treinamento escolhido pela Rede Neural foi C1, C3, C4, C5, C6, C7, C9, C11, C12, C18, C22, 
C23, C25, C30, C31, C32, C33, C34, C35, C38, C39, C41. Todos os compostos desse conjunto de treinamento estão presentes no conjunto de treinamento gerado no modelo PLS, sendo que o conjunto PLS apresenta 4 compostos a mais, C8, C28, C29, C36. Isto ocorre por que a própria Rede Neural escolhe os compostos para fazer a validação do modelo, enquanto que no modelo PLS, a validação do modelo só ocorre com o conjunto de treinamento, validação interna, e com o conjunto de teste, validação externa. $\mathrm{O}$ valor de $\mathrm{R}$ obtido foi 0,84015 , resultando em um $\mathrm{R}^{2}$ igual a 0,7044 . Valor considerado bom, pois como já foi dito (subitem 2.4.7), um valor para o $\mathrm{R}^{2}$ aceitável deve está a cima de 0,6.

Figura 32- Modelo ANN gerado com os compostos do conjunto de treinamento

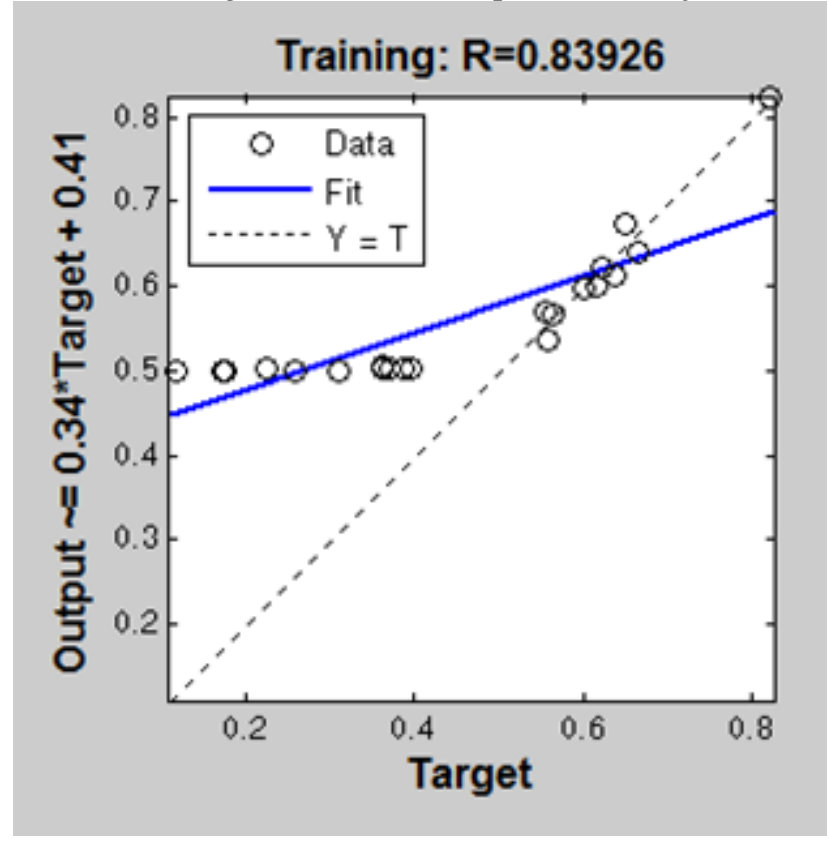

A Figura 33 mostra o resultado para o conjunto de teste. Os compostos selecionados para gerar esse modelo foram C2, C10, C13, C15, C19, C21, C26, C27, C37, C40. Percebe-se que o conjunto de teste utilizado é o mesmo do PLS. O valor de R obtido foi 0,85383, resultando em um $\mathrm{R}^{2}$ igual a 0,7290 . Portanto, o modelo obtido consegue explicar $72,90 \%$ da variabilidade da atividade biológica. 


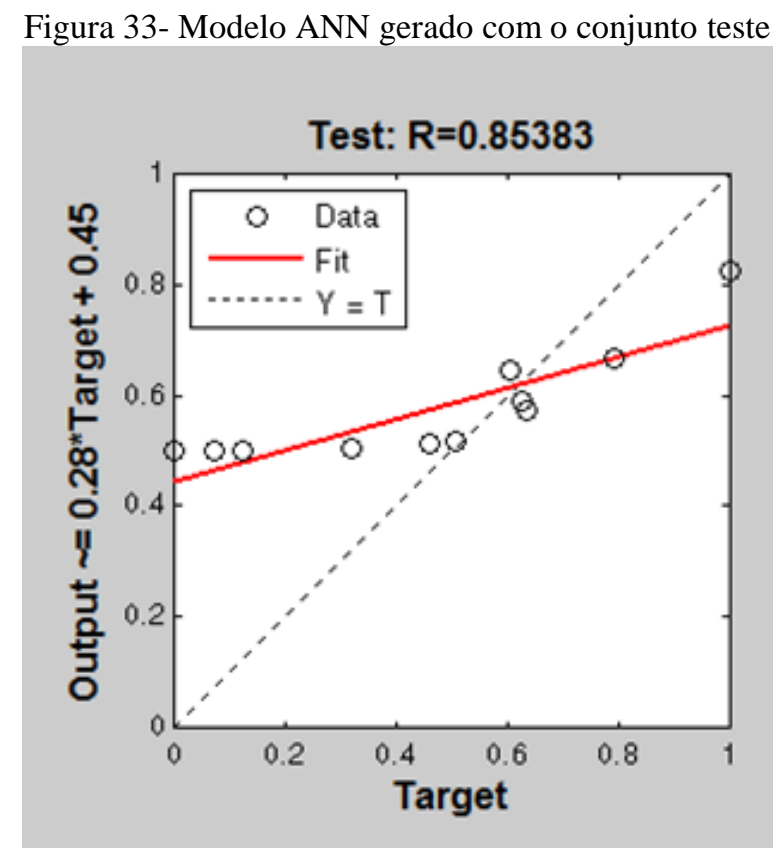

O conjunto selecionado para fazer a validação do modelo foi o C8, C28, C29, C36. O valor de $\mathrm{R}$ obtido para esse conjunto foi 0,84241, gerando um $\mathrm{R}^{2}$ igual 0,7096, valor também considerado bom, levando em consideração o que é colocado pela literatura, já abordado anteriormente.

Figura 34- Validação do modelo ANN

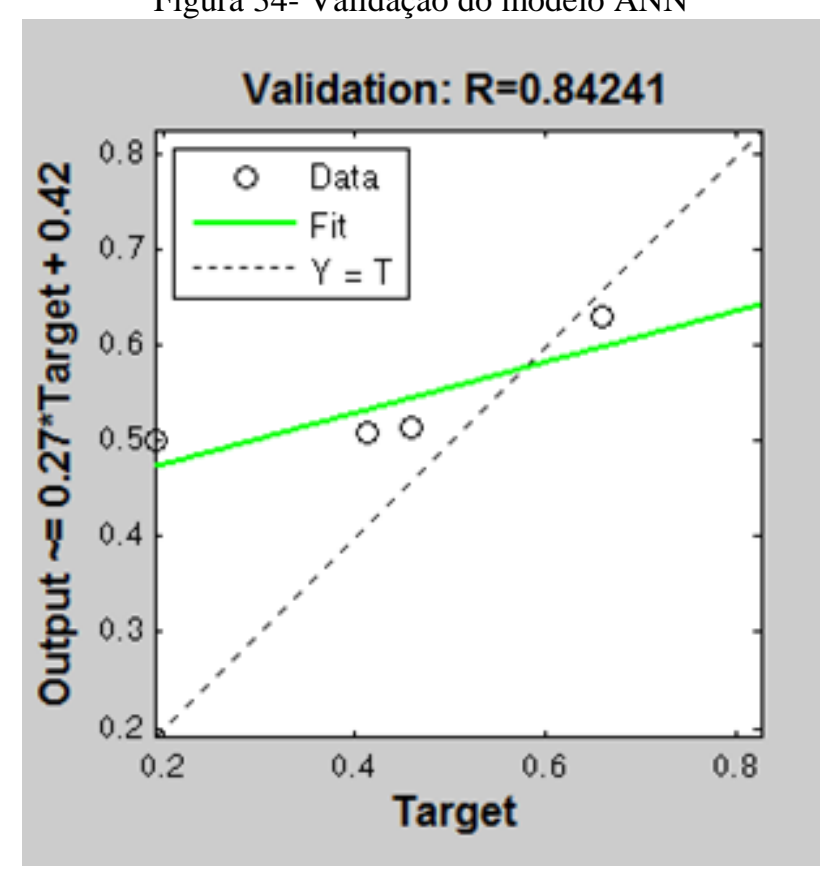

A Figura 35 mostra o erro médio quadrado para os conjuntos de treino e teste e validação. 
Figura 35- Erro Quadrático Médio para os conjuntos de treino, teste e validação.

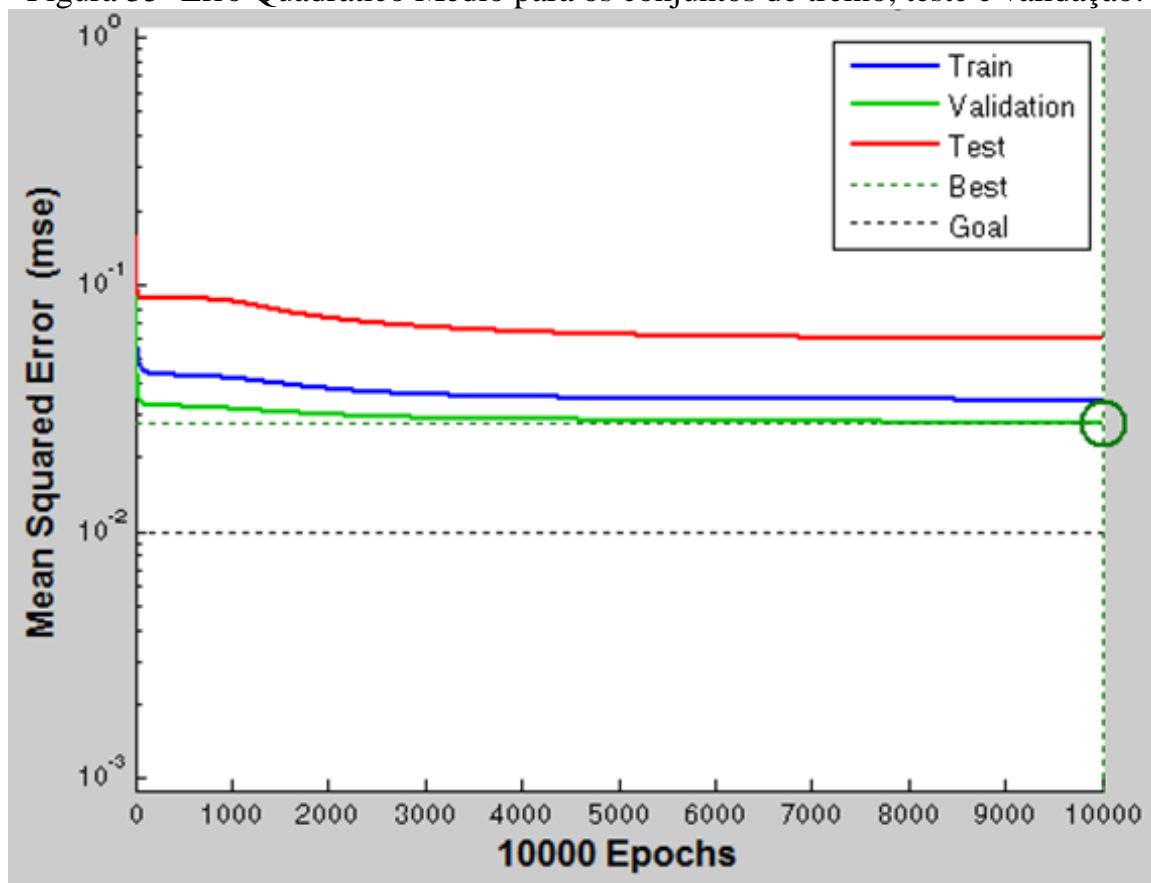

Nota-se através da Figura 35 que o conjunto com o menor MSE é o de validação e o maior erro é creditado ao conjunto de teste. Percebe-se também o decaimento desse erro com o aumento do número de epochs, número máximo de interação dos neurônios. O objetivo era chegar a um erro 0,01, abaixo desse erro, a rede é considerada viciada. No entanto, tanto o conjunto de treino e teste quanto o de validação alcançaram um dentro da faixa de 0,1 , erro considerado pequeno e ideal, como mostrado pela ANN (figura 35).

O modelo gerado no PLS foi melhor, descrevendo $82,52 \%$ da variabilidade da atividade biológica, enquanto que o modelo gerado utilizando a técnica de Redes Neurais descreve $72,90 \%$ e a sua validação descreve 70,96 .

A diferença nos resultados entre esses dois modelos pode ser explicado pelo tipo de método utilizado. Enquanto o modelo PLS é gerado através de uma regressão linear, a ANN utilizando uma regressão não linear. Como não se sabe qual a relação entre as variáveis independentes e a variável dependente, isto é, se ocorre uma relação linear ou não, a geração desses modelos são justificadas. Como o modelo PLS é melhor que o modelo ANN, isso sugere que a relação entre as variáveis dependente e independe possuem comportamento linear. Portanto, mesmo se tratando de técnicas diferentes, os dois modelos conseguem explicar, de forma satisfatória, a relação da estrutura química dos compostos com a atividade biológica. 
"Nós somos aquilo que fazemos repetidamente. Excelência, então, não é um modo de agir, mas um hábito".

(Aristóteles)

"Por vezes sentimos que aquilo que fazemos não é senão uma gota de água no mar. Mas o mar seria menor se lhe faltasse uma gota".

(Madre Teresa de Calcutá) 


\section{CONSIDERAÇÕES FINAIS}

O presente trabalho teve como objetivo a geração de modelos que consigam relacionar a estrutura química de moléculas com a atividade biológica. Dois foram os modelos gerados utilizando diferentes métodos.

A técnica de Algoritmo Genético, AG, foi considerada satisfatória para a seleção das melhores variáveis para a construção do modelo. O melhor modelo PLS gerado foi obtido com o número ótimo de 5 variáveis latentes, VL. Tal modelo passou em todos os testes de validação (testes de validação cruzada, randomização, detecção de amostras anômalas e validação externa). O mesmo conseguiu explicar aproximadamente $82,52 \%$ da variabilidade da atividade biológica.

O outro modelo foi gerado utilizando a técnica de Redes Neurais Artificiais, ANN. Esta técnica dividiu o conjunto de dados em três subconjuntos, treinamento, teste e validação e calculou o R para todos eles. O valor obtido não se distanciou muito de um conjunto para o outro, consequentemente a diferença do $\mathrm{R}^{2}$ também foi pequena. Esse modelo foi capaz de ajustar 72,90\% das informações disponíveis no modelo, resultado considerado bom, levando em consideração o que é posto pela literatura.

Portanto, mesmo se tratando de técnicas diferentes, os dois modelos obtidos, PLS e ANN, foram considerados satisfatórios para explicar a relação quantitativa da estrutura química com a atividade biológica. As diferenças de valores desses modelos ocorrem, justamente, porque o PLS é caracterizado como sendo um método linear, enquanto que o ANN se trata de um método não linear. Como o modelo PLS foi considerado melhor que o modelo ANN, por ajustar melhor as informações disponíveis no modelo, pode-se concluir que as variáveis selecionadas $\left(\mathrm{R} 2 \mathrm{~V}+, \mathrm{E} 1 \mathrm{e}, \mathrm{RDF} 145 \mathrm{u}, \mathrm{E}_{\mathrm{LUMO}+4}, \mathrm{HATS} 7 \mathrm{v}, \mathrm{BEHe} 3\right)$ possuem comportamento linear em relação à atividade biológica.

Logo, a partir dos estudos realizados, torna-se possível prever a atividade biológica de novas moléculas dessa classe de compostos, visando compostos mais ativos para o tratamento da esquizofrenia. 


\section{REFERÊNCIAS BIBLIOGRÁFICAS}

ALMEIDA, V. L.; LOPES, J.S D.; OLIVEIRA, S. R.; DONNICE.; C.L.; MONTANARI, C.A.; Estudos de relações Estrutura-Atividade Quantitativas (QSAR) de Bis-benzamidinas com atividade antifúngica. Química Nova, v.33, n.7, p. 1482-1489, 2010.

Disponível em: < http://www.scielo.br/pdf/qn/v33n7/a11v33n7.pdf>

Acesso em: 10 Out.2013.

ARROIO, A.; HONÓRIO, K. M.; WEBER, K. C.; MELLO, P. H. O ensino de Química Quântica e o Computador na perspectiva de projetos. Química Nova, v. 28, n. 2, p. 260-363, 2005.

Disponível em: < http://www.scielo.br/pdf/\%0D/qn/v28n2/23663.pdf>

Acesso em: 20 Ago. 2013.

ASSIS, J.C.; VILLARES, C.C.; BRESSAN, R.A.; Conversando sobre a esquizofrenia; Segmento Farma, São Paulo, 2007.

ATKINS, P., PAULA, J.DE., FRIEDMN., R.; Quanta, Matéria e Mudança- uma abordagem molecular para a Físico-Quimica; Rio de Janeiro: LTC, 2011. 426p.

BEAR, M.F.; CONNORS, B.W.; PARADISO, M.A. - Neurociências, desvendando o sistema nervoso. $2^{\mathrm{a}}$ edição, Artes Médicas, Porto Alegre, 131 - 162, 2002.

BISHOP, C. M.; Neural Networks for Pattern Recognition. Oxford Press; 1995.

BISHOP, C. M., Pattern Recognition and Machine Learning. Springer Science+Business Media, 2006.

BRESSAN, R.A.; PILOWSKY, L.S.; Hipótese glutamatérgica da esquizofrenia; Ver. Bras. Psiquiatria, 2003.

BROWN, Frank. Editoral Opinion: Chemoinformatics- a ten year update. Current Opinion in Drug Discovery and Development; V.8, p. 296-302, 2005.

BROWN, N., LEWIS, R.A.; Exploiting QSAR methods in lead optimization. Current Opinion in Drug Discovery, v.9, p. 419-419, 2006.

CARDOSO, M.G.P.; Papel dos Anti-Psicóticos Típicos vs Atípicos na Sintomatologia Negativa da Esquizofrenia; Covilhã, 2011. 40p. Dissertação (Mestrado em Medicina). Ciências da Saúde, Universidade da Beira Interior, 2011.

CROSS , S.S; HARRISON, R.F; KENNEDY, R.L; Introduction to neural networks; The Lancet, vol. 346, no. 8982, pp. 1075-1079, Oct. 1995.

CASTRO, L. N DE., ZUBEN, F. J. V.; Redes Neurais Artificiais; DCA/FEEC/Unicamp.

CHEN, X.; SASSANO, M.F.; ZHENG, L, SETOLA, V.; CHEN, M.; BAI, X.; FRYE, S. V.; WETSEL, W. C.; ROTH, B.L.; JIN, J.; Structure-Functional Selectivity Relationship Studies 
of $\beta$-Arrestin- Biased Dopamine D2 Receptor Agonists, Journal of Medicinal Chemistry, American Chemical Society, may, 2012.

CONSONNI, V.; TODESCHINI, R.; PAVAN, M. Structure/response correlations and similarity/diversity analysis by GETAWAY descriptors. 1. Theory of the novel 3D molecular descriptors. Journal of Chemical Information and Computer Science 2002, 42, 682-692.

DOROFKI, M., ELSHAFIE, A. H., JAAFAR, O., KARIM, O. A.; Comparison of Artificial Neural Network Transfer Functions Abilities to Simulate Extreme Runoff Data; IPCBEE, vol. 33, p. 39-44, 2012.

DREW, P., BOTTACI, L., DUTHIE, G. S., MONSON., J. R. T. Artificial neural networks, The Lancet, vol. 350, n. 9085. p. 1175-1176, 18-Oct-1997.

DUDEK, A.Z., ARRODZ, T., GÁLVEZ, J. Computational Methods in Developing Quantitative Structure-activity Relationships (QSAR): a review. Combinatorial Chemistry and High Throughput Screening, v.9, p. 213-228, 2006.

ERIKSSON, L.; JAWORSKA, J.; WORTH, A.P.; CRONN, M.T.D.; MCDOWELL, R.M.; GRAMATICA, P. Methods for Reliability and Uncertainty Assessment and for Applicability Evaluation of classification- and Regression-Baded QSARs. Environmrntal Health Perspectives; v.11, p.1261-1375, 2003.

FALKAI, P.; WOBROCK, T.; LIEBERMAN, J.; GLENTHOJ, B.; GATTAZ, W.F; MÖLLER, H.J.; Diretrizes da Federação Mundial das Sociedades de Psiquiatria Biológica para o Tratamento Biológico da Esquizofrenia Parte 1: Tratamento agudo; Rev. Psiq. Clín. 33, supl 1; p. 7-64, 2006.

FERREIRA, M.C.; Multivariate QSAR; J. Braz. Chem. Soc. V. 13. N. 6. p. 752-753, 2002.

FERREIRA, M.M., ANTUNES, A.M., MELGO, M.S., VOLPE, P.L.O.; Quimiometria I: calibração multivariada, um tutorial; Quim. Nova, V.22, N.5, 1999.

Disponível em:

<http://quimicanova.sbq.org.br/qn/qnol/1999/vol22n5/v22_n5_\%20(15).pdf >

Acesso em 11 de out. 2013.

FERREIRA, M.M.C., KIRALJ, R.; Métodos Quimiométricos em Relações Quantitarivas Estrutura Atividade (QSAR). In: MONTANARI, C.A.; Química Medicinal: Métodos e Fundamentos em Planejamento de Fármacos; São Paulo: Editora da Universidade de São Paulo, 2011.

FERREIRA, M.M.C., MONTANARI, C.A. GAUDIO, A.C.; Seleção de Variáveis em QSAR; Quim. Nova, V.25, N. 3, p. 439-448, 2002.

FLOWER, D.R. Modeling G-protein-coupled receptors for drug design. Biochimica ET Biophysica Acta, v. 1422, p. 207-234, 1999. 
FOYE, W.O., LEMKE, T. L., WILLIAMS, D.A; Principles of Medicinal Chemistry. 4ed. Baltimore: Williams \& wilkins, 995p. 1995

FRISCH M. J. TRUCKS G. W., SCHLEGEL H. B., SCUSERIA G. E., ROBB M. A. E CHEESEMAN J. R.; SCALMANI, G.; BARONE, V.; MENNUCCI, B.; PETERSSON, G. A.; NAKATSUJI, H.; CARICATO, M.; LI, X.; HRATCHIAN, H. P.; IZMAYLOV, A. F.; BLOINO, J.; ZHENG, G.; SONNENGERG, J. L.; HADA, M.; EHARA, M.; TOYOTA, K.; FUKUDA, R.; HASEGAWA, J.; ISHIDA, M.; NAKAJIMA, T.; HONDA, Y.; KITAO, O.; NAKAI, H.; VREVEN, T.; MONTGOMERY, J. A; PERALTA, J. E.; OGLIARO, F.; BEARPARK, M.; HEYD, J. J.; BROTHERS, E.; KUDIN, K. N.; STAROVEROV, V. N.; KOBAYASHI, R.; NORMAND, J.; RAGHAVACHARI, K.; RENDELL, A.; BURANT, J. C.; IYENGAR, S. S.; TOMASI, J.; COSSI, M.; REGA, N.; MILLAM, J. M.; KLENE, M.; KNOX, J. E.; CROSS, J. B.; BAKKEN, V.; ADAMO, C.; JARAMILLO, J.; GOMPERTS, R.; STRATMANN, R. E.; YAZYEV, O.; AUSTIN, A. J.; CAMMI, R.; POMELLI, C.; OCHTERSKI, J. W.; MARTIN, R. L.; MOROKUMA, K.; ZAKRZEWSKI, V. G.; VOTH, G. A.; SALVADOR, P.; DANNENBERG, J. J.; DAPPRICH, S.; DANIELS, A. D.; FARKAS, O.; FORESMAN, J. B.; ORTIZ, J. V.; CIOSLOWSKI, J.; FOX, D. J.; Gaussian 09; n. de 2009. [Programa de Computador].

GANELLIN, C.R., ROBERTS, S.M. Medicinal Chemistry: The role of Organic Chemistry in drug research. 2.ed. San Diego: Academic Press, 127p. 1994.

GARCIA, G.C.; RUIZ, I.L.; GÓMEZ-NIETO, M.A.; DOMEL, J.A.C.; PLAZA, A.G. From Wiener Index to molecules. Journal of Chemical Information and Modelling, 2005, 45, 231-238.

GELADI, P., B.R. KOWALSKI, B.R; Partial Least-Squares regression: a tutorial, Anal. Chim. Acta, 185, p. 1-17, 1986.

GRAMATICA, P. WHIM descriptors of shape. QSAR \& Combinatorial Chemistry, 2006, $25,327-332$.

GRAMATICA, P. Principles of QSAR models validation Internal and external. QSAR and Combinatorial Science. V.26, p.694-701, 2007.

GOH, A.T.C; Back-propagation neural networks for modeling complex systems, Artificial Intelligence in Engineering; vol. 9, no. 3, pp. 143-151, Jan. 1995.

GONZÁLES, M.P.; TERÁN, C.; TEIJEIRA, M.; HELGUERA, A.M; Radial distribution function descriptors: an alternative for predicting A2 A adenosine receptors agonists; N.41, Elselvier, Journal of Medicinal Chemistry, p. 56-62., 2005.

GUYTON, A.C; HALL, J.E. Tratado de Fisiologia Médica. 11. Ed. São Paulo: Elsevier. 2006, 1264p.

HAYKIN, S.; Neural networks: a comprehensive foundation, 2 edition. Prentice-Hall, 1999.

HOHENBERG, P.; KOHN, W.; Inhomogeneous Electron Gas; United States of American, Rev. Physical, v.136, n.3B, Nov, 1964. 
INFOMETRIX INC. Pirouette 3.10. Woodinville, 2002. [Programa de Computador].

KOHN, W.; SHAM, L.J.; Self-Consistent Equations Including Exchange and Correlation Effects; Rev Physical, United States of American, v.140, n.4A, November, 1965.

JESEN, F.; Introduction to Computational Chemistry; $2^{\circ}$ ed.Chichester: John Wiley \& Sons Ltd, p. 599, 2007.

KATRITZKY, A.R.; GORDEEVA, E.V. Traditional topological indices vs electronic, geometrical, and combined molecular descriptors in QSAR/QSPR research. Journal of Chemical Information and Computer Sciences, 1993, 33, 835-857.

KUBINYI, H. QSAR: Hansch analysis and related approaches. New York: VCH, 1993, 240p.

LEK, S., DELACOSTE, M., DIMOPOUlOS, I., LAUGA, J., AULAGNIER, S.; Application of neural networks to modelling nonlinear relationships in ecology; vol. 90, p. 39-52, 1996.

LIMA, E. F.; Estudo da Modelagem do receptor carnabinoide CB1 e suas interações com o $\Delta$ ' - THC. 2009. Tese (Doutorado em Ciências- Físico-Química)- Instituto de Química de São Carlos, Universidade de São Paulo, 2009.

LIMA, L.M.; Química Medicinal moderna: desafios e contribuição brasileira. Quím. Nova, V. 30, n. 6, p. 1456-1468, 2007.

Disponível em: < http://www.scielo.br/pdf/qn/v30n6/a15v30n6.pdf>

Acesso em: 20 Ago. 2013.

LIU, P., LONG, W.; Current Mathematical Methods Used in QSAR/QSPR Studies; International Journal of Molecular Sciences, N.10, p. 1978-1998, 2009.

MARTINS, J. P.A., FERREIRA, M.M.C.; QSAR MODELING: Um novo Pacote Computacional Open Source para Gerar e Validar Modelos QSAR. Quím. Nova, V. 36, n. 4, p. 554-560, 2013.

Disponível em: < http://www.scielo.br/pdf/qn/v36n4/v36n4a13.pdf>

Acesso em: 15 out. 2013.

MATINS, A.l; Cientistas Brasileiros usam Técnica que auxiliará tratamento contra a Esquizofrenia; Toque da Ciência, ISSn 2177-8280, p. 1-3, 2012.

MATHWORKS, INC. MatLab, versão R2011a. [Programa de Computador].

MILliE, D. F., WECKMAN, G. R., YOUNG, W. A., IVEY, J. E., CARRICK, H. J., FAHNENSTIEL, G. L.; Modeling microalgal abundance with artificial neural networks: Demonstration of a heuristic 'Grey-Box' to deconvolve and quantify environmental influences; Environmental Modelling \& Software, vol. 38, p. 27-39, 2012.

MINISTÉRIO DA SAÚDE, Secretaria de Atenção à Saúde; consulta pública ${ }^{\circ} 5$, de 14 de junho de 2012. Disponível em: 
< http://portal.saude.gov.br/portal/arquivos/pdf/cp_05_esquizofrenia_2012.pdf> Acesso em: 23 Ago. 2013.

MORGON, N. R., CUSTÓDIO; Funções de base: O ajuste Variacional; Chemkeys, 2001. Disponível em: <http://chemkeys.com/br/2001/02/18/funcoes-de-base-o-ajuste-variacional/> Acesso em: 25 set. 2013

MOREIRA, F.A., GUIMARÃES, F.S; Mecanismo dos Antipsicóticos: Hipótese Dopaminérgica; Rev, Medina de Ribeirão Preto, V. 40, N.1. p. 63-71, Ribeirão Preto, 2007.

MOURA, P. R., VIDAL, F.A.P.; Transdução de sinais: Uma revisão sobre proteína G. Medica Scientia, vol. 21, No. 1, p. 31-36, Porto Alegre, 2011.

MUSCATEllo, M. R. A., BRUNO, A., PANDOUlFO, G., MICO, U., SCIMECA., G., NARDO, F. DI., SANTORO, V., SPINA, E., ZOCCALI, R. A.; Effect of aripiprazole augmentation of clozapine in schizophrenia: A double-blind, placebo-controlled study. Elsevier, p. 93-99, 2010.

NEVES, P.J.; COSTA, J.B.M.; NDUJAE, P.M. TOP - um programa de cálculo de descritores topológicos para uso em correlações entre estrutura e atividade. Química Nova 1998, 21, 709-713.

NILSSON, J.; DE JONG, S.; SMILDE, A. K. Multiway Calibration in 3D QSAR; Journal of Chemometrics, V. 11, p. 511-524, 1997

PADRÓN, J.A.; CARRASCO, R.; PELLÓN, R.F. Molecular descriptor base on molar refractivity partition using Randic-type graph-theoretical invariant. Journal of Pharmacy and Pharmaceutical Sciences, 2002, V. 5, p. 258-266.

PIELA, L.; Ideas of Quantum chemistry; Elsevier, 2007.

PURVES, D., ALGUSTINE, G.J., FITZPATRICK, D., HALL, W.C., LAMANTIA, A.S., MCNAMARA, J.O., WILlIAMS, S.M.; Neuroscience, 3th ed. 2004, Sunderland, Massachusetts, USA Sinauer Associates, Inc. p. 832.

ROCHA, J. R.; Planejamento de Inibidores das Enzimas Gliceraldeído-3-fosfato desidrogenase e diidroorotato desidrogenase de Trypanosama cruzi. 2010. 201 p. Tese (Doutorado em Físico-química). Instituto de Química de São Carlos, Universidade de São Paulo, São Carlos, 2010.

SANDERSON, R.T. Electronegativities in inorganic chemistry. Journal of Chemical Education. 1955, 23, 539-544.

SANDERSON, R.T. Electronegativity and bond energy. Journal of American Chemical Society. 1983, 105, 2259-2261. 
SENA, M.M., POPPI, R.J.; Avaliação do uso de Métodos Quimiométricos em análise de solos. Quim.Nova, V. 23, N.4, p. 547-556, 2000.

Disponível em:<http://www.scielo.br/pdf/qn/v23n4/2656.pdf>

Acesso em: 11 de Out. 2013.

SILVA, R.C.B.; ESQUIZOFRENIA: UMA REVISÃO; Universidade Federal de São Paulo UNIFESP Psicologia USP, 2006, 17(4), p.263-285.

SOUSA, F.S., FERNANDES, P.A., RAMOS, M.J.; General Performance of Density Functionals; J. Phys. Chem. A 2007, n. 111, p. 10439-10452.

SPIEGEL, A. M. Multations in $\mathrm{G}$ proteins and $\mathrm{G}$ protein coupled receptor in endocrine disease. Journal of Clincal Endocrinology Metabolismo, v. 18, p. 2434-2442, 1996.

STANDAERT, G.D; GALANTER. Farmacologia da Neurotransmissão Dopaminérgica. In: GOLAN, D.E. Princípios de Farmacologia: a base fisiopatológica da farmacoterapia; Rio de Janeiro: Guanabara Kooga, 2009. p. 167-187.

STANTON, D.T. Evaluation and use of BCUT descriptors in QSAR and QSPR studies. Journal of Chemical Information and Computer Science, 1999, 39, 11-20.

SUTTON, P., BOYDEN, S.; Genetic Algorithms: A general Search Procedure; Am J. Phys, 62, 5994; 1994.

TADON, R., NASRALLAH, H.A., KESHAVAN, M.S.; Schizophrenia, "just the facts" 4. Clinical features and conceptualization; Schizophr Res, V. 110, p. 1-23. 2009.

TAFNER, M.A.; Redes Neurais Artificiais: Aprendizado e plasticidade. Rev. Cérebro \& Mente, N.5. 1998.

Disponível em < http://www.cerebromente.org.br/n05/tecnologia/rna.htm>.

Acesso em 04 de Nov. 2013.

TODESCHINI, R.; CONSONNI, V. Handbook of Molecular Descriptors, Weinheim: Wiley-VCH, 2000. p.667.

TODESCHINI, R., CONSONNI, V., PAVAN, M.; Dragon 2.1. Milano, 2002 [Programa de computador].

VAN DE WATERBEEMD, H.; ROSE, S. Quantitative approache to structure-activity relationship. In: WERMUTCH, C.G. (Ed). The practice of medicinal chemistry. 2.ed. London: Elsevier Academic Press, 2003.

VAN OS, J., KENIS, G., RUTTEN, B.P.F; The Environment and Schizophenia; V. 468. P. 203-212, Nature, 2010.

VIANNA, J.D.M., FAZZIO, A., CANUTO, S., Teoria Quântica de Moléculas e Sólidos: Simulação Computacional. São Paulo: Livraria da Física, 2004.

VILLARES, C. C.; REDKO, C.P.; MARI, J. J.; Concepções de doença por familiares de pacientes com diagnóstico de esquizofrenia; Rev Bras Psiquiatria, 1999. 
WEBER, K. C; Modelagem Molecular de compostos Aripiperazínicos e suas interações com o receptor 5-HT $\mathbf{1 A}_{\mathbf{1 A}}$. Tese (Doutorado em Ciências- Físico-Química) - Instituto de Química de São Carlos, Universidade de São Paulo, 2008.

WOLD, S., ERIKSSON, L.; Statical Validation of QSAR results. In: H. Van de Walterbeemed (org). Chemometric Methods Molecular Design. VCH: Weinheim, 1998, p. 309-318. 